\title{
IV. Die Organisation der politischen Durchdringung der NVA 1956-1961
}

\section{Zentrale Institutionen und Instrumente der SED zur Steuerung des Militärs}

\section{Politbüro, Sicherheitskommission und Nationaler Verteidigungsrat}

Das Politbüro des ZK der SED war für die konkrete Ausformung der zivil-militärischen Beziehungen in der DDR von zentraler Bedeutung1. In diesem Gremium wurden die militärpolitischen Grundsatzentscheidungen getroffen. Nominell kam dem Politbüro allein die Aufgabe zu, zwischen den Plenartagungen die politische Arbeit des $\mathrm{ZK}$ zu leiten ${ }^{2}$. Faktisch fungierte jedoch das Politbüro und nicht der Parteitag, wie vom Statut der SED festgesetzt ${ }^{3}$, als wichtigstes politisches Führungsorgan der SED 4 . Auf der Basis des „demokratischen Zentralismus" kontrollierte die Parteiführung damit den gesamten Parteiapparat, da dieser zentralisiert auf das Politbüro ausgerichtet war. Wegen der fehlenden Gewaltenteilung in der staatlichen Ordnung der DDR hatte die Parteiführung über diesen Parteiapparat wiederum Zugriff auch auf alle staatlichen und gesellschaftlichen Institutionen, da die Untergliederungen der Partei diesen vorgelagert waren ${ }^{5}$. Demzufolge war beim Politbüro auch die übergeordnete Entscheidungskompetenz auf militärischem Gebiet konzentriert. Das höchste Parteigremium konnte nach eigenem Ermessen alle wichtigen Fragen, die die Streitkräfte und ihr Verhältnis zur SED betrafen, an sich ziehen ${ }^{6}$.

So beschloß das Politbüro beispielsweise am 8. November 1956 den Einsatz der NVA zur Unterdrückung konterrevolutionärer Aktionen? ${ }^{7}$. Darüber hinaus ent-

1 Vgl. u. a. Brunner, Staatsapparat und Parteiherrschaft in der DDR, S. $1003 \mathrm{ff}$.; Diedrich, Die bewaffneten Organe der DDR, S. 8 f.; Schroeder, Der SED-Staat, S. 397 ff.

2 Statut der Sozialistischen Einheitspartei Deutschlands, 1954, S. 118.

3 Ebenda, S. 117.

4 Vgl. Brunner, Staatsapparat und Parteiherrschaft in der DDR, S. 1003 f.

5 Schroeder, Der SED-Staat, S. $411 \mathrm{f}$.

6 Nach den Erkenntnissen der Staatsanwaltschaft II beim Berliner Landgericht war das Politbüro das „höchste und unkontrollierte Machtorgan“ in der DDR. In der Anklageschrift gegen frühere Mitglieder des Politbüros heißt es, über eine „umfassende Instrumentalisierung des gesamten Staatsapparates" habe es "Aufbau, Organisation, Struktur und personelle Zusammensetzung" der für Militär- und Sicherheitsfragen zuständigen staatlichen Organe und bewaffneten Kräfte gesteuert. Die Entscheidungen des Politbüros seien für alle Gremien und Organe nicht nur der SED, sondern auch des Staates verbindlich gewesen. Diese seien anschließend „durch formal vorgeschaltete staatliche Organe übernommen und bestätigt, im übrigen durch Entscheidungen nachgeordneter Organe und Funktionsträger konkretisiert und ergänzt“" worden. Jochum, „Das Politbüro auf der Anklagebank“, S. 134.

7 Maßnahmen zur Unterdrückung konterrevolutionärer Aktionen. Protokoll Nr. 57/56 der 
schied das Politbüro auch über alle wichtigen Personalfragen. So wurde etwa Generalmajor Heinrich Dollwetzel durch den Beschluß vom 3. Juli 1956 wegen mangelnder Fähigkeiten von der kommissarischen Leitung des Ministeriums für Nationale Verteidigung entbunden ${ }^{8}$. Von herausragender Bedeutung für das Verhältnis zwischen der SED und der NVA waren darüber hinaus vor allem die Grundsatzentscheidungen des Politbüros zur Stellung und zu den Kompetenzen der Partei in den Streitkräften. Darunter fällt unter anderem der Beschluß „Über die Rolle der Partei in der NVA" vom 14. Januar 1958, der nach Gründung der NVA hinsichtlich der Einflußnahme auf die rein militärischen Diskussions- und Entscheidungsprozesse maßgebliche organisatorische Voraussetzungen neu fixierte 9 . Auch der Beschluß über den zeitweiligen Dienst von Offizieren und Generalen als Soldaten in den unteren Einheiten wurde am 20. Januar 1959 durch das Politbüro gefälltt ${ }^{10}$. Er ist exemplarisch für die Eingriffe des höchsten Parteigremiums in die innere Ordnung der NVA, die die spezifisch militärischen Organisationszusammenhänge tiefgreifend berührten.

Aufgrund der Fülle von Themen, mit denen sich das Politbüro befaßte, fand eine eingehende Erarbeitung und Beratung vieler Beschlüsse nicht statt ${ }^{11}$. Vielmehr erfolgte die Beschlußfassung zumeist auf der Grundlage bereits zuvor ausgearbeiteter Vorlagen. In militärischen Belangen wurden diese vor allem von der Sicherheitskommission, dem Nationalen Verteidigungsrat, der ZK-Abteilung für Sicherheitsfragen oder dem Ministerium für Nationale Verteidigung verfaßt. So war etwa der Beschluß „Über die Rolle der Partei in der NVA“ bereits am 8. Januar 1958 in der Sicherheitskommission beschlossen worden. Doch erst nachdem ihn das Politbüro in dieser Fassung am 14. Januar 1958 bestätigt hatte, trat er in Kraft ${ }^{12}$. Nach der Beschlußfassung wurden die Vorgänge zur Umsetzung an die jeweils zuständigen Parteigremien und militärischen Institutionen verwiesen. Am 28. April 1958 beispielsweise berichtete Stoph über notwendige Veränderungen in der Struktur und Bewaffnung der NVA, die im Rahmen einer Beratung des Ministeriums für Nationale Verteidigung mit dem Vereinten Kommando entwickelt worden waren. Das Politbüro beschloß diese neue Konzeption, mit deren Verwirklichung wiederum der Minister beauftragt wurde ${ }^{13}$.

In Phasen, in denen die SED-Führung ihren Einfluß in der NVA gefährdet sah oder aber die Verwirklichung von Parteibeschlüssen - wie im Fall der neuen „Bestimmungen für die Politorgane der NVA“ und der „Instruktion für die Parteiorga-

Sitzung des Politbüros des ZK der SED, 8. November 1956, SAPMO-BArch, DY 30/J IV 2/2/511, Bl. 2, $8 \mathrm{ff}$.

8 Protokoll Nr. 32/56 der Sitzung des Politbüros des ZK der SED, 3. Juli 1956, SAPMOBArch, DY 30/J IV 2/2/468, Bl. 7.

9 Über die Rolle der Partei in der NVA. Protokoll Nr. 4/58 der Sitzung des Politbüros des ZK der SED, 14. Januar 1958, SAPMO-BArch, DY 30/J IV 2/2/576, Bl. $190 \mathrm{ff.}$

10 Beschluß über den zeitweiligen Einsatz von Generalen, Admiralen und Offizieren in den unteren Einheiten als Soldaten. Protokoll Nr. 4/59 der Sitzung des Politbüros des ZK der SED, 20. Januar 1959, SAPMO-BArch, DY 30/J IV 2/2/628, Bl. 10, $152 \mathrm{ff}$.

11 Vgl. Brunner, Staatsapparat und Parteiherrschaft in der DDR, S. $1004 \mathrm{f}$.

12 Über die Rolle der Partei in der NVA. Beschluß der Sicherheitskommission des ZK der SED, 8. Januar 1958, SAPMO-BArch, DY 30/IV 2/12/9, Bl. $36 \mathrm{ff}$.

13 Protokoll Nr. $19 / 58$ der Sitzung des Politbüros des ZK der SED, 28. April 1958, SAPMOBArch, DY 30/J IV 2/2/591, Bl. 6, 68 . 
nisationen der SED in der NVA" von 1957 - als problematisch antizipiert wurde, beschloß das Politbüro, die Umsetzung selbst federführend zu übernehmen ${ }^{14}$. Herausragendes Beispiel hierfür ist die „Eggersdorfer Tagung“ vom Juni 1957, auf der eine Abordnung des Politbüros den leitenden Parteiarbeitern in der NVA den zukünftigen Kompetenzzuwachs des Parteiapparates in den Streitkräften erläuterte, der vor allem auf der Veränderung der militärischen Führungsprinzipien beruhte ${ }^{15}$.

Im September 1953 hatte das Politbüro die Einsetzung einer „Kommission für Sicherheitsfragen" beschlossen. Diese sogenannte Sicherheitskommission ${ }^{16}$ diente als ein Fachorgan des höchsten Parteigremiums, dessen Aufgabe es war, sich mit Fragen der "Sicherheit und Verteidigung des Landes“ zu befassen ${ }^{17}$. Nach Angaben von Ulbricht, dem Vorsitzenden der Sicherheitskommission, war deren Existenz „nur den leitenden Funktionären“ der SED bekannt, die auf diesem Gebiet tätig waren. Entsprechend den spezifischen Aufgaben gehörten dem Gremium zuletzt unter anderem Grotewohl als Vorsitzender des Ministerrates, Stoph als Minister für Nationale Verteidigung, Mielke als Minister für Staatssicherheit, Karl Maron als Minister des Innern und Honecker als ZK-Sekretär für Sicherheitsfragen an ${ }^{18}$.

Die Sicherheitskommission befaßte sich vorrangig mit Fragen der inneren Sicherheitslage. Nach den Erfahrungen des 17. Juni 1953 sollte sie insbesondere Rahmenbedingungen zur Absicherung des SED-Regimes in der DDR schaffen und die dahingehenden Maßnahmen koordinieren ${ }^{19}$. Die Sicherheitskommission fällte zudem eine Reihe von Beschlüssen, die den militärischen Bereich und die Beziehungen der SED zur NVA betrafen. Im Zusammenhang mit dem Komplex innere Sicherheit etwa legte die Sicherheitskommission im „Beschluß über die Maßnahmen der Stärkung der Verteidigungsbereitschaft der DDR“ vom 9. Januar 1958 den Einsatz der NVA bei der „Zerschlagung innerer Unruhen" fest ${ }^{20}$. Sie fällte aber beispielsweise auch hinsichtlich der Besetzung der höchsten militärischen Führungspositionen weitreichende Entscheidungen. So beschloß die Kommission am 15. April 1957 die

14 Vgl. Protokoll Nr. 21/57 der Sitzung des Politbüros des ZK der SED, 16. Mai 1957, SAPMO-BArch, DY 30/J IV 2/2/541, Bl. 6.

15 Protokoll der Eggersdorfer Tagung, 12./13. Juni 1957, BA-MA, VA-P-01/037, Bl. $1 \mathrm{ff}$.

16 Vgl. u. a. Wenzel, Kriegsbereit: Der Nationale Verteidigungsrat der DDR, S. $17 \mathrm{ff}$.; Diedrich, Die bewaffneten Organe der DDR, S. 14.; Wagner, Der Nationale Verteidigungsrat der DDR, S. 173 ff. Die Staatsanwaltschaft II am Berliner Landgericht hat konstatiert, die Sicherheitskommission sei dem Politbüro als „Hilfsorgan“ in der Entscheidungskompetenz nachgeordnet und an dessen Vorgaben gebunden gewesen. Die Sicherheitskommission habe Beschlüsse gefaßt zum Teil parallel zum Politbüro und auch „über dessen Beschlüsse hinaus, jedoch stets in Übereinstimmung mit der vom Politbüro vorgegebenen Grundlinie“. Jochum, „Das Politbüro auf der Anklagebank“, S. 134, 138.

17 Wagner, Der Nationale Verteidigungsrat der DDR, S. $173 \mathrm{f}$.

18 Bildung des Nationalen Sicherheitsrates. Ulbricht an Chruschtschow, SAPMO-BArch, DY 30/IV 2/202/66, Bl. 73. Die Zusammensetzung der Sicherheitskommission wurde offenbar maßgeblich von Ulbricht als 1. Sekretär des ZK der SED bestimmt. Vgl. Arbeitsprotokoll Nr. 8/58 der Sitzung des Politbüros des ZK der SED, 12. Februar 1958, SAPMO-BArch, DY 30/J IV 2/2A/613, o. Pag.

19 Wagner, Der Nationale Verteidigungsrat der DDR, S. 173.

20 Beschluß über die Maßnahmen zur Stärkung der Verteidigungsbereitschaft der DDR. Protokoll der 19. Sitzung der Sicherheitskommission des ZK der SED, 9. Januar 1958, BA-MA, DVW 1/39561, Bl. 2 ff. 
„Nomenklatur der leitenden Kader des Ministeriums für Nationale Verteidigung“, die festlegte, daß diese Positionen durch das Politbüro beziehungsweise durch die Sicherheitskommission, also durch Parteigremien zu besetzen waren ${ }^{21}$.

Am 8. Dezember 1959 bestätigte das Politbüro den „Entwurf des Gesetzes über die Bildung des Nationalen Verteidigungsrates der DDR"22, der durch den Beschluß der Volkskammer vom 10. Februar 1960 in Kraft trat ${ }^{23}$. Damit ging die Funktion der Sicherheitskommission auf diese formal staatliche Institution über, die als das „zentrale militärische Führungsorgan“ nunmehr die Aufgabe hatte, die „allseitige staatliche Sicherung " und die „Verteidigung der Republik" zu organisieren ${ }^{24}$. Der Vorsitzende und die Mitglieder des Nationalen Verteidigungsrates wurden formal vom Präsidenten der DDR berufen und durch die Volkskammer bestätigt ${ }^{25}$. Diese Kompetenz ging im September 1960 auf den neugebildeten Staatsrat über ${ }^{26}$. Tatsächlich war die Zusammensetzung des Nationalen Verteidigungsrates schon im Vorfeld durch das Politbüro beschlossen worden. Unter dem Vorsitz von Ulbricht gehörten dem Gremium, dessen Sekretär Honecker war, ausschließlich hohe SEDFunktionäre an. 1960 waren von Seiten der NVA Mitglieder zum einen Stoph mit vollem Stimmrecht, der noch bis Mitte des Jahres den Posten des Ministers für Nationale Verteidigung innehatte, ferner mit nur beratender Stimme Hoffmann zunächst als Chef des Hauptstabes und ab Juli 1960 als Minister für Nationale Verteidigung sowie Waldemar Verner als Chef der Politischen Verwaltung ${ }^{27}$.

Im Grundsatz lag die Zuständigkeit, „alle Gesetzesvorlagen zu Fragen des militärischen Schutzes und der Sicherheit" zu bestätigen, bevor sie in der Volkskammer beraten wurden, beim neugeschaffenen Staatsrat als formal höchstem Exekutivorgan der DDR. Die Vorlage der Gesetzentwürfe für den Staatsrat erfolgte jedoch durch den Nationalen Verteidigungsrat ${ }^{28}$, der „in Friedenszeiten die Entwürfe aller Gesetze und Verordnungen auf militärischem Gebiet und auf dem Gebiete der Si-

21 Nomenklatur der leitenden Kader des Ministeriums für Nationale Verteidigung. Protokoll der 16. Sitzung der Sicherheitskommission des ZK der SED, 15. April 1957, BA-MA, DVW $1 / 39558, \mathrm{Bl} .6,9 \mathrm{ff}$.

22 Protokoll Nr. 54/59 der Sitzung des Politbüros des ZK der SED, 8. Dezember 1959, SAPMO-BArch, DY 30/J IV 2/2/678, Bl. 124.

23 Vgl. u. a. Lapp, Die Nationale Volksarmee 1956-1990, S. 1921 ff.; Wenzel, Kriegsbereit: Der Nationale Verteidigungsrat der DDR, S. $29 \mathrm{ff}$.; Wagner, Der Nationale Verteidigungsrat der DDR, S. $169 \mathrm{ff}$. Die Staatsanwaltschaft II am Berliner Landgericht hat im Rahmen des Politbüroprozesses festgestellt, der Nationale Verteidigungsrat sei „als formal selbständiges und oberstes, kollektives Führungsorgan der Landesverteidigung" zwar mit „weitreichenden Kompetenzen versehen" gewesen. In der Entscheidungsbefugnis sei er jedoch dem Politbüro „nachgeordnet und an dessen Vorgaben gebunden“ gewesen. Jochum, „Das Politbüro auf der Anklagebank", S. 134.

24 Statut des Nationalen Verteidigungsrates der DDR. Protokoll Nr. 54/59 der Sitzung des Politbüros des ZK der SED, 8. Dezember 1959, SAPMO-BArch, DY 30/J IV 2/2/678, Bl. $129 f$.

25 Ebenda, Bl. 129.

26 Änderung bzw. Ergänzung des Statuts des Nationalen Verteidigungsrates. Protokoll der 4. Sitzung des Nationalen Verteidigungsrates der DDR, 20. Januar 1961, BA-MA, DVW 1/39461, Bl. 9.

27 Protokoll Nr. 54/59 der Sitzung des Politbüros des ZK der SED, 8. Dezember 1959, SAPMO-BArch, DY 30/J IV 2/2/678, Bl. 124.

28 Grundsätze über die Zuständigkeit der höchsten Staatsorgane für Fragen des militärischen Schutzes und der Sicherheit der DDR. Protokoll der 5. Sitzung des Nationalen Verteidigungsrates der DDR, 3. Mai 1961, BA-MA, DVW 1/39462, Bl. $66 \mathrm{f}$. 
cherung der Verteidigungskraft der Republik“ zu bestätigen hatte ${ }^{29}$. Da seine "grundsätzlichen Beschlüsse“ aber wiederum zunächst dem Politbüro zur Bestätigung vorzulegen waren ${ }^{30}$, wird deutlich, daß es sich beim Nationalen Verteidigungsrat tatsächlich um keine staatliche Institution, sondern primär um ein sicherheits- und militärpolitisches Fach- und Koordinationsorgan des Politbüros handelte.

Auch durch die Kontrolle des Nationalen Verteidigungsrates stellte die SEDFührung ihren Einfluß in der NVA sicher, da der Nationale Verteidigungsrat „die oberste militärische Kommandogewalt ... gegenüber allen bewaffneten Kräften der DDR“ ausübte 31 . In Friedenszeiten fungierte der Hauptstab der NVA als sein militärisches „Planungs- und Koordinationsorgan“. Im Kriegsfall übernahm die 1. operative Führungsstaffel des Ministeriums für Nationale Verteidigung die Funktion als militärisches „Planungs- und Führungsorgan“32. Dem Nationalen Verteidigungsrat oblag die „Ausarbeitung der militärischen Konzeption der DDR auf der Grundlage der politischen Zielsetzung der Regierung ... und in Übereinstimmung mit der militärischen Planung des Vereinten Kommandos der Länder des Warschauer Vertrages"33. Auf militärischem Gebiet sollte er dementsprechend die Hauptaufgaben der bewaffneten Kräfte - also auch der NVA - im Rahmen der Landesverteidigung und der Aufrechterhaltung der staatlichen Sicherheit bei konterrevolutionären Putschversuchen festlegen sowie ihre Gesamtstärke und die Prinzipien für die Gliederung, Ausbildung und Ausrüstung. Ferner hatte er die Funktion, den Einsatz der bewaffneten Kräfte im Innern sowie im Kriegsfall zu leiten und mit dem Vereinten Kommando des Warschauer Paktes zu koordinieren ${ }^{34}$.

\section{ZK-Abteilung für Sicherheitsfragen und Politische Verwaltung des Ministeriums für Nationale Verteidigung}

„Für die praktische Durchführung der Politik und der Beschlüsse der Partei“ bestanden im ZK der SED spezifische Abteilungen ${ }^{35}$. In bezug auf die DDR-Streitkräfte und alle militärischen Belange oblag diese Aufgabe der ZK-Abteilung für Sicherheitsfragen und ihrem „Sektor NVA“. Die Abteilung wurde bis 1956 von Gustav Röbelen, 1956-1959 und 1961-1972 von Walter Borning sowie zwischenzeitlich 1959-1960 von Bruno Wansierski geleitet ${ }^{36}$. Sie stand ihrerseits unter der

29 Zuständigkeitsbereich und Aufgabengebiet des Nationalen Verteidigungsrates der DDR. Protokoll Nr.54/59 der Sitzung des Politbüros des ZK der SED, 8. Dezember 1959, SAPMO-BArch, DY 30/J IV 2/2/678, Bl. 137.

30 Protokoll Nr. 54/59 der Sitzung des Politbüros des ZK der SED, 8. Dezember 1959, SAPMO-BArch, DY 30/J IV 2/2/678, Bl. 124.

31 Statut des Nationalen Verteidigungsrates der DDR. Protokoll Nr. 54/59 der Sitzung des Politbüros des ZK der SED, 8. Dezember 1959, SAPMO-BArch, DY 30/J IV 2/2/678, Bl. 130.

32 Ebenda.

33 Ebenda, Bl. 129.

34 Zuständigkeitsbereich und Aufgabengebiet des Nationalen Verteidigungsrates der DDR. Protokoll Nr. 54/59 der Sitzung des Politbüros des ZK der SED, 8. Dezember 1959, SAPMO-BArch, DY 30/J IV 2/2/678, Bl. $134 \mathrm{f}$.

35 Statut der Sozialistischen Einheitspartei Deutschlands, 1954, S. 119.

36 Vgl. u.a. Diedrich, Die bewaffneten Organe der DDR, S. 8 ff.; Fricke, Die DDR-Staatssicherheit, S. 78 ff.; Lapp, Die Nationale Volksarmee 1956-1990, S. 1929 ff. 
Aufsicht des jeweiligen ZK-Sekretärs für Sicherheitsfragen ${ }^{37}$. Bis 1956 war dies Alfred Neumann, anschließend bis 1983 Erich Honecker.

Die ZK-Abteilung für Sicherheitsfragen hatte in bezug auf die NVA vor allem drei Aufgaben ${ }^{38}$. Erstens mußte sie als militärisches Fachreferat für die übergeordneten Entscheidungsgremien - vor allem das Politbüro, die Sicherheitskommission und den Nationalen Verteidigungsrat - die Beratungen und Beschlüsse vorbereiten. So hatte das Politbüro im Rahmen des Beschlusses „Über die Rolle der Partei in der NVA“ vom 14. Januar 1958 die „Änderungen: 1. der Instruktion für die Arbeit der Parteiorganisationen“ und „2. der Bestimmungen für die Arbeit der Politorgane“ festgelegt. „Die Dokumente wurden von der Politischen Verwaltung in Zusammenarbeit mit der Abteilung für Sicherheitsfragen des Zentralkomitees und unter Mitwirkung der Mitglieder des Zentralkomitees in der Nationalen Volksarmee ausgearbeitet." Daraufhin gingen sie als Vorlage der ZK-Abteilung für Sicherheitsfragen am 12. Juni 1958 zur Beschlußfassung an das Politbüro ${ }^{39}$, das die Neufassungen am 17. Juni 1958 bestätigte.

Zweitens mußte die ZK-Abteilung für Sicherheitsfragen als nachgeordneter Arbeitsausschuß die Beschlüsse der übergeordneten Entscheidungsinstanzen an die Parteiorgane und die staatlichen Institutionen weiterleiten, ihre Implementierung im Detail vorbereiten und diese anschließend überwachen. Beispielsweise unterrichtete der Leiter der ZK-Abteilung für Sicherheitsfragen Wansierski am 9. Februar 1960 den Chef der Verwaltung Kader des Ministeriums für Nationale Verteidigung Munschke über die Kaderentscheidungen, die die Sicherheitskommission am 28. Januar 1960 beschlossen hatte. Diese hatte unter anderem Kursteilnehmer für den Besuch der Höheren Militärakademie des Generalstabes der sowjetischen Streitkräfte, den neuen Kommandeur der 1. Flieger-Division und die Zusammensetzung des Kollegiums des Ministeriums für Nationale Verteidigung bestätigt. Die Verwaltung Kader wurde jetzt ihrerseits damit beauftragt, diese Beschlüsse der Sicherheitskommission umzusetzen ${ }^{40}$.

Drittens fungierte die ZK-Abteilung für Sicherheitsfragen als ständige Kontrollinstanz der Parteiführung innerhalb der Streitkräfte, die jedoch unabhängig von den militärischen Organisationsstrukturen agierte. Ihre Überwachungsaufgaben richteten sich dabei sowohl auf den rein militärischen Bereich als auch auf den Parteiapparat der SED in der NVA.

Die ZK-Abteilung für Sicherheitsfragen führte auf diese Weise im Parteiauftrag parallel zum Ministerium für Nationale Verteidigung Dienstaufsicht in den Streitkräften. Sie überprüfte etwa bei Stabsübungen und Truppenmanövern den allgemeinen Stand der Einsatzbereitschaft ${ }^{41}$. In der Regel kontrollierte die Abteilung im Rahmen sogenannter Brigadeeinsätze die Arbeit der einzelnen Dienstbereiche der NVA. Hier ging es vor allem darum, bestehende Mängel zu analysieren und diese durch direkte Interventionen zu beseitigen. Dabei waren zudem immer wieder die politischen Zielvorstellungen der SED zu erläutern sowie sicherzustellen, daß diese

37 Lapp, Die Nationale Volksarmee 1956-1990, S. 1930.

38 Ebenda, S. 1929 f.

39 Vorlage an das Politbüro, 12. Juni 1958, SAPMO-BArch, DY 30/IV 2/12/9, Bl. 61.

40 Wansierski an Munschke, 9. Februar 1960, SAPMO-BArch, DY 30/IV 2/12/28, Bl. $24 \mathrm{f}$.

41 Vgl. Bericht über die allseitige Überprüfung des Standes der Einsatzbereitschaft des Stabes der 1. MSD am 18. März 1960, 1960, SAPMO-BArch, DY 30/IV 2/12/22, Bl. $194 \mathrm{ff}$. 
im Rahmen der praktischen Arbeit berücksichtigt wurden. So führte die ZK-Abteilung für Sicherheitsfragen beispielsweise vom 24. März bis 30 . April 1960 einen Brigadeeinsatz in der Verwaltung Kader des Ministeriums für Nationale Verteidigung durch. In dessen Ergebnis wurde hinsichtlich der Personalentwicklung des Offizierskorps das „Fehlen eines umfassenden Systems der Qualifizierung der Kader" sowie „konkreter und damit meßbarer Qualifikationsmerkmale für die einzelnen Dienststellungen" moniert ${ }^{42}$.

Einer permanenten kritischen Einschätzung unterzog die ZK-Abteilung für Sicherheitsfragen auch das Ministerium für Nationale Verteidigung und die militärische Truppenführung. So teilte etwa Wansierski Ende 1961 Honecker mit, das Referat des Ministers für Nationale Verteidigung zur Auswertung des Ausbildungsjahres 1961 habe nach Meinung der Abteilung den "Anforderungen“ entsprochen. "Offene Kritik“ an der Arbeit des Ministeriums sei aber „fast nicht vorhanden“ gewesen ${ }^{43}$. Darüber hinaus wurde ebenso auch die Tätigkeit anderer staatlicher Institutionen in der NVA überprüft, so etwa des $\mathrm{MfS}^{44}$ und der Militärstaatsanwaltschaft ${ }^{45}$.

Eine entscheidende Aufgabe der ZK-Abteilung für Sicherheitsfragen war die Steuerung und Kontrolle der Kaderpolitik. Ihr Leiter Borning äußerte, man gehe davon aus, „maßgeblich für die Entwicklung der Kader in der Nationalen Volksarmee verantwortlich" $\mathrm{zu} \operatorname{sein}^{46}$. So meldete er beispielsweise im Januar $1961 \mathrm{dem}$ Sekretär des Nationalen Verteidigungsrates Honecker eine „Verletzung der Prinzipien der Arbeit mit den Nomenklaturkadern des Nationalen Verteidigungsrates durch das Ministerium für Nationale Verteidigung". Der Minister hatte die Neubesetzung des Stellvertretenden Chefs des Hauptstabes befohlen. Dieser Kaderbefehl war aber offenbar weder mit der ZK-Abteilung für Sicherheitsfragen abgesprochen noch dem Nationalen Verteidigungsrat zur Bestätigung vorgelegt worden ${ }^{47}$.

Die ZK-Abteilung für Sicherheitsfragen fungierte zudem auch als externe Kontrolleinheit für den innerhalb der militärischen Strukturen installierten Parteiapparat der SED - also die Politorgane unter Leitung der Politischen Verwaltung und die Parteiorganisationen der SED in der NVA, auf deren Tagungen und Delegiertenkonferenzen sie beispielsweise präsent war. Die Abteilung kontrollierte die gesamte praktische Arbeit des Parteiapparates wie auch des politischen Führungspersonals in der NVA. So äußerte sie etwa im Juni 1958 insbesondere als Reaktion auf die Schwierigkeiten der Politischen Verwaltung, den Politbürobeschluß „Über die Rolle der Partei in der NVA“ umzusetzen, diese befinde sich „nicht immer auf der

42 Bericht der Brigade des ZK der SED in der Verwaltung Kader des Ministeriums für Nationale Verteidigung, 15. Juni 1960, SAPMO-BArch, DY 30/IV 2/12/22, B1. 271.

43 Information über die Auswertung des Ausbildungsjahres 1961 durch das Ministerium für Nationale Verteidigung und die Kommandos Grenze und Volksmarine, 19. Dezember 1961, SAPMO-BArch, DY 30/IV 2/12/15, Bl. $187 \mathrm{f}$.

44 Erfahrungen und Schlußfolgerungen aus den Brigadeeinsätzen des ZK der SED in der 1. MSD, 4. MSD, in Sonderobjekten und Objekten der Luftverteidigung, 23. Juni 1959, SAPMO-BArch, DY 30/IV 2/12/21, Bl. $242 \mathrm{ff}$.

45 Bericht der Brigade der ZK-Abteilung für Sicherheitsfragen über die Überprüfung der Militäroberstaatsanwaltschaft, 1960, SAPMO-BArch, DY 30/IV 2/12/23, Bl. $6 \mathrm{ff}$.

46 Borning an Honecker, 26. September 1957, SAPMO-BArch, DY 30/IV 2/12/30, Bl. 1.

47 Borning an Honecker, 5. Januar 1961, SAPMO-BArch, DY 30/IV 2/12/29, Bl. 2. 
Höhe ihrer Aufgaben“. Vor allem Dölling als Chef der Verwaltung erkenne „nicht immer richtig die Schwerpunkte in der Arbeit“, weshalb es „keine klare Orientierung" gebe 48 .

Weiterhin kontrollierte die ZK-Abteilung für Sicherheitsfragen auch die Personalpolitik innerhalb des Parteiapparates. So mußte etwa der neue Sekretär einer Regimentsparteiorganisation nicht nur durch das übergeordnete Politorgan, sondern gemäß der Kadernomenklatur auch durch die ZK-Abteilung für Sicherheitsfragen in seiner Dienststellung bestätigt werden ${ }^{49}$.

Die Politische Verwaltung des Ministeriums für Nationale Verteidigung wiederum fungierte innerhalb der Streitkräfte als zentrale Kontrollinstanz der SED ${ }^{50}$. Um diese Funktion erfüllen zu können, sollte sie „alle wichtigen Organe der Nationalen Volksarmee durchdringen" 51 . Die Politische Verwaltung war das "leitende Organ der politischen Arbeit in den Verbänden und Truppenteilen“. Dementsprechend waren ihr „alle übrigen Politorgane unterstellt“, deren „Anleitung und Kontrolle" sie zu organisieren hatte ${ }^{52}$. Als politisches Führungsgremium innerhalb des Ministeriums oblag ihr die Aufgabe, die „systematische Hebung der Kampfbereitschaft, die Festigung der Disziplin und die Erhöhung des politischen Bewußtseins und der Moral" der NVA-Angehörigen anhand des Parteiapparates in der NVA zu steuern. Die Politische Verwaltung mußte nicht nur die politische Ausbildung, sondern aus der Perspektive der Partei auch die militärische Ausbildung analysieren und bewerten ${ }^{53}$. Dies geschah nicht zuletzt im Rahmen von Inspektionen und Brigadeeinsätzen in der Truppe ${ }^{54}$.

Eine zentrale Aufgabe der Politischen Verwaltung war die Einflußnahme auf die Entscheidungen des Ministeriums in Personalfragen ${ }^{55}$. Dabei hatte sie nicht nur "Auswahl, Ausbildung und Einsatz der politischen Kader" zu koordinieren. Vielmehr war die Politische Verwaltung darüber hinaus zuständig für die „Einreichung von Vorschlägen über Einsatz und Beförderung von Kadern, die der Nomenklatur der Regierung und des Zentralkomitees" angehörten ${ }^{56}$. Dies betraf Führungspositionen sowohl im Parteiapparat als auch in der Truppenführung. Die Verwaltung prüfte den jeweiligen Kadervorschlag dabei in erster Linie hinsichtlich seiner politischen Eignung. So war etwa die Beförderung des Chefs der Luftstreitkräfte/Luft-

48 Einschätzung der verantwortlichen Kader der Politischen Verwaltung und Vorschläge zur qualifizierten Besetzung einiger wichtiger Funktionen, 9. Juni 1958, SAPMO-BArch, DY 30/IV 2/12/27, Bl. $25 \mathrm{f}$.

49 Vgl. Wansierski an Verner, 29. Februar 1960, SAPMO-BArch, DY 30/IV 2/12/29, Bl. 39.

50 Vgl. u. a. Lapp, Die Nationale Volksarmee 1956-1990, S. $1932 \mathrm{ff}$.

51 Material für die Aussprache des Genossen Ulbricht mit dem Genossen Verner, 1959, SAPMO-BArch, DY 30/IV 2/12/11, Bl. 466.

52 Bestimmungen für die Arbeit der Politorgane, 1957, S. $12 \mathrm{f}$.

53 Ebenda, S. 6 f.

54 Vgl. Maßnahmen zur Durchführung der Beschlüsse des 4. Plenums des ZK und des Beschlusses des Kollegiums des Ministeriums für Nationale Verteidigung über die Veränderung der Arbeitsweise der leitenden Organe, 1959, SAPMO-BArch, DY 30/IV 2/12/11, B1. 97.

55 Vgl. Mitteilung der Abteilung Kader der Politischen Verwaltung an Wansierski, 19. Februar 1960, SAPMO-BArch, DY 30/IV 2/12/28, Bl. 36.

56 Bestimmungen für die Arbeit der Politorgane, 1957, S. 15. 
verteidigung Generalmajor Heinz Keßler zum Generalleutnant erst möglich, nachdem sie von der Politischen Verwaltung „befürwortet" worden war ${ }^{57}$.

Der Chef der Politischen Verwaltung war zugleich „Stellvertreter für politische Arbeit des Ministers für Nationale Verteidigung “58. 1956 bekleidete diesen Posten Generalmajor Friedrich Dickel, 1956-1957 Oberst G. Grünberg, 1958-1959 Generalmajor Rudolf Dölling und 1959-1978 Vizeadmiral Waldemar Verner. Formal unterstand die Politische Verwaltung daher dem Ministerium. Diese Zuordnung innerhalb der Struktur der NVA wurde aber dadurch relativiert, daß sie darüber hinaus „mit den Rechten einer Abteilung des Zentralkomitees“ der SED ausgestattet war $^{59}$. Entsprechend dem daraus resultierenden doppelten Unterstellungsverhältnis hatte die Politische Verwaltung sowohl dem ZK als auch dem Minister „über alle grundlegenden Fragen der politischen Arbeit" in der NVA Bericht zu erstat$\operatorname{ten}^{60}$.

Eine präzisere Festlegung der übergeordneten Weisungsbefugnis hatte die SEDFührung anscheinend zunächst nicht für nötig erachtet. Aufgrund der Tatsache, daß der Aufbau der Streitkräfte direkt durch die Partei kontrolliert wurde, hielt man eine Kompetenzenkollision zwischen den politischen und militärischen Führungsinstanzen innerhalb des Ministeriums offenbar nicht für wahrscheinlich. Insofern fanden die betreffenden Regelungen im „Statut für die politischen Organe, Parteiund Jugendorganisationen der KVP der DDR " von 195461 zunächst auch Eingang in die "Bestimmungen für die Arbeit der Politorgane der NVA“ von 1957. Dabei hatte die SED-Führung jedoch offensichtlich die Autonomisierungstendenzen innerhalb der neugeschaffenen Militärbürokratie unterschätzt, die sich nach der Umwandlung der KVP in reguläre Streitkräfte verstärkt entfalteten.

Bereits durch den Politbürobeschluß vom 14. Januar 1958 leitete die SED eine Klärung der Kompetenzen ein ${ }^{62}$, die dann in die überarbeiteten „Bestimmungen für die Arbeit der Politorgane der NVA “ von 1958 einging. Die Berichterstattung der Politischen Verwaltung erfolgte jetzt zwar weiterhin an das ZK und den Minister ${ }^{63}$. Die Parteiführung hatte jedoch eindeutig festgelegt, daß die Politische Verwaltung „in ihrer Eigenschaft als leitendes Parteiorgan“ nunmehr „ausschließlich dem Zentralkomitee verantwortlich" war ${ }^{64}$. Dem Minister für Nationale Verteidigung wurde allein das Recht eingeräumt, ihr „Hinweise für die Inangriffnahme und die Lösung bestimmter Aufgaben zu geben und Informationen anzufordern" 65 .

Parallel zur Reduzierung der ministeriellen Einflußnahme wurden jedoch die Kompetenzen der Politischen Verwaltung in militärischen Fragen erweitert und damit gleichzeitig ihre Stellung als Kontrollorgan der Parteiführung innerhalb der

57 Verner an die ZK-Abteilung für Sicherheitsfragen, 14. August 1959, SAPMO-BArch, DY 30/IV 2/12/27, Bl. 119.

58 Bestimmungen für die Arbeit der Politorgane, 1957, S. 12.

59 Ebenda.

60 Ebenda, S. 13.

61 Statut für die politischen Organe, Partei- und Jugendorganisationen der KVP der DDR, 1954, BA-MA, DVH 3/2010, Bl. $95 \mathrm{f}$.

62 Über die Rolle der Partei in der NVA. Protokoll Nr. 4/58 der Sitzung des Politbüros des ZK der SED, 14. Januar 1958, SAPMO-BArch, DY 30/J IV 2/2/576, Bl. 193.

63 Bestimmungen für die Arbeit der Politorgane, 1958, S. 41.

64 Ebenda, S. 40.

65 Ebenda, S. 30. 
NVA betont. Der Chef der Verwaltung war jetzt explizit dazu verpflichtet, „Bedenken, Unstimmigkeiten in der Befehlsgebung, Verletzung der Parteibeschlüsse und der Gesetze der Arbeiter-und-Bauern-Macht durch Kommandeure sowie schwerwiegende besondere Vorkommnisse sofort an das Zentralkomitee zu melden" 66.

\section{Das Kadernomenklatursystem}

Während die führenden Parteigremien die Kontrolle der NVA vor allem auf institutioneller Ebene verwirklichen sollten, indem sie den militärischen Führungsorganen vorgeschaltet waren, diente das Kadernomenklatursystem ${ }^{67}$ auf personeller Ebene als zentrales Steuerungsinstrument. Anhand des Kadernomenklatursystems entschied die SED-Führung über die Vergabe der Führungspositionen innerhalb des Staatsapparates, die sie - so auch in den Streitkräften - auf diese Weise ausschließlich mit hohen Parteikadern besetzen konnte. So wurde etwa Stoph als Mitglied des Politbüros und des ZK 1956 Minister für Nationale Verteidigung68. Die Führungspositionen waren in spezifischen Verzeichnissen, den Kadernomenklaturen, zusammengefaßt, die den leitenden Parteiorganen der SED zugeordnet wurden. Diese hatten die Verantwortung „für die personelle Besetzung der wichtigsten Funktionen mit geeigneten Genossen"69. Im Zentrum des Kadernomenklatursystems stand die Hauptnomenklatur des ZK, auf die sich die Kadernomenklaturen der übrigen leitenden Parteiorgane bezogen 70 . "Nur mittels der Nomenklatur" war es nach Auffassung der SED „möglich, die gesamte Kaderarbeit auf der Grundlage des demokratischen Zentralismus ... von einem Zentrum aus, dem Zentralkomitee, zu leiten"71. Die SED-Funktionäre, die durch das Kadernomenklatursystem in staatliche Führungspositionen wie die des Ministers für Nationale Verteidigung gelangt waren, garantierten die Verwirklichung dieses Prinzips ihrerseits auch auf den nachgeordneten Bürokratieebenen anhand eigener Kadernomenklaturen.

Die politische Zielsetzung, die der Anwendung des Kadernomenklatursystems zugrunde lag, formulierte die SED programmatisch in den „Vorläufigen Richtlinien für die Arbeit mit der Kadernomenklatur des ZK der SED“ vom September 1960: „Die Anwendung der Kadernomenklatur trägt dazu bei, in personeller Hinsicht die führende Rolle der Arbeiterklasse in der DDR entsprechend den Prinzipien des

66 Ebenda, S. $44 \mathrm{f}$.

67 Vgl. u. a. Lapp, Die Nationale Volksarmee 1956-1990, S. 1956 ff.; Wagner, Das Nomenklatursystem, S. 3 ff.; Wagner, Gerüst der Macht, S. 87 ff.; Wenzel, Kriegsbereit: Der Nationale Verteidigungsrat der DDR, S. $46 \mathrm{ff}$.

68 Auch Hoffmann, Keßler und Verner waren als führende Militärs bereits bei Gründung der NVA Mitglieder des ZK. Dölling wurde 1958 als Kandidat ins ZK gewählt.

69 Vorläufige Richtlinien für die Arbeit mit der Kadernomenklatur des ZK der SED. Protokoll Nr. 36/60 der Sitzung des Sekretariats des ZK der SED, 26. September 1960, SAPMOBArch, DY 30/J IV 2/3/704, Bl. 228.

70 Die Nomenklaturkader der NVA wurden ausschließlich durch die leitenden Parteiorgane ZK, Politbüro und Nationaler Verteidigungsrat bestätigt. In der Kadernomenklatur des Ministerrates als höchstem Organ der Exekutive waren die Führungspositionen der Streitkräfte im Gegensatz zu denen des übrigen Staatsapparates nicht aufgeführt. Vgl. Wagner, Gerüst der Macht, S. 91, $98 \mathrm{f}$.

71 Vorläufige Richtlinien für die Arbeit mit der Kadernomenklatur des ZK der SED. Protokoll Nr. 36/60 der Sitzung des Sekretariats des ZK der SED, 26. September 1960, SAPMOBArch, DY 30/J IV 2/3/704, Bl. 227. 
Marxismus-Leninismus zu sichern."72 Die Übertragung des Kadernomenklatursystems vom Parteiapparat auch auf die staatlichen Institutionen war allerdings erst möglich geworden, nachdem die SED die verantwortlichen Positionen der staatlichen Bürokratie mit leitenden Parteikadern besetzt hatte ${ }^{73}$. Erst jetzt war die SED dazu in der Lage, das Kadernomenklatursystem als alleiniges Entscheidungsinstrument bei der Besetzung von Führungspositionen innerhalb der gesamten staatlichen Bürokratie durchzusetzen. Rein fachspezifische Auswahlkriterien wie Qualifikation oder persönliche Eignung hatten dadurch nur noch eine nachrangige Bedeutung. Im Rahmen des Kadernomenklatursystems entschieden die jeweils zuständigen Parteiorgane nunmehr primär über die „zweckmäßigste Auswahl und Verteilung der politisch zuverlässigsten Partei- und prinzipienfesten Genossen“. Erst in zweiter Linie wurden sie „nach ihren Fähigkeiten und Kenntnissen“ beurteilt, jedoch in jedem Fall „entsprechend den Gesamtinteressen der Partei“74. Dieser Grundsatz des Kadernomenklatursystems hatte wie auch im Fall der NVA die entscheidende Konsequenz, daß das reguläre bürokratische Dienst- beziehungsweise Vorgesetztenverhältnis ausgehöhlt wurde. So war beispielsweise ein General nicht mehr allein dem Minister als Dienstherrn unterstellt. Vielmehr unterlag er als Nomenklaturkader auch einer parteimäßigen Rechenschaftspflicht. Als Funktionär war er „für die Erfüllung seiner Aufgaben“ zudem auch „dem leitenden Parteiorgan gegenüber verantwortlich, das ihn entsprechend der Nomenklatur gewählt, bestätigt und eingesetzt" hatte ${ }^{75}$.

Bei Gründung der NVA waren alle militärischen Führungskader bereits in der Nomenklatur der leitenden Kader des Ministeriums des Innern erfaßt. In ihr war detailliert festgelegt, welche leitenden Parteiorgane die Besetzung von Führungspositionen der KVP zu bestätigen hatten ${ }^{76}$. Die Listen der Nomenklaturkader des Po-

72 Ebenda.

731952 hatte das Sekretariat des ZK der SED die „Richtlinien für die Personalpolitik im Staatsapparat und der volkseigenen Wirtschaft" beschlossen. Demnach sollte zur Verwirklichung einer „einheitlichen Personalpolitik" nunmehr der „Grundsatz der Nomenklatur in allen Zweigen des Staatsapparates und der volkseigenen Wirtschaft" angewandt werden. Richtlinien für die prinzipiellen Fragen der Personalpolitik des Staatsapparates sowie der Wirtschaftsorgane. Protokoll Nr. 175/52 der Sitzung des Sekretariats des ZK der SED, 26. Juni 1952, SAPMO-BArch, DY 30/J IV 2/3/304, Bl. 6, $26 \mathrm{ff}$.

74 Vorläufige Richtlinien für die Arbeit mit der Kadernomenklatur des ZK der SED. Protokoll Nr. 36/60 der Sitzung des Sekretariats des ZK der SED, 26. September 1960, SAPMOBArch, DY 30/J IV 2/3/704, Bl. 228.

75 Ebenda.

76 Das Politbüro hatte in bezug auf die KVP folgende Dienststellungen zu bestätigen: Den Chef der KVP und alle seine Stellvertreter, den Stellvertreter des Chefs des Stabes, die Chefs Rückwärtige Dienste, für Bauwesen und Unterbringung, für Ausbildung und Lehranstalten und für Bewaffnung sowie alle Chefs der selbständigen Verwaltungen, ferner alle Chefs der territorialen Verwaltungen, alle Kommandeure der Bereitschaften und den Chef der KVPHochschule Dresden, zudem die Chefs der Verwaltungen Aero-Klub und VP-See sowie deren Stellvertreter und den Chef der Flottenbasis der VP-See. Darüber hinaus mußte das Politbüro sämtlichen Ernennungen innerhalb der Dienstgrade Oberst bis Generalmajor zustimmen. Das Sekretariat des ZK hatte alle Chefs der unselbständigen Verwaltungen und deren Stellvertreter zu bestätigen, ferner alle Abteilungsleiter des Stabes der KVP im Generalsrang, alle Leiter der Offiziersschulen, alle Stellvertreter der Chefs der Territorialen Verwaltungen, den Chef der Politschule, den Politstellvertreter und alle Stellvertreter des Chefs der Flottenbasis VP-See sowie den Stabschef der Flottenbasis, die Leiter des Seehydrographi- 
litbüros und des ZK-Sekretariates wurden in der „Hauptnomenklatur des ZK der SED“ vom 6. September 1955 nochmals leicht verändert ${ }^{77} .1956$ wurden beide Kadernomenklaturen unter Berücksichtigung der neuen Bezeichnungen für die militärischen Ränge und Dienststellungen dann offenbar direkt auf die NVA übertragen. Sie galten im Grundsatz bis zum Inkrafttreten der neuen ZK-Hauptnomenklatur 1961.

Anscheinend sah es die SED aber aufgrund der strukturellen Veränderungen innerhalb der Militärorganisation nach der Umwandlung der KVP in die NVA als notwendig an, bei Nomenklaturen der militärischen Führungskader einige Modifikationen vorzunehmen. Dies geschah vor allem durch den Beschluß der Sicherheitskommission vom 15. April 1957. Er bestätigte die „Nomenklatur der leitenden Kader des Ministeriums für Nationale Verteidigung". Der Beschluß hatte insbesondere zur Folge, daß die Zuständigkeit zur Besetzung eines Großteils der militärischen Nomenklaturkader, die bisher vom Politbüro bestätigt wurden, auf die Sicherheitskommission übertragen wurde. Das Politbüro bestätigte anschließend nur noch die Dienststellungen aller Stellvertreter des Ministers für Nationale Verteidigung, ferner der Chefs der Verwaltung Kader, der Rückwärtigen Dienste, der Seestreitkräfte und der Militärbezirke sowie sämtliche Ernennungen zum General und Admiral, darüber hinaus alle Beförderungen innerhalb der Generalsdienstgrade ${ }^{78}$. Der Nationale Verteidigungsrat wiederum beschloß auf seiner konstituierenden Sitzung am 16. März 1960 eine eigene Nomenklatur, die die Nomenklatur der Sicherheitskommission in bezug auf die militärischen Führungskader in einigen wesentlichen Positionen modifizierte. Bis auf den Posten des Ministers ging die Kompetenz zur Besetzung der Spitzenfunktionen der NVA, die bis dahin noch zur Nomenklatur des

schen Dienstes und der Offiziersschulen der VP-See, darüber hinaus die Stellvertreter des Chefs des Stabes der Verwaltungen des Aero-Klubs und der VP-See, alle Stellvertreter des Chefs des Aero-Klubs, alle Leiter der Schulen der Verwaltung des Aero-Klubs sowie den Standortältesten von Groß-Berlin und seinen Politstellvertreter. Die ZK-Abteilung für Sicherheitsfragen hatte hinsichtlich des Parteiapparates in der KVP folgende Nomenklaturkader zu bestätigen: Die Parteisekretäre der Parteiorganisation des Stabes der KVP, der Parteiorganisation bei der Verwaltung VP-See und der Parteiorganisation bei der Verwaltung des Aero-Klubs, ferner alle Abteilungsleiter der Politverwaltung, alle Politstellvertreter der Regimentskommandeure, alle Stellvertreter des Chefs der Politschule, den Politstellvertreter des Seehydrographischen Dienstes der VP-See und die Leiter der Politabteilungen der Sonderobjekte. Bei den militärischen Dienststellungen waren es alle Stellvertreter der Chefs der Bereitschaften, alle Regimentskommandeure, alle Stellvertreter der Leiter der Offiziersschulen und Schulen der drei Teilstreitkräfte, den Stadtkommandanten von Groß-Berlin, alle Chefs der Divisionen der VP-See sowie den Leiter der Kaderabteilung der VP-See, die Chefs des Waffenarsenals sowie des Bergungs- und Rettungskommandos der VP-See, zudem den Leiter der Ausbildungsabteilung der Verwaltung des Aero-Klubs und der Leiter der Kaderverwaltung des Aero-Klubs. Darüber hinaus waren alle Beförderungen zum Oberst zu bestätigen. Nomenklatur der leitenden Kader des Ministeriums des Innern. Protokoll Nr. 11/54 der Sitzung des Politbüros des ZK der SED, 23. Februar 1954, SAPMO-BArch, DY $30 / J$ IV $2 / 2 / 349$, Bl. $6,33 \mathrm{ff}$.

77 Hauptnomenklatur des ZK der SED. Protokoll Nr. 41/55 der Sitzung des Politbüros des ZK der SED, 6. September 1955, SAPMO-BArch, DY 30/J IV 2/2/438, Bl. 13 ff., 21.

78 Nomenklatur der leitenden Kader des Ministeriums für Nationale Verteidigung. Protokoll der 16. Sitzung der Sicherheitskommission des ZK der SED, 15. April 1957, BA-MA, DVW $1 / 39558$, Bl. $9 \mathrm{ff}$. 
Politbüros gehört hatte, nunmehr ebenso auf den Nationalen Verteidigungsrat über ${ }^{79}$.

Grundlegend neu festgelegt wurde die Liste der militärischen Führungskader dann in der „Hauptnomenklatur des ZK der SED“, die das Politbüro am 17. Januar 1961 bestätigte ${ }^{80}$. Der Sektor Nationale Verteidigung der Nomenklatur bestand jetzt aus insgesamt 400 Kaderpositionen. Bezüglich des Politbüros wurden die Festlegungen der Nomenklatur des Nationalen Verteidigungsrates von 1960 übernommen. Die Nomenklatur des Nationalen Verteidigungsrates umfaßte nun einschließlich der Politfunktionen die Dienststellungen des 1. Stellvertreters des Ministers und Chefs des Hauptstabes, des Stellvertreters des Ministers und Chefs der Luftstreitkräfte und Luftverteidigung, des Stellvertreters des Ministers und Chefs der Politischen Verwaltung und des Stellvertreters des Ministers für Ausbildung, ferner des Chefs Rückwärtige Dienste sowie der Chefs der Verwaltungen Kader, Ausbildung, Panzer, Artillerie, Nachrichten, Pionierwesen und Aufklärung. Außerdem gehörten zur Nomenklatur des Nationalen Verteidigungsrates die Stellvertreter der Chefs des Hauptstabes, der Verwaltung Kader und der Politischen Verwaltung sowie die Chefs der 12., 14. und 15. Verwaltung, darüber hinaus die Chefs der Militärbezirke und des Kommandos der Seestreitkräfte und deren Stellvertreter sowie die Stellvertreter des Chefs der Luftstreitkräfte/Luftverteidigung, die Kommandeure der Divisionen der Landstreitkräfte, Luftstreitkräfte/Luftverteidigung und der Flottillen der Seestreitkräfte sowie der Kommandeur und 1. Stellvertreter der Militärakademie „Friedrich Engels" und der Leiter des Instituts für deutsche Militärgeschichte. Schließlich umfaßte die Nomenklatur auch die Dienststellungen des Leiters der Auslandsabteilung, des Militärattachés in der UdSSR, in der VR Polen, in der ČSR und in der VR China sowie des Militäroberstaatsanwaltes.

Die Nomenklatur enthielt jedoch nur wenige Funktionen des Parteiapparates, die statt dessen in der Nomenklatur der ZK-Abteilung für Sicherheitsfragen geführt wurden. Dies mag daran gelegen haben, daß der Nationale Verteidigungsrat formal als staatliches Organ gelten sollte. In der Nomenklatur der ZK-Abteilung für Sicherheitsfragen waren rund 335 Nomenklaturkader aufgeführt, zu denen neben leitenden Funktionen des Parteiapparates ${ }^{81}$ Dienststellungen der militärischen Truppenführung 82 gehörten.

79 Nomenklatur des Nationalen Verteidigungsrates der DDR. Protokoll der 1. Sitzung des Nationalen Verteidigungsrates der DDR, 16. März 1960, BA-MA, DVW 1/39458, Bl. 3, $21 \mathrm{f}$.

80 Hauptnomenklatur des ZK der SED. Protokoll Nr. 3/61 der Sitzung des Politbüros des ZK der SED, 17. Januar 1961, SAPMO-BArch, DY 30/J IV 2/2/745, Bl. 7, $22 \mathrm{ff}$.

81 Hier bestätigte die ZK-Abteilung für Sicherheitsfragen den Sekretär der Kreisleitung des Ministeriums für Nationale Verteidigung, die Abteilungsleiter der Politischen Verwaltung, die Leiter der Politabteilungen der Sonderobjekte des Ministeriums, der Divisionen der Landstreitkräfte, Luftstreitkräfte und der Flottillen der Seestreitkräfte, deren Stellvertreter sowie die Parteisekretäre der Kommandos der Militärbezirke, der Luftstreitkräfte/Luftverteidigung, der Seestreitkräfte und des Ministeriums. Zudem umfaßte die Nomenklatur die Leiter der Politabteilungen der Sonderobjekte der Kommandos der Teilstreitkräfte, ferner die Parteisekretäre der Regimenter der Militärbezirke, der Luftstreitkräfte/Luftverteidigung, der Regierungsfliegerstaffel, des Ministeriums und der Schulen sowie den Parteisekretär und den Leiter der Politabteilung der Militärakademie. Nomenklatur des Sektors Nationale Verteidigung, 1961, SAPMO-BArch, DY 30/IV 2/12/29, Bl. $208 \mathrm{ff}$.

82 Im einzelnen waren es die Dienststellungen der Chefs der Verwaltungen Finanzen, Kraftfahrzeuge, Organisation-Planung, Werbung und Auffüllung sowie der Medizinischen Ver- 


\section{Der Parteiapparat}

\section{Die Politorgane}

Die Politorgane waren nach Gründung der NVA zunächst die entscheidende Institution in den Streitkräften, die der SED eine direkte Kontrolle der Diskussions- und Entscheidungsprozesse auf allen Ebenen der militärischen Truppenführung garantieren sollte ${ }^{83}$. Unterhalb der Politischen Verwaltung des Ministeriums für Nationale Verteidigung setzten sie sich zunächst aus den Politabteilungen der Militärbezirke der Landstreitkräfte sowie der Kommandos der Seestreitkräfte und der Luftstreitkräfte/Luftverteidigung zusammen. Auf der anschließenden Ebene befanden sich die Politabteilungen der Divisionen und aller gleichgestellten Einheiten der übrigen Teilstreitkräfte ${ }^{84}$. Die Leiter der Politabteilungen waren jeweils Stellvertreter für politische Arbeit ihrer Kommandeure ${ }^{85}$. Politstellvertreter gab es in der NVA darüber hinaus von der Regiments- hinunter bis zur Kompanieebene.

Nominell waren die Politorgane die „leitenden Organe“ der SED für die „politische Arbeit" in der NVA ${ }^{86}$. Sie hatten die Verantwortung für die verschiedenen Formen der politischen Erziehung ${ }^{87}$. Die davon ausgehende Politisierung der Armeeangehörigen war auf die „systematische Hebung der Kampfbereitschaft, die Festigung der Disziplin und die Erhöhung des politischen Bewußtseins und der Moral gerichtet" 88 . Eine weitere Aufgabe der Politorgane war die Anleitung und Kontrolle der Arbeit der Parteiorganisationen der SED in der NVA, die sie bei der Erziehung der Parteimitglieder unterstützen sollten ${ }^{89}$.

Die zentrale Funktion der Politorgane war es aber, das militärische Führungspersonal aller Einheiten und Truppenteile zu überwachen und sicherzustellen, daß es die politischen Vorgaben und Zielsetzungen der SED berücksichtigte. Die „Bestimmungen für die Arbeit der Politorgane der NVA" von 1957 kleideten dies in die

waltung, ferner der Chefs Chemische Dienste und Transportwesen. Darüber hinaus gehörten zu der Nomenklatur die Abteilungsleiter der Verwaltung Kader, die Chefs Operativ der Kommandos der Militärbezirke und der Seestreitkräfte, die Leiter der Kaderabteilungen der Teilstreitkräfte, die stellvertretenden Divisionskommandeure der Landstreitkräfte, Luftstreitkräfte und der Flottillen der Seestreitkräfte, Stabsdienststellungen im Kommando Luftstreitkräfte/Luftverteidigung, die Kommandeure der Schulen sowie die Chefs der Bezirkskommandos und der Chef der Organisations-Abteilung Berlin. Auch die Regimentskommandeure der Teilstreitkräfte und des Ministeriums für Nationale Verteidigung mußten durch die ZK-Abteilung für Sicherheitsfragen bestätigt werden. Die Tatsache, daß die SEDFührung die Vergabe von Kommandeursposten in den Streitkräften durch ein leitendes Parteiorgan sogar noch auf dieser verhältnismäßig niedrigen Ebene kontrollierte, zeigt, wie groß das Sicherheitsbedürfnis der Partei war. Zudem bestätigte die ZK-Abteilung für Sicherheitsfragen alle Beförderungen zum Oberst und die Delegierungen an die Militärakademien der UdSSR. Nomenklatur des Sektors Nationale Verteidigung, 1961, SAPMO-BArch, DY $30 / \mathrm{IV} 2 / 12 / 29, \mathrm{Bl} .206 \mathrm{ff}$.

83 Vgl. u. a. Glaser, Zur Entwicklung der militärischen Einzelleitung, S. $102 \mathrm{ff} . ;$ Haueis, Die führende Rolle der SED in der Nationalen Volksarmee, S. $435 \mathrm{ff}$.

84 Bestimmungen für die Arbeit der Politorgane, 1957, S. 12, 16, 21.

85 Ebenda, S. 12, 22.

86 Ebenda, S. 5.

87 Ebenda, S. $13 \mathrm{f}$.

88 Ebenda, S. 6 f.

89 Ebenda, S. 8 f. 
Formel, es sei Aufgabe der Politorgane, die „Autorität der Kommandeure und Vorgesetzten“ zu festigen, weshalb sie diese „bei der Erfüllung ihrer Pflichten“ unterstützen und ihnen „bei ihrer ideologischen, militärischen und kulturellen Entwicklung" helfen sollten ${ }^{90}$. Tatsächlich aber nahmen die Politorgane nicht mittels der politischen Erziehung Einfluß auf die militärische Truppenführung. Entscheidend war vielmehr das Kontrollmoment. Denn die Politorgane hatten auch die Pflicht, „das politische Bewußtsein und die Moral in den Verbänden und Truppenteilen regelmäBig zu analysieren" und den Kommandeuren und übergeordneten Politorganen über deren „Zustand“ zu berichten ${ }^{11}$. Die Politorgane und Politstellvertreter wirkten in diesem Zusammenhang nicht nur direkt auf die Truppenführung ein. Sie fungierten darüber hinaus als separater Kontroll- und Meldeweg neben der militärischen Befehlskette, der bei den zentralen Entscheidungsgremien der SED-Führung endete. Die Partei verfügte somit über ein eigenes Instrument, mit welchem sie die Situation in den Streitkräften auf allen Ebenen permanent überwachen konnte.

Die Kompetenz der Politorgane beschränkte sich jedoch nicht nur auf den politischen Bereich. Sie sollten sich auch „intensiv mit allen Fragen der militärischen ... Ausbildung beschäftigen und rechtzeitig Maßnahmen zur Beseitigung der Mängel ergreifen, die die Erhöhung der Kampfbereitschaft der Truppen behinderten" 92 . Dabei hatten vor allem die Leiter der Politabteilungen eine herausgehobene Stellung. Als Stellvertreter für politische Arbeit der Kommandeure der Militärbezirke, Kommandos und Divisionen der Teilstreitkräfte hatten sie die Pflicht, „Bedenken, Unstimmigkeiten in der Befehlsgebung, Verletzungen der Parteibeschlüsse und der demokratischen Gesetze durch Kommandeure und schwerwiegende besondere Vorkommnisse" an die übergeordneten politischen Organe zu melden ${ }^{93}$. Aber auch die Politstellvertreter von der Regiments- bis hinab zur Kompanieebene waren berechtigt, die Befehle der Kommandeure zu überwachen und Einfluß auf deren Inhalt zu nehmen. Die latente Drohung, negativ über die Arbeit der Kommandeure und Stäbe zu berichten, ermöglichte es, die militärische Entscheidungsfindung im Sinne der Partei zu beeinflussen. Die Stellung der Politstellvertreter innerhalb des militärischen Befehlsgefüges wurde nach Gründung der NVA anfangs noch zusätzlich durch ihre dienstrechtlichen Befugnisse gestärkt. Aufgrund der Tatsache, daß die Innendienstvorschrift der KVP nach 1956 zunächst offenbar in Ermangelung eines Ersatzes weiterhin gültig blieb, unterstand ein Politstellvertreter dienstlich zwar seinem Kommandeur, zugleich war er aber „der direkte Vorgesetzte des gesamten Personalbestandes" der Einheit ${ }^{94}$. Diese Regelung stärkte seine ohnehin schon exponierte Stellung zusätzlich.

Die Effizienz der Politorgane und ihr Einfluß auf die militärische Truppenführung blieben zunächst aber anscheinend hinter den Erwartungen der SED zurück. Ihre Arbeit wurde als „unbefriedigend“ eingeschätzt ${ }^{95}$.

90 Ebenda, S. $7 \mathrm{f}$.

91 Ebenda, S. 10.

92 Ebenda, S. 7.

93 Ebenda, S. 21, 28.

94 Vorläufige Innendienstvorschrift der Kasernierten Volkspolizei DV-10/3, 1953, S. 24.

95 Entwurf des Referats des Ministers für Nationale Verteidigung für die Eggersdorfer Tagung, 1957, SAPMO-BArch, DY 30/IV 2/12/10, Bl. 10. 
Viele Kommandeure wehrten sich nachhaltig gegen die politischen Eingriffe in ihren fachlichen Zuständigkeitsbereich, weshalb die Kontrolle durch die Politorgane nur eine beschränkte Wirkung erzielte ${ }^{96}$. Offenbar wurde im Offizierskorps die "Zweckmäßigkeit" der Politorgane massiv angezweifelt und „verschiedentlich

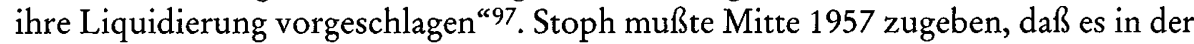
NVA noch immer "den sogenannten unpolitischen Offizier, den Nurfachmann" gab98. Die SED forderte deshalb, die Politorgane müßten „ihren Einfluss auf die militärische Führungsarbeit unbedingt verstärken“. Es dürfe „keine militärische Handlung geben[,] bei der der Politstellvertreter seine Meinung nicht geltend“ mache ${ }^{99}$. Die Politorgane seien „das politische Organ der Truppenführung “100. Doch mußte die Partei einräumen, daß etwa während der Aufstände in Polen und Ungarn 1956 nicht jeder Leiter der Politabteilungen in der Lage gewesen sei, „selbständig die politische Führung zu gewährleisten"101.

Die Probleme waren nicht zuletzt auch das Ergebnis organisatorischer Defizite. Ursächlich hierfür war die zentralistische Struktur der Politorgane, weshalb die Steuerung und Kontrolle jeder Ebene allein über die übergeordnete Instanz, nicht aber horizontal ausgeübt werden konnte. Die Schwierigkeiten wurden noch dadurch verstärkt, daß die Leiter der Politabteilungen und die Politstellvertreter in ihren Einheiten zugleich auch Vorgesetzte mit Disziplinarbefugnis waren. Dies sei, so Stoph, der Grund dafür gewesen, warum sie oftmals den Vorgesetzten „zu stark herausgekehrt, und anstelle der Hilfe und Anleitung einfach kommandiert" hät$\operatorname{ten}^{102}$.

Die SED sah sich damit konfrontiert, daß viele Politstellvertreter eine ähnliche Verhaltensweise wie die Kommandeure entwickelten, der sie eigentlich entgegentreten sollten. So reklamierten auch sie eine unabhängige Entscheidungsgewalt in ihrem Tätigkeitsbereich. Die Mitarbeiter der Politorgane begannen offenbar zum Teil selbst, sich der Parteikontrolle zu entziehen. Das führte dazu, daß Parteiprinzipien ignoriert und die Parteiorganisationen zunehmend anhand von Befehlen militärisch geführt wurden. Diese Tendenz verstärkte sich noch dadurch, daß die Leiter der Politabteilungen das Recht hatten, Beschlüsse der Parteigrundorganisationen der SED in der NVA eigenständig aufzuheben ${ }^{103}$. Stoph äußerte als Reaktion darauf, die Disziplinargewalt der Politoffiziere müsse sich auf „die ihnen unmittelbar unterstellten Genossen beschränken“. In der Parteiorganisation sei der Politoffizier "gleichberechtigtes Mitglied“104.

96 Vgl. Kap. VI. dieser Studie.

97 Entwurf des Referats des Ministers für Nationale Verteidigung für die Eggersdorfer Tagung, 1957, SAPMO-BArch, DY 30/IV 2/12/10, Bl. 8.

98 Protokoll der Eggersdorfer Tagung, 12./13. Juni 1957, BA-MA, VA-P-01/037, Bl. 47.

99 Entwurf des Referats des Ministers für Nationale Verteidigung für die Eggersdorfer Tagung, 1957, SAPMO-BArch, DY 30/IV 2/12/10, B1. 13.

100 Ebenda, Bl. 10.

101 Ferner hieß es, die Politstellvertreter warteten im allgemeinen „noch zu sehr auf Anweisungen von oben“. Einschätzung des politisch-moralischen Zustandes und der Stimmungen der Verbände und Truppenteile, 1956, BA-MA, VA-01/1752, Bl. 92 f.

102 Protokoll der Eggersdorfer Tagung, 12./13. Juni 1957, BA-MA, VA-P-01/037, Bl. 53.

103 Ebenda.

104 Ebenda. 
Die Parteiführung nahm diese Mißstände offenbar ab Mitte 1957 zum Anlaß, hinsichtlich der Kompetenzen der Politorgane organisatorische Veränderungen einzuleiten. Intern hieß es, es sei falsch zu denken, daß von den Politorganen „die ganze politische Arbeit geleistet" werden müsse ${ }^{105}$. Die SED-Führung verlangte daher von der Politischen Verwaltung, „die Qualität der politischen Führungsarbeit zu verbessern". Die operative Anleitung und Kontrolle beschränke sich bisher fast ausschließlich auf die Politorgane und Politstellvertreter, während die Parteisekretäre und Parteileitungen vernachlässigt würden ${ }^{106}$. Die Politorgane hätten als leitende Parteiorgane jetzt aber vor allem „die Aufgabe[,] die Parteiorganisation durch ihre Anleitung zu befähigen[,] die führende Rolle [der SED] in der Armee zu verwirklichen"107.

Deutlich sichtbar wurden die eingeleiteten organisatorischen Veränderungen in bezug auf die Aufgaben der Politorgane dann im Politbürobeschluß „Über die Rolle der Partei in der NVA" vom 14. Januar 1958. Dort heißt es unter anderem, die Politstellvertreter seien ,verantwortlich für die gewissenhafte Durchführung der Befehle und Direktiven des Ministers für Nationale Verteidigung und ihrer vorgesetzten Kommandeure auf den Gebieten der politischen Massenarbeit, der Kulturarbeit, des Politunterrichtes usw." ${ }^{108}$. In spezifisch militärischen Fragen kam den Politstellvertretern jetzt primär eine Überwachungsfunktion zu. Die direkte Einflußnahme auf Entscheidungen der militärischen Truppenführung sollte fortan im Rahmen kollektiver Entscheidungsprozesse verwirklicht werden, indem die Kommandeure verpflichtet wurden, alle wichtigen militärischen Maßnahmen vor der Beschlußfassung in den Parteileitungen der Einheiten und den Militärräten zu beraten ${ }^{109}$. Diese organisatorische Verschiebung und die Aufwertung der Parteiorganisationen im System der politischen Durchdringung des Militärs war bereits durch die neue "Instruktion für die Arbeit der Parteiorganisationen der SED in der NVA" von 1957 eingeleitet worden ${ }^{110}$. Gleichzeitig verloren die Politstellvertreter damit aber auch an Einfluß innerhalb des Parteiapparates. Denn gegenüber den Parteiorganisationen hatten sie nunmehr ,unter Wahrung der innerparteilichen Demokratie ausschließlich das Recht und die Pflicht der Beratung"111. Im Hinblick auf die dienst- und disziplinarrechtlichen Konsequenzen dieser Veränderungen blieb der Politbürobeschluß jedoch ungenau und verwies nur auf die „allgemeingültigen Bestimmungen"112. Eine detaillierte Regelung dieser Frage scheint es aber zunächst nicht gegeben zu haben ${ }^{113}$.

105 Entwurf des Referats des Ministers für Nationale Verteidigung für die Eggersdorfer Tagung, 1957, SAPMO-BArch, DY 30/IV 2/12/10, Bl. 11.

106 Probleme für einen Diskussionsbeitrag zur Beratung von Mitgliedern des Politbüros mit leitenden Parteifunktionären in der NVA, 1957, SAPMO-BArch, DY 30/IV 2/12/9, Bl. 18.

107 Entwurf des Referats des Ministers für Nationale Verteidigung für die Eggersdorfer Tagung, 1957, SAPMO-BArch, DY 30/IV 2/12/10, Bl. 11.

108 Ưber die Rolle der Partei in der NVA. Protokoll Nr. 4/58 der Sitzung des Politbüros des ZK der SED, 14. Januar 1958, SAPMO-BArch, DY 30/J IV 2/2/576, Bl. 194.

109 Ebenda, Bl. 193.

$110 \mathrm{Vgl}$. S. $99 \mathrm{ff}$.

111 Über die Rolle der Partei in der NVA. Protokoll Nr. 4/58 der Sitzung des Politbüros des ZK der SED, 14. Januar 1958, SAPMO-BArch, DY 30/J IV 2/2/576, Bl. 194.

112 Ebenda.

113 Vgl. Plan zur Auswertung und Durchführung des Beschlusses des Politbüros vom 14. Ja- 
Die überarbeiteten „Bestimmungen für die Arbeit der Politorgane der NVA“ vom Juni 1958 schufen in dieser Frage vorläufig Klarheit. So unterstanden die Leiter der Politabteilungen dem Kommandeur ihrer Einheit ausschließlich in ihrer Funktion als Stellvertreter für politische Arbeit. „Disziplinar [sic!]" waren sie jedoch dem „nächsthöheren Kommandeur unterstellt" ${ }^{114}$. Auf diese Weise wurden die Politstellvertreter dem direkten Zugriff ihrer jeweiligen Einheitsführer entzogen, was die Erfüllung ihres Kontrollauftrages erleichterte. Die Unabhängigkeit der Politorgane gegenüber der militärischen Truppenführung verbesserte sich auch dadurch, daß sie nicht mehr "vom Minister für Nationale Verteidigung auf Vorschlag des Chefs der Politischen Verwaltung"115, sondern allein „entsprechend der Nomenklatur auf Vorschlag des Chefs der Politischen Verwaltung und der Leiter der Politabteilungen " eingesetzt wurden ${ }^{116}$.

Anscheinend gab es innerhalb des Parteiapparates massive Probleme, die organisatorischen Veränderungen zu vermitteln. Möglicherweise scheute sich die Parteiführung auch, vor allem den Einflußverlust der Politstellvertreter sofort im Detail bekanntzugeben. Zumindest bewirkte der Politbürobeschluß zunächst offenbar keine Klärung über die veränderten Kompetenzen, was innerhalb der Politorgane zu einer gewissen Unsicherheit hinsichtlich der eigenen Rolle führte. Im März 1958 konstatierte die ZK-Abteilung für Sicherheitsfragen, es gebe über „die Rolle und Funktion des Politstellvertreters ... zur Zeit noch grosse Diskussionen “117. Einige Politstellvertreter fragten sich, ob ihre "Funktion überhaupt noch notwendig“ sei ${ }^{118}$. Unter anderem kam es zu Auseinandersetzungen zwischen Politstellvertretern und Parteisekretären hinsichtlich der Frage, wer die ,größeren ,Machtbefugnisse“" habe ${ }^{119}$. Die Irritationen innerhalb der Politorgane gingen sogar so weit, daß geäußert wurde, es gebe ,in absehbarer Zeit keine Politstellvertreter mehr ..., sondern nur noch Parteisekretäre" 120 . Anscheinend erzeugte die unklare Lage bei einem Teil der Politoffiziere eine gewisse Verweigerungshaltung. Im folgenden Monat kritisierte die ZK-Abteilung für Sicherheitsfragen, daß viele Politstellvertreter „nicht von dem Wunsch erfüllt“" seien, „zum Sekretär der Parteiorganisation gewählt zu werden“ 121 .

Die Politische Verwaltung war in dieser Phase offenbar nicht dazu in der Lage, die strukturellen Änderungen gegenüber den unterstellten Politorganen schlüssig zu erklären und umzusetzen. Daraus resultierte unter anderem eine „falsche Ausle-

nuar 1958 „Über die Rolle der Partei in der NVA“, 1. Februar 1958, BA-MA, VA-P-01/7535, Bl. $155 \mathrm{f}$.

114 Bestimmungen für die Arbeit der Politorgane, 1958, S. 29 f.

115 Bestimmungen für die Arbeit der Politorgane, 1957, S. 5.

116 Bestimmungen für die Arbeit der Politorgane, 1958, S. 30.

117 Arbeitstagung der Abteilungsleiter für Sicherheitsfragen, 28./29. März 1958, SAPMOBArch, DY 30/IV 2/12/5, Bl. 7.

118 Ebenda, Bl. 9.

119 Bericht über die Stimmungen der Armeeangehörigen und Erscheinungen in der politischen Arbeit in der zweiten Monatshälfte März 1958, 1958, BA-MA, VA-01/1752, Bl. 82.

120 Bericht über die Stimmungen der Armeeangehörigen und Erscheinungen in der politischen Arbeit in der ersten Monatshälfte März 1958, 1958, BA-MA, VA-01/1752, Bl. 75.

121 Information über die bisherige Auswertung der Beschlüsse des 35. Plenums des ZK und des Beschlusses des Politbüros vom 14. Januar 1958 in der NVA, 21. April 1958, SAPMOBArch, DY 30/IV 2/12/9, Bl. 48. 
gung des Politbürobeschlusses" durch einige Politabteilungen. Diese sahen sich veranlaßt, „einen einfachen Umtausch durchzuführen, d.h. automatisch alle Politstellvertreter zu Parteisekretären zu wählen"122. Offenbar hatten die Politorgane auf dieser Ebene noch nicht realisiert, daß der Politstellvertreter nicht etwa durch den Parteisekretär ersetzt werden sollte, sondern daß es die Absicht war, letzteren in seiner Funktion parallel zum Politstellvertreter zu stärken.

Ursächlich war die Fehlentwicklung offensichtlich dadurch ausgelöst worden, daß die Politische Verwaltung unter Federführung ihres Chefs Dölling die Existenz des Politbürobeschlusses zunächst nur den Leitern der Politabteilungen und den Kommandeuren im Rahmen einer Beratung bekanntgegeben hatte. Der Beschluß wurde ihnen jedoch nur in Teilen „sinngemäß “ erläutert. Die Parteiorganisationen ihrerseits erfuhren ihn im Wortlaut erst sehr viel später, was einen „erheblichen Zeitverlust“ zur Folge hatte123. Der Grund hierfür könnte gewesen sein, daß sich die Politische Verwaltung anfangs selbst unsicher war, welche praktischen Konsequenzen der Politbürobeschluß haben würde, und sie sich wegen des Fehlens präziser Hinweise der führenden Parteigremien hinsichtlich der Auslegung nicht selbständig vorwagen wollte. Möglicherweise aber wurde die Umsetzung wegen des Einflußverlustes der Politstellvertreter auch bewußt verzögert.

Der Leiter der ZK-Abteilung für Sicherheitsfragen Borning kritisierte die Politische Verwaltung in diesem Zusammenhang sogar öffentlich in der Zeitung „Die Volksarmee“: „Die unmittelbare operative[,] praktische Hilfe bei der Durchführung des Beschlusses in den Grundorganisationen wurde durch die Politische Verwaltung nur ungenügend verwirklicht. "124 Dieser ungewöhnliche Schritt sollte möglicherweise von eigenen Versäumnissen ablenken. Die Ursache für die mangelhafte Umsetzung des Politbürobeschlusses dürfte nicht zuletzt bei der ZK-Abteilung für Sicherheitsfragen selbst gelegen haben, die offenbar nicht dazu in der Lage gewesen war, die Politische Verwaltung mit den entscheidenden Informationen zu versorgen. Für diese Vermutung spricht, daß sie zweieinhalb Monate nach dem Politbürobeschluß etwa hinsichtlich der neuen Stellung des Politstellvertreters im Regiment, über die offensichtlich noch immer „keine völlige Klarheit“ bestand, eher tastend als bestimmt bemerkte: „Unsere Meinung zu dieser Frage ist, da im Regiment eine gewählte Parteileitung besteht und dazu ein hauptamtlicher Parteisekretär, dass dieser, wenn man so sprechen will, auch der höchste Parteifunktionär ... ist." 125 Die „Korrektur dieser unklaren Linie“, konnte dann anscheinend erst durch das direkte Eingreifen Honeckers als zuständigem ZK-Sekretär für Sicherheitsfragen erreicht werden ${ }^{126}$.

122 Bericht über die Vorbereitung und Durchführung der Berichtswahlversammlung in den Parteiorganisationen der NVA, Mai 1958, BA-MA, VA-P-01/031, Bl. $11 \mathrm{f}$.

123 Information über die bisherige Auswertung der Beschlüsse des 35. Plenums des ZK und des Beschlusses des Politbüros vom 14. Januar 1958 in der NVA, 21. April 1958, SAPMOBArch, DY 30/IV 2/12/9, Bl. 46.

124 Borning, Unter Führung der Partei erringen wir Erfolge, S. 2.

$125 \mathrm{Vgl}$. Arbeitstagung der Abteilungsleiter für Sicherheitsfragen, 28./29. März 1958, SAPMOBArch, DY 30/IV 2/12/5, Bl. $7 \mathrm{f}$.

126 Bericht über den Stand der Durchführung der Beschlüsse des V. Parteitages der SED in der NVA, 20. Oktober 1958, SAPMO-BArch, DY 30/IV 2/12/10, Bl. 239. 
Diese offensichtlichen Abstimmungsschwierigkeiten waren aber vermutlich auch auf die Tatsache zurückzuführen, daß die SED in dieser Phase keine langfristig geplante, in sich schlüssige Militärpolitik verfolgte. Die zunehmende Orientierung der SED-Führung an der chinesischen Militärpolitik, deren zentrales Element die politische Durchdringung des Militärs mittels der Parteiorganisationen und nicht der Politorgane war, dürfte eine weitere Ursache für die auftretenden Probleme gewesen sein. Anscheinend gab es kein ausgereiftes Konzept für die Implementierung des chinesischen Ansatzes. Der Umstand, daß dieses Modell nicht einfach kopiert werden konnte, sondern mit dem bereits bestehenden sowjetischen verbunden werden mußte, erzeugte zusätzliche Friktionen. Ulbricht selbst hatte auf der Eggersdorfer Tagung im Juni 1957 die Unsicherheit des Politbüros hinsichtlich der Veränderungen des Parteiapparates in der NVA zum Ausdruck gebracht, indem er sagte: „Wir behaupten nicht, daß das die endgültige abgeschlossene Auffassung ist." 127

Dienstrechtlich wurden die Stellung und Aufgabe der Politorgane und Politstellvertreter dann schließlich in der neuen Innendienstvorschrift der NVA geregelt, die am 1. Februar 1959 in Kraft trat. Sie bestätigte die Festlegungen, die durch das Politbüro und die „Bestimmungen für die Arbeit der Politorgane der NVA“ von 1958 zuvor fixiert worden waren. In der Innendienstvorschrift heißt es etwa in bezug auf den Stellvertreter für politische Arbeit eines Regimentes, er unterstehe in seiner spezifischen Funktion dem Kommandeur und sei diesem rechenschaftspflichtig. Der Politstellvertreter war jedoch nur noch innerhalb seines Verantwortungsbereiches "anordnungs- und weisungsberechtigt". Dies bedeutete eine Zurückstufung in der militärischen Hierarchie, denn seine Stellung als Vorgesetzter des gesamten Personalbestandes der Einheit hatte er jetzt eingebüßt. Diese Bestimmung der Vorläufigen Innendienstvorschrift war in der neuen Innendienstvorschrift nicht mehr enthalten. Sie ließ darüber hinaus aber auch den Kompetenzverlust des Politstellvertreters innerhalb des Parteiapparates klar hervortreten. So hatte der Politstellvertreter eines Regimentes zwar weiter die politische Arbeit zu organisieren und die „Stellvertreter für politische Arbeit der Bataillone und der Kompanien anzuleiten“, gegenüber den Parteiorganisationen besaß er von nun an jedoch „unter Wahrung der innerparteilichen und innerverbandlichen Demokratie ausschließlich das Recht der Beratung"128.

Eine endgültige Klärung der Kompetenzen der Parteisekretäre und Politstellvertreter erbrachte dies anscheinend noch immer nicht. Die Zuständigkeiten dürften sich in der Praxis zudem oft überschnitten haben, so daß eine sachlogische Zuordnung der konkreten Entscheidungen vermutlich nicht immer ohne weiteres möglich war. So sah sich Dölling noch Anfang 1959 dazu gezwungen, die weiter bestehende Frage zu klären, ob „der Parteisekretär dem Politstellvertreter etwas zu sagen“ habe "oder umgekehrt“. Eine solche Gegenüberstellung des Parteisekretärs und des Politstellvertreters sei jedoch falsch, so Dölling. Er versuchte dieses Problem letztlich aufzulösen, indem er beide auf ein gemeinsames Ziel festlegte: Als qualifiziertes

127 Protokoll der Eggersdorfer Tagung, 12./13. Juni 1957, BA-MA, VA-P-01/037, Bl. 150.

128 Innendienstvorschrift der Nationalen Volksarmee DV-10/3, 1959, S. 22 f. 
Parteimitglied habe der Politstellvertreter „entscheidenden Anteil an der Formulierung der Beschlüsse der entsprechenden Parteiorganisation" 129.

\section{Die Parteiorganisationen}

Mit den Parteiorganisationen verfügte die SED über ein weiteres Instrument der politischen Kontrolle und Einflußnahme in den Streitkräften ${ }^{130}$. In den Parteiorganisationen waren unabhängig vom Dienstgrad alle SED-Mitglieder in der NVA organisiert. Ihre Aufgabe war zunächst vor allem die „politisch-ideologische und moralische Erziehung“ nicht nur der Parteimitglieder, sondern aller Armeeangehörigen „im Geiste des Marxismus-Leninismus“. Auf diese Weise sollten sie die „Durchführung der Beschlüsse der Partei“ in der militärischen Sphäre sicherstellen ${ }^{131}$. Dabei waren die Parteigrundorganisationen der SED auf der Ebene der Bataillone und selbständigen Kompanien die eigentlichen Träger der Parteiarbeit in der NVA, die die "führende Rolle" der SED in der Armee verwirklichen sollten ${ }^{132}$. Sie waren dazu verpflichtet, die Parteimitglieder „zum aktiven parteimäßigen Handeln “ 133 zu erziehen sowie zwischen ihnen und "den parteilosen Angehörigen der Armee enge Verbindungen herzustellen" ${ }^{134}$. Das übergeordnete Ziel der Parteiarbeit war dabei "die Schaffung einer stets kampfbereiten, disziplinierten und schlagkräftigen“ NVA ${ }^{135}$.

Um dies zu erreichen, sollten vor allem die Grundorganisationen an der Basis einen „kompromißlosen Kampf gegen alle Mängel und Unzulänglichkeiten, die die Erfüllung des Ausbildungsprogrammes" behinderten, führen. In diesem Zusammenhang hatten sie „alle Mitglieder zur selbstkritischen Einschätzung ihrer Arbeit zu erziehen und die Kritik von unten zu entwickeln"136. Formal galt dies auch für die Arbeit der Kommandeure. Denn die Parteiorganisationen hatten auch die Aufgabe, deren „Autorität ... ständig zu festigen“ sowie „auf die militär-wissenschaftli-

129 Protokoll der 2. Tagung der II. Delegiertenkonferenz der Parteiorganisationen der SED in der NVA, 25./26. März 1959, BA-MA, VA-P-01/556, Bl. 77.

130 Vgl. u. a. Wenzke, Die Nationale Volksarmee, S. 439; Hübner, Zur Rolle der Partei in der Nationalen Volksarmee, S. $416 \mathrm{ff}$.; Haueis, Die führende Rolle der SED in der Nationalen Volksarmee, S. $442 \mathrm{ff}$.

131 Instruktion für die Arbeit der Parteiorganisationen, 1957, S. 4.

132 Ebenda, S. 10f. Die Grundorganisationen konnten wiederum auf der darunterliegenden Ebene der Kompanien der Bataillone und der Züge der selbständigen Kompanien in Parteigruppen unterteilt werden. Auf Regimentsebene wurden die Grundorganisationen ihrerseits der Parteileitung einer Regimentsparteiorganisation unterstellt. Instruktion für die Arbeit der Parteiorganisationen, 1957, S. $17 \mathrm{ff}$. Diese Struktur wurde durch die neue Instruktion vom Juni 1958 insofern modifiziert, als die Parteigrundorganisationen jetzt auf der darüberliegenden Ebene der Regimenter und selbständigen Bataillone gebildet wurden. Auf der Ebene der Bataillone und selbständigen Kompanien konnten nunmehr Parteiorganisationen mit den Rechten einer Grundorganisation gegründet werden, während auf der darunterliegenden Ebene der Kompanien der Bataillone und der Züge der selbständigen Kompanien weiterhin Parteigruppen gebildet wurden. Instruktion für die Arbeit der Parteiorganisationen, 1958, S. $12 \mathrm{ff}$.

133 Instruktion für die Arbeit der Parteiorganisationen, 1957, S. 5.

134 Ebenda, S. 9.

135 Ebenda, S. 3.

136 Ebenda, S. $10 f$. 
che Bildung der Offiziere Einfluß zu nehmen und die notwendige Kontrolle auszuüben" 137 .

Hinsichtlich der militärischen Truppenführung fiel den Parteiorganisationen eine grundsätzliche Kontrollfunktion zu. Die Grundorganisationen sollten mit den Kommandeuren und Politstellvertretern die Stimmungen der Armeeangehörigen und die Mängel im Leben der Truppe beraten und diesen „Vorschläge zur Verbesserung der Ausbildungs- und Erziehungsarbeit" machen. Bei deren Nichtbeachtung hatten sie "das Recht und die Pflicht", sich an alle übergeordneten Polit- und Parteiorgane bis zum ZK zu wenden ${ }^{138}$. Obwohl die gesamte Parteiarbeit in der NVA von der Politischen Verwaltung geleitet wurde ${ }^{139}$, waren die Parteiorganisationen somit berechtigt, die Politorgane zu umgehen und sich notfalls direkt an die SEDFührung zu wenden. Diese besaß mit den Parteiorganisationen eine von den Politorganen getrennte Institution zur Kontrolle der militärischen Führer.

Während die Mitglieder der Parteiorganisationen auf allen Ebenen der NVA regelmäßig zu Delegiertenkonferenzen, Parteiaktivtagungen und Mitgliederversammlungen zusammenkamen, organisierten die gewählten Parteileitungen die laufende Arbeit der Parteiorganisationen. Die Leitungen wurden von der Mitgliederversammlung der Parteiorganisation für ein Jahr gewählt. Ihre Mitglieder durften während der Wahlperiode in keine andere Einheit versetzt werden. Für die Arbeit der Parteileitung als „kollektives Leitungsorgan“ war ein hauptamtlicher Parteisekretär verantwortlich, der aus dem Kreis der Leitungsmitglieder gewählt wurde und anschließend von der übergeordneten Politabteilung bestätigt werden mußte ${ }^{140}$.

Im Anschluß an den XX. Parteitag der KPdSU, auf dem Nikita S. Chruschtschow, 1953-1964 Erster Sekretär des ZK, Stalins Alleinherrschaft verurteilt hatte, kam auch im militärischen Bereich die Frage nach der Stellung und den Kompetenzen der Parteiorganisationen der SED auf die Tagesordnung. Stoph sagte im März 1956, es sei jetzt notwendig, die „Normen des Parteilebens hinsichtlich der kollektiven Führung streng einzuhalten"141. Nach dem XX. Parteitag müsse man erkennen, daß die "größte Kraft" der SED in der NVA die Parteiorganisationen seien $^{142}$.

Diese Zielvorstellung und der wirkliche Einfluß der Parteiorganisationen in den Streitkräften vor allem auf die militärische Truppenführung klafften jedoch weit auseinander. Der damalige Chef der Politischen Verwaltung Dickel mußte im März 1956 einräumen, es gebe „noch immer solche Parteiorganisationen, deren Parteiarbeit unregelmäßig und losgelöst von den praktischen Aufgaben ihrer Einheit organisiert" werde ${ }^{143}$. Ein halbes Jahr später bemerkte der Chef der Verwaltung Kader Munschke, die Parteiorganisationen spielten nicht die Rolle „wie draußen im zivilen

137 Ebenda, S. 4 f.

138 Ebenda, S. 12.

139 Ebenda, S. 7.

140 Ebenda, S. $13 \mathrm{ff}$.

141 Protokoll der Delegiertenkonferenz der Parteiorganisationen der SED im Dienstbereich des Ministeriums für Nationale Verteidigung, 5.-11. März 1956, BA-MA, VA-P-01/036, Bl. 229.

142 Ebenda, Bl. 236.

143 Ebenda, Bl. 27. 
Leben“. Ihre Arbeit werde „eingeengt, weil die Kritik beim Kommandeur“ aufhöre ${ }^{144}$.

Um diese aus Sicht der SED-Führung unbefriedigende Situation zu ändern, zeigte sich Stoph daher „damit einverstanden“, in der Frage der Kritik die „bisher geübte Praxis“ zu überprüfen. Er stellte jedoch klar: „Aber ich möchte nochmals unterstreichen, Befehle werden nicht kritisiert. Aber man kann sich unterhalten über die Ausführung der Befehle bzw.[,] wenn es notwendig ist [,] auch über den Mißbrauch von Befehlen. " 145 Hier zeigte sich die Sorge des Ministers für Nationale Verteidigung, die Autorität der Vorgesetzten könnte einen substantiellen Schaden nehmen mit nicht zu kontrollierenden Folgen für die militärische Ordnung.

Insbesondere auf der 30. ZK-Tagung im Januar 1957 beschloß die SED-Führung, den Einfluß der Parteiorganisationen in den Streitkräften ebenso wie im gesamten Staatsapparat massiv zu verstärken. Daran anknüpfend war die Partei bestrebt, im Rahmen der Neuwahl der Parteileitungen im Februar 1957 nunmehr in allen Einheiten der NVA Parteiorganisationen und Parteigruppen zu bilden ${ }^{146}$. Stoph hob die neue Position der Parteiführung zur Rolle der Parteiorganisationen in der NVA auf der Eggersdorfer Tagung im Juni 1957 hervor: „Das Politbüro läßt sich davon leiten, daß die entscheidende Voraussetzung für die Erhöhung der Kampf- und Einsatzbereitschaft der Nationalen Volksarmee die volle Entfaltung der Kraft der Parteiorganisationen ist und überträgt ihnen deshalb eine noch größere Verantwortung für die Lösung der ... Ausbildungs- und Erziehungsaufgaben." 147

Vor allem sollten die Parteiorganisationen in der NVA neben ihrer Funktion als Erziehungs- und Mobilisierungsorgane jetzt auch auf die Diskussions- und Entscheidungsprozesse der militärischen Truppenführung Einfluß nehmen. Dazu mußten jedoch zuerst die organisatorischen Voraussetzungen geschaffen werden. Dies geschah durch die neue "Instruktion für die Arbeit der Parteiorganisationen der SED in der NVA“, die am 21. Mai 1957 in Kraft trat. Den Parteiorganisationen wurde das Recht eingeräumt, auf Parteiversammlungen und Beratungen „zu allen die Parteiorganisation interessierenden Fragen Stellung zu nehmen "148. Auf diese Weise implementierte die Instruktion das kollektive Führungsprinzip, da es den Parteiorganisationen nun explizit erlaubt war, „dem Kommandeur ihrer Einheit Vorschläge zur Verbesserung“ der Erziehung, Ausbildung und Kaderarbeit zu machen ${ }^{149}$. Dieses Recht beinhaltete auch Verbesserungsvorschläge bezüglich der „Kampfausbildung und aller Seiten des Lebens der Truppe“150.

Diese Regelungen griffen massiv in die Entscheidungsautonomie der militärischen Truppenführung ein, da der Partei jetzt ein umfassendes Mitspracherecht in

144 Protokoll Nr. 7/56 über die Sitzung des Kollegiums des Ministeriums für Nationale Verteidigung, 21. September 1956, BA-MA, VA-01/2030, Bl. 114.

145 Ebenda, Bl. 123.

146 Zeittafel zur Militärgeschichte, S. 76. Denn nach Gründung der Streitkräfte hatte Anfang 1956 in 14,7 Prozent der Einheiten auf Kompanieebene noch keine Parteiorganisation existiert. Protokoll der Delegiertenkonferenz der Parteiorganisationen der SED im Dienstbereich des Ministeriums für Nationale Verteidigung, 5.-11. März 1956, BA-MA, VA-P-01/036, Bl. 438.

147 Protokoll der Eggersdorfer Tagung, 12./13. Juni 1957, BA-MA, VA-P-01/037, Bl. 6.

148 Instruktion für die Arbeit der Parteiorganisationen, 1957, S. 6 f.

149 Ebenda, S. 6.

150 Ebenda, S. 13. 
spezifisch militärischen Belangen zugestanden wurde. Die Tatsache, daß die Instruktion „Kritik an Befehlen, Dienstvorschriften und an jener Tätigkeit der Kommandeure, die unmittelbar mit der militärischen Führung" zusammenhing, wie von Stoph gefordert, nicht gestattete ${ }^{151}$, konnte jedoch in der Praxis nicht die unabhängige Entscheidungsfindung der Vorgesetzten sicherstellen. Die Trennung zwischen der unerlaubten Kritik an Befehlen einerseits und den erlaubten Verbesserungsvorschlägen andererseits dürfte sich als kaum praktikabel erwiesen haben. Eine Überschneidung war vermutlich in der Praxis nicht zu vermeiden. Denn die Instruktion forderte ausdrücklich, „die Kritik und Selbstkritik ohne Ansehen der Person zu entfalten "152. Sie verpflichtete die Parteiorganisationen, „dafür Sorge zu tragen, daß unterschiedslos für alle Mitglieder eine einheitliche Parteidisziplin ... gesichert" wurde ${ }^{153}$. Das bedeutete, auch Offiziere und Kommandeure mußten sich nunmehr für ihre Dienstdurchführung öffentlich vor den Mitgliedern ihrer Parteiorganisation, die ihnen zugleich dienstlich unterstellt waren, selbstkritisch rechtfertigen und sich möglicherweise durch diese sanktionieren lassen.

Anscheinend war sich Stoph darüber im klaren, daß angesichts dieses Eingriffes in die militärische Autonomie ein Konflikt zwischen Partei und Offizierskorps drohte. Auf der Eggersdorfer Tagung im Juni 1957 versuchte er daher zu vermitteln: Es gebe "Verwirrungen", in welchem Umfang man Kritik am Kommandeur zulassen könne. Stoph betonte, das „Prinzip der Einzelleitung“, der ungeteilten Befehlsgewalt, müsse "ständig und für alle Befehle“ gelten: „Deshalb ist es auch nicht zulässig, die Befehle und Vorschriften auf Parteiversammlungen zu kritisieren.“ Das bedeute jedoch nicht, daß der Kommandeur "eine Sonderstellung in der Partei“ einnehme. Weder könne er „in der Partei befehlen“ noch stehe er „außerhalb der Kritik“. Ohne Kritik und Selbstkritik sei es „unmöglich, die vorhandenen Mängel in der Ausbildung und Erziehung zu beseitigen“. Stoph stellte fest: „So wie die Parteiorganisation mit dem Kommandeur gemeinsam darüber berät, wie sie die Befehle des Kommandeurs unterstützen kann, wird sie und muß sie den Kommandeur kritisieren, wenn es in seiner Arbeit, in seinem persönlichen Verhalten Mängel und Schwächen gibt." 154 Stophs Ausführungen waren jedoch nicht dazu geeignet, die Grenze der Parteikontrolle klarer zu bestimmen. In erster Linie sollten sie daher vermutlich der akuten Verunsicherung der Offiziere und dem vorhandenen Protest begegnen.

Tatsächlich ließ sich die kollektive Führung im Rahmen von Versammlungen der Parteiorganisationen nur schwer verwirklichen. Zum einen wehrte sich das Offizierskorps massiv gegen den drohenden Kompetenzverlust. Zum anderen erwies sich dieser strukturelle Ansatz als außerordentlich ineffizient, da die Parteiorganisationen im ganzen als kollektives Entscheidungsgremium zahlenmäßig zu groß waren. Anstatt die Entscheidungen etwa eines Kommandeurs im Sinne der Partei zu beeinflussen, konnte in den Parteiversammlungen in erster Linie nur eine Grundsatzkritik geübt werden, die die Stellung der Vorgesetzten aber dauerhaft beschädigen mußte.

151 Ebenda, S. 6.

152 Ebenda.

153 Ebenda, S. 5.

154 Protokoll der Eggersdorfer Tagung, 12./13. Juni 1957, BA-MA, VA-P-01/037, Bl. $50 \mathrm{f}$. 
Dies war ein entscheidender Grund, warum die Instruktion in der zweiten Jahreshälfte 1957 nur eine begrenzte Wirkung entfalten konnte. Das Politbüro mußte sich Anfang 1958 eingestehen, daß einige Kommandeure und leitende Offiziere „die Parteiorganisationen noch immer als Organe " ansähen, „die ausschließlich zur Unterstützung ihrer Arbeit zur Verfügung " stünden. Sie glaubten, deren „Tätigkeit befehlen zu können" und würden die Anwendung der Kritik und Selbstkritik unterbinden, was die weitere „Entwicklung der Arbeit der Parteiorganisationen in der Armee" hemme. Eine Reihe von Offizieren habe noch immer die "falsche Einstellung“, „daß das Prinzip der Einzelleitung, die Befehlsgebung und die Struktur der Armee nicht mit den allgemeinen Prinzipien der Parteiarbeit und der innerparteilichen Demokratie zu vereinbaren" seien ${ }^{155}$.

Als Reaktion darauf war die SED-Führung dann offenbar ab Ende 1957 zu der Auffassung gelangt, daß es "auf Grund der vorhandenen Unzulänglichkeiten in der politischen Arbeit und der Tätigkeit der Parteiorganisationen“ notwendig war, „einige tiefgreifende Veränderungen vorzunehmen" 156 .

Daher wurde im Politbürobeschluß vom 14. Januar 1958 „Über die Rolle der Partei in der NVA“ die „kollektive Beratung aller wichtigen politischen und militärischen Maßnahmen der Kommandeure mit den Parteiorganisationen und in den Militärräten" nunmehr ausdrücklich festgeschrieben. Die Parteiorganisationen sollten also schon zu den Maßnahmen Stellung nehmen, bevor sie durch den Kommandeur befohlen wurden, und nicht, wie bisher, erst im nachhinein das Ergebnis der Maßnahmen kritisch bewerten. Dieses Recht der Parteiorganisationen wurde vor allem im Hinblick auf die Arbeit der militärischen Truppenführung weiter gestärkt: Der Politbürobeschluß gab den Parteiorganisationen das Recht, „in Parteiversammlungen kritisch die Ergebnisse der Erziehung und Ausbildung, den Zustand der Einsatzbereitschaft und die dienstliche Tätigkeit aller Offiziere zu beurteilen sowie Vorschläge zur Verbesserung der Arbeit zu machen“, wobei der Grundsatz der „bedingungslosen Ausführung von Befehlen" nicht berührt werden sollte, jedoch die „Ergebnisse der durchgeführten Befehle kritisch geprüft“ werden konnten ${ }^{157}$. Der Politbürobeschluß implementierte jedoch insofern eine grundlegende strukturelle Modifikation, als die Parteiversammlungen jetzt in erster Linie als Sanktionsinstanz fungierten, während die eigentliche Steuerung der militärischen Truppenführung anhand der kollektiven Führung von den Parteisekretären ausgeübt werden sollte. Hier zeigte sich deutlich eine Tendenz zur Ausdifferenzierung des Kontrollapparates. Die Kommandeure wurden jetzt ihrerseits dazu verpflichtet, „die Sekretäre der Parteiorganisationen der Bataillone, der Regimenter und selbständigen Einheiten in der Regel zu den Beratungen der jeweiligen militärischen Leitungen hinzuzuziehen und vor wichtigen Entscheidungen zu hören "158. In den Grundorganisationen war

155 Über die Rolle der Partei in der NVA. Protokoll Nr. 4/58 der Sitzung des Politbüros des ZK der SED, 14. Januar 1958, SAPMO-BArch, DY 30/J IV 2/2/576, Bl. $191 \mathrm{f}$.

156 Stellungnahme der ZK-Abteilung für Sicherheitsfragen, 30. Dezember 1957, SAPMOBArch, DY 30/IV 2/12/9, Bl. 2.

157 Über die Rolle der Partei in der NVA. Protokoll Nr. 4/58 der Sitzung des Politbüros des ZK der SED, 14. Januar 1958, SAPMO-BArch, DY 30/J IV 2/2/576, Bl. 193.

158 Ebenda, Bl. 193. 
damit „der Parteisekretär der höchste Parteifunktionär ... und nicht mehr, wie bisher, der Politstellvertreter" 159.

Trotz der erweiterten Kompetenzen der Parteiorganisationen bestand noch immer die Gefahr, daß die militärische Truppenführung die Parteisekretäre über wichtige Entscheidungen nicht informierte. Dem begegnete die SED auf zweifache Art. Erstens legte die neue „Instruktion für die Arbeit der Parteiorganisationen der SED in der NVA" von 1958 fest, daß die Parteisekretäre nicht mehr nur von den militärischen Leitungen gehört werden mußten, sondern jetzt sogar das Recht hatten, selbständig „an den Beratungen der militärischen Leitung der betreffenden Einheit oder Dienststelle teilzunehmen und dort ihre Meinung zu sagen"160. Dies wertete ihre Position gegenüber der militärischen Truppenführung auf und gab ihnen die Möglichkeit, auf alle Diskussions- und Entscheidungsprozesse schon innerhalb der militärischen Führungsstäbe direkten Einfluß zu nehmen.

Zweitens zielte die SED darauf ab, nicht nur die Parteisekretäre in die militärischen Stäbe zu integrieren, sondern umgekehrt die vorgesetzten Offiziere, vor allem die Kommandeure, in die Leitungen der Parteiorganisationen zu wählen. Auf diese Weise erreichte die Partei gewissermaßen automatisch eine Transparenz der militärischen Entscheidungsprozesse, da trotz der institutionellen Trennung der Leitungsgremien eine personelle Übereinstimmung hergestellt wurde. Die Umsetzung dieser Zielsetzung leitete das Politbüro mit dem Hinweis ein, „die erfahrensten und qualifiziertesten Parteimitglieder" seien in die Parteileitungen zu wählen ${ }^{161}$. Dölling führte dazu aus: „In die Parteileitungen kommen die besten und erfahrensten Parteimitglieder, wozu selbstverständlich auch die Kommandeure zählen."162 Zum Sinn dieser Maßnahme fügte die Politische Verwaltung erläuternd hinzu: „Um ... den Kommandeur zu einem richtigen parteimäßigen Verhalten und Handeln zu bringen, ist die Wahl ... in die Parteileitungen wünschenswert. "163 Die in den Jahren zuvor "vorhandene Tendenz, keine Kommandeure ... in die Parteileitungen zu wählen“, konnte jetzt zunehmend „überwunden“ werden ${ }^{164}$. Im Rahmen der Parteiwahlen im Frühjahr 1958 wurden zum Beispiel 58 Prozent der Regimentskommandeure in die Parteileitungen der Grundorganisationen gewählt ${ }^{165}$. In der Regel waren der Kommandeur, der Parteisekretär und der Politstellvertreter jetzt in beiden Leitungsgremien vertreten. War der Kommandeur kein Mitglied der Parteileitung, wurde er üblicherweise zu den Leitungsbesprechungen der Parteiorganisation hinzugezogen ${ }^{166}$. Eine Trennung der fachlichen Zuständigkeiten sowie der mi-

159 Vorschläge zur Durchsetzung und Erfüllung des Beschlusses des Politbüros vom 14. Januar 1958, SAPMO-BArch, DY 30/IV 2/12/9, Bl. 32.

160 Instruktion für die Arbeit der Parteiorganisationen, 1958, S. 10.

161 Über die Rolle der Partei in der NVA. Protokoll Nr. 4/58 der Sitzung des Politbüros des ZK der SED, 14. Januar 1958, SAPMO-BArch, DY 30/J IV 2/2/576, Bl. 194.

162 Protokoll Nr. $1 / 58$ über die Sitzung des Kollegiums des Ministeriums für Nationale Verteidigung, 24. Februar 1958, BA-MA, AZN/28178, Bl. 16.

163 Plan zur Auswertung und Durchführung des Beschlusses des Politbüros vom 14. Januar 1958 „Über die Rolle der Partei in der NVA“, 1. Februar 1958, BA-MA, VA-P-01/7535, Bl. 148.

164 Bericht über die Vorbereitung und Durchführung der Berichtswahlversammlung in den Parteiorganisationen der NVA, Mai 1958, BA-MA, VA-P-01/031, Bl. 11.

165 Armee für Frieden und Sozialismus, S. 170.

166 Bericht über die Ergebnisse des Brigadeeinsatzes des Sektors Nationale Verteidigung des 
litärischen und der politischen Diskussions- und Entscheidungsprozesse war nun kaum mehr einzuhalten, wodurch die Verwirklichung der kollektiven Führung in der NVA in einem umfassenden Maß garantiert wurde ${ }^{167}$. Die Politische Verwaltung konstatierte im Mai 1958 zufrieden: „Die Parteileitungen setzen immer mehr die Forderungen des Politbürobeschlusses durch und fordern von den Kommandeuren die kollektive Beratung der politischen und militärischen Fragen." 168 Die funktional nicht notwendige Dopplung der Führungsgremien bewirkte in der Folgezeit offenbar, daß die Beratungen in den militärischen Stäben und Leitungen zunehmend zu reinen Befehlsausgaben denaturierten, während konstruktive fachliche Kritik zumeist nur noch in den Parteileitungen geübt wurde ${ }^{169}$.

Die Parteiorganisationen konnten ihren Einfluß auf die militärische Truppenführung so entscheidend erweitern, daß sich die Entwicklung teilweise sogar in das entgegengesetzte Extrem verkehrte. Die ZK-Abteilung für Sicherheitsfragen kritisierte, daß in dem „Bestreben der Parteisekretäre und Parteileitungen, den Parteiorganisationen die ihnen zustehenden Rechte einzuräumen und die führende Rolle der Partei zu sichern, ... eine Reihe von Parteileitungen über das Ziel hinausschießen“ würde und sogar „funktionelle Pflichten der Kommandeure" übernäh$\mathrm{me}^{170}$.

Wie stark sich der Einfluß der Partei in der NVA vergrößerte, zeigt sich insbesondere daran, daß seit 1958 nun auch gegen Offiziere verstärkt Parteistrafen ${ }^{171}$ ausgesprochen wurden ${ }^{172}$. Für sich genommen, wären diese Parteistrafen unerheblich ge-

ZK in der 6. Flottille der NVA, 15.-25. Juli 1959, SAPMO-BArch, DY 30/IV 2/12/21, Bl. 303.

167 Von Seiten der ZK-Abteilung für Sicherheitsfragen hieß es diesbezüglich: „In der Regel werden alle wichtigen politischen und militärischen Entscheidungen im Kollektiv beraten und festgelegt, wobei die Meinung der jeweiligen Parteileitung maßgeblich berücksichtigt wird. Hierbei wirkt sich die Wahl zahlreicher Kommandeure und leitender Offiziere in die Parteileitungen positiv aus. Einschätzung der Erfüllung des Politbürobeschlusses vom 14. Januar 1958, 1959, SAPMO-BArch, DY 30/IV 2/12/9, Bl. 243.

168 Bericht über die Vorbereitung und Durchführung der Berichtswahlversammlung in den Parteiorganisationen der NVA, Mai 1958, BA-MA, VA-P-01/031, Bl. 8.

$169 \mathrm{Vgl}$. Volk/Squarr, Zum inneren Zustand der NVA, S. 253.

170 Einleitung für die Aussprache und Beratung mit den Parteisekretären zu dem Thema: „Die Ergebnisse bei der Erfüllung des Beschlusses des Politbüros vom 14. Januar 1958 auf dem Gebiet der Verwirklichung der führenden Rolle der Partei in den Einheiten und Truppenteilen des MB III“, 1958, SAPMO-BArch, DY 30/IV 2/12/9, Bl. 125.

171 In den $\int \$$ I. 7. ff. des Parteistatuts der SED von 1954 heißt es: „Wer gegen die Einheit und Reinheit der Partei verstößt, ihre Beschlüsse nicht erfüllt, die innerparteiliche Disziplin nicht achtet, die Parteidisziplin verletzt oder seine Mitgliedschaft und ihm übertragene Funktionen mißbraucht, im öffentlichen Leben sich eines Parteimitgliedes nicht würdig zeigt, ist von der Grundorganisation oder einem höheren Parteiorgan zur Verantwortung zu ziehen. Je nach der Art des Vergehens können folgende Parteistrafen beschlossen werden: a) die Verwarnung, b) die Rüge, c) die strenge Rüge, d) die Versetzung in den Kandidatenstand auf die Dauer eines Jahres, e) der Ausschluß aus der Partei." Statut der Sozialistischen Einheitspartei Deutschlands, 1954, S. 112.

172 Im Jahresbericht der „Parteikontrollkommissionen“ (PKK) von 1958 heißt es, während es 1957 auf der Basis „der damaligen Instruktion ... ein Parteiverfahren gegen Offiziere durch seine [sic!] Grundorganisation so gut wie nicht gegeben“ habe, seien 1958 ,allein in der 1. Hälfte des Berichtsjahres von 118 Parteiverfahren“" gegen Offiziere „102 in den Mitgliederversammlungen behandelt" worden. Jahresbericht der PKK'en in der NVA für das Jahr 1958, SAPMO-BArch, DY 30/IV 2/12/9, Bl. 146. Parteikontrollkommissionen gab es in der 
blieben. Sie waren jedoch zumeist mit disziplinar- beziehungsweise strafrechtlichen Sanktionen verknüpft, die bei nicht parteikonformem Verhalten gleichzeitig drohten. Aus diesem Grund kam es dann zu Doppel- oder Mehrfachbestrafungen von Offizieren. So bedeutete etwa ein Parteiausschluß in der Regel gleichzeitig die Entlassung aus der NVA ${ }^{173}$.

Diese Entwicklung wurde vor allem durch zwei institutionelle Neuerungen ermöglicht. Zum einen waren die Parteiorganisationen in der modifizierten „Instruktion für die Arbeit der Parteiorganisationen der SED in der NVA“ vom Juni 1958 jetzt dazu angehalten, auf Parteiversammlungen eine ausdrücklich „kämpferische Atmosphäre zu schaffen“, um „die Ergebnisse der Erziehung und Ausbildung, den Zustand der Einsatzbereitschaft, die dienstliche und gesellschaftliche Tätigkeit aller Armeeangehörigen“ - also auch der Offiziere - „sowie die Ergebnisse der durchgeführten Befehle kritisch zu beurteilen und Vorschläge zur Verbesserung der Arbeit zu machen "174. Gestrichen worden war damit die Bestimmung in der Instruktion von 1957, die die Kritik an Befehlen, Dienstvorschriften und der Tätigkeit der Kommandeure verbot, die in unmittelbarem Zusammenhang mit der militärischen Führung standen. Denn diese Bestimmung, so die Politische Verwaltung, sei „vielfach dazu benutzt" worden, „um unter dem Deckmantel ,dienstlicher Belange' eine Kritik an fehlerhafter Arbeit, Mängeln, Versäumnissen einzelner Offiziere ... zu unterbinden" 175 .

Zum zweiten wurde die Regelung in der „Instruktion für die Durchführung von Parteiverfahren gegen Mitglieder und Kandidaten der SED in der NVA" von 1957, daß bei Offizieren vom Bataillonskommandeur an aufwärts Parteiverfahren „,in der Regel" durch die Parteikontrollkommissionen durchgeführt werden sollten ${ }^{176}$, in der Neufassung der Instruktion von 1958 gestrichen. Alle Parteiverfahren - eben auch die der höheren Offiziere - waren jetzt in der Regel „in der Mitgliederversammlung der Grundorganisation“ durchzuführen. Nur noch bei „besonders schweren Vergehen gegen das Parteistatut, insbesondere dann, wenn die Behandlung in der Grundorganisation die militärische Disziplin zersetzen oder militärische Geheimnisse gefährden" konnte, sollten Parteiverfahren an eine Parteikontrollkommission verwiesen werden ${ }^{177}$.

Zusätzlich zu diesen internen Veränderungen verstärkte die SED-Führung die politische Durchdringung des Militärs auch anhand des militärexternen Parteiapparates. Der Politbürobeschluß vom 14. Januar 1958 schuf die organisatorischen

NVA bei den Politabteilungen und der Politischen Verwaltung. Sie waren Schiedsgerichte der SED zur Durchführung nichtöffentlicher Parteiverfahren. Vgl. Instruktion für die Arbeit der Parteiorganisationen, 1957, S. 29.

173 Haueis, Die führende Rolle der SED in der Nationalen Volksarmee, S. 435.

174 Instruktion für die Arbeit der Parteiorganisationen, 1958, S. 9.

175 Plan zur Auswertung und Durchführung des Beschlusses des Politbüros vom 14. Januar 1958 „Über die Rolle der Partei in der NVA“, 1. Februar 1958, BA-MA, VA-P-01/7535, Bl. 134.

176 Instruktion für die Durchführung von Parteiverfahren gegen Mitglieder und Kandidaten der SED in der NVA. Protokoll Nr. 22/57 der Sitzung des Politbüros des ZK der SED, 21. Mai 1957, SAPMO-BArch, DY 30/J IV 2/2/542, Bl. 44.

177 Instruktion für die Durchführung von Parteiverfahren gegen Mitglieder und Kandidaten der SED in der NVA. Protokoll Nr. 26/58 der Sitzung des Politbüros des ZK der SED, 17. Juni 1958, SAPMO-BArch, DY 30/J IV 2/2/598, Bl. 94. 
Grundlagen für Interventionen ziviler Parteiorganisationen in die militärische Sphäre ${ }^{178}$. Die Bezirks- und Kreisleitungen der SED wurden „verpflichtet, die Arbeit der Parteiorganisationen innerhalb der in ihrem Bereich liegenden Einheiten zu unterstützen und die Durchführung der Beschlüsse der Partei zu kontrollieren“. Die Parteileitungen, Politabteilungen und Politstellvertreter in den NVA-Einheiten hatten ihrerseits mit den zivilen Parteileitungen nicht nur eine enge Verbindung zu halten, sondern „sie in allen wesentlichen Fragen der politischen und gesellschaftlichen Arbeit zu konsultieren"179. Über die Verbindung des militärischen mit dem zivilen Parteiapparat realisierte die SED zugleich auch dessen Vernetzung mit den militärischen Institutionen auf der jeweiligen Organisationsebene.

\section{Die Kaderpolitik}

Prinzipiell galt in der Personalpolitik der DDR-Streitkräfte ${ }^{180}$ der Grundsatz: „Für die Arbeit mit den Offizieren in der Nationalen Volksarmee sind die Kommandeure verantwortlich." Diese mußten die ihnen unterstellten Offiziere nach ihrer „politischen, militärischen, fachlichen und moralischen Eignung und Qualifikation beurteilen“. Auf dieser Grundlage sollten sie „Schlußfolgerungen über deren Entwicklungs- und Verwendungsfähigkeit" anstellen sowie Vorschläge über die Besetzung von Planstellen in den jeweiligen Truppenteilen, Einheiten und Dienststellen ausarbeiten. Zudem hatten sie Empfehlungen hinsichtlich der Versetzung von Offizieren oder ihrer Qualifizierung - etwa an den Militärakademien - auszusprechen ${ }^{181}$.

Tatsächlich jedoch verfügten die Kommandeure nur über einen sehr geringen $\mathrm{Ge}$ staltungsspielraum in Personalfragen. Sie hatten grundsätzlich nicht die Kompetenz, Entscheidungen unabhängig und eigenverantwortlich zu treffen. Das lag zum einen an der starken Zentralisierung der Kaderpolitik der NVA, zum anderen aber vor allem an ihrer umfassenden politischen Durchdringung durch die Organe der SED.

Schon Ende 1956 waren durch den Befehl Nr. 129/56 des Ministers für Nationale Verteidigung innerhalb der NVA spezielle Kadernomenklaturen geschaffen worden: Zum einen waren dies auf der Ebene des Ministeriums für Nationale Verteidigung die Nomenklaturen für den Minister sowie für den Chef der Politischen Verwaltung, zum anderen auf der Ebene der Teilstreitkräfte die Nomenklaturen der Chefs der Militärbezirke der Landstreitkräfte und der Chefs der Luftstreitkräfte/ Luftverteidigung sowie der Seestreitkräfte. 1960 wurde dann zusätzlich unterhalb dieser beiden Ebenen eine Kadernomenklatur der Divisionskommandeure geschaffen $^{182}$. Die Kadernomenklaturen regelten die Zuständigkeit dieser Nomenklaturvorgesetzten für die Ernennung, Beurteilung, Beförderung und Versetzung der Offiziere, die nicht in den Kadernomenklaturen der leitenden Parteiorgane - Polit-

178 Vgl. Instruktion für die Arbeit der Parteiorganisationen, 1958, S. 8.

179 Über die Rolle der Partei in der NVA. Protokoll Nr. 4/58 der Sitzung des Politbüros des ZK der SED, 14. Januar 1958, SAPMO-BArch, DY 30/J IV 2/2/576, Bl. 196.

180 Vgl. Lapp, Die Nationale Volksarmee 1956-1990, S. $1944 \mathrm{ff}$.

181 Bestimmungen über die Arbeit mit den Offizieren der NVA, 18. Juni 1957, BA-MA, VA-01/5038, Bl. 3.

182 Teilbeitrag der Verwaltung Kader zur Einarbeitung in die Gesamtanalyse und Grundkonzeption der Entwicklung der NVA, 10. März 1967, BA-MA, VA-01/5679, Bl. 157. 
büro, Sicherheitskommission beziehungsweise Nationaler Verteidigungsrat und ZK-Abteilung für Sicherheitsfragen - geführt wurden ${ }^{183}$. Dabei umfaßten die Kadernomenklaturen des Ministers und des Chefs der Politischen Verwaltung - jeweils gesondert nach Truppen- und Politoffizieren - alle Offiziersdienststellungen vom Regimentskommandeur an aufwärts sowie alle Offiziersdienststellungen des Ministeriums und der ihm unmittelbar unterstellten Truppenteile und Dienststellen. Der Minister war im übrigen für die Ernennung zum ersten Offiziersdienstgrad und alle Beförderungen oberhalb des Dienstgrades Hauptmann zuständig ${ }^{184}$. Die Kadernomenklaturen der Chefs der Militärbezirke der Landstreitkräfte und der übrigen Teilstreitkräfte enthielten in der Fassung von 1961 die Dienststellungen der Bataillonskommandeure und stellvertretenden Regimentskommandeure, die bis dahin zur Kadernomenklatur des Ministers gehört hatten, sowie alle Dienststellungen ihrer Kommandos und der unmittelbar unterstellten Truppenteile. Zudem wurde den Chefs der Militärbezirke und Teilstreitkräfte auch die Zuständigkeit für Beförderungen im Dienstgrad bis zum Hauptmann übertragen ${ }^{185}$. Die 1960 geschaffenen Nomenklaturen der Kommandeure der Verbände umfaßten jetzt alle Offiziersdienststellungen bis zum stellvertretenden Bataillonskommandeur und gleichgestellte Funktionen ${ }^{186}$.

Die zentrale Zuständigkeit für die operative Kaderarbeit lag jedoch bei der „Verwaltung Kader" des Ministeriums für Nationale Verteidigung und für die Politoffiziere bei der „Abteilung Kader der Politischen Verwaltung“. Auf der darunterliegenden Ebene der Teilstreitkräfte steuerten die „Kaderabteilungen“ der Militärbezirke, der Seestreitkräfte und der Luftstreitkräfte/Luftverteidigung die Personalführung 187 . Darüber hinaus gab es in den Einheiten spezielle Kaderoffiziere, die die Kaderarbeit gemeinsam mit den Kommandeuren zu organisieren hatten. Einerseits sollten die Kaderoffiziere diese „bei der Auswahl, Verteilung, Qualifizierung und Beförderung" der Offizierskader beraten, andererseits hatten sie zugleich die Aufgabe, die Kaderpolitik der Kommandeure zu überwachen, denn sie mußten „die Einhaltung der festgelegten Prinzipien“ kontrollieren und Verstöße melden ${ }^{188 .}$

Von der Verwaltung Kader des Ministeriums bis zu den Kaderoffizieren der Einheiten führten die Kaderorgane Perspektivpläne über die Offiziere der jeweiligen Einheiten, die anhand der „Vorschläge und Entscheidungen der Kommandeure“ er-

183 Ebenda, Bl. 155. Der Nomenklaturvorgesetzte eines militärischen Führungskaders war jedoch nicht automatisch auch sein direkter Vorgesetzter. Hier existierten parallel zueinander zwei Unterstellungsverhältnisse.

184 Entwurf der Grundsätze für die Arbeit mit der Kadernomenklatur in der NVA und die Verantwortung der Vorgesetzten für die Arbeit mit den Kadern. Protokoll der Sitzung der Leitung des Ministeriums für Nationale Verteidigung, 23. Januar 1961, BA-MA, AZN/28072, Bl. 222.

185 Ebenda, Bl. 222, 224, 226.

186 Ebenda, Bl. 222. Bis dahin waren sie neben den Regimentskommandeuren, für die diese Regelung weiter galt, ausschließlich dazu berechtigt gewesen, Offiziere außerhalb der Kadernomenklatur in den Dienststellungen Kompaniechef und Zugführer sowie Gleichgestellte innerhalb ihrer Einheit in eine gleiche Dienststellung zu versetzen. Teilbeitrag der Verwaltung Kader zur Einarbeitung in die Gesamtanalyse und Grundkonzeption der Entwicklung der NVA, 10. März 1967, BA-MA, VA-01/5679, Bl. 156.

187 Bestimmungen über die Arbeit mit den Offizieren der NVA, 18. Juni 1957, BA-MA, VA-01/5038, Bl. $6 \mathrm{f}$.

188 Ebenda, Bl. 4. 
stellt wurden und als wichtige Grundlage bei den Personalentscheidungen dienten ${ }^{189}$. Die Hinweise der Kommandeure hatten in erster Linie aber nur informativen Charakter. Korrigieren konnten sie die Entscheidungen der Kaderorgane nicht. Die Politische Verwaltung monierte, die Kommandeure würden zum Teil sogar gänzlich ignoriert: „Es darf nicht sein, daß die Kommandeure nur am Rande oder[,] wenn im Prinzip die Kadervorschläge bereits erarbeitet sind, von den betreffenden Kaderoffizieren informiert werden.“ Auch könne ein Kaderoffizier „nicht einfach mit dem Kaderoffizier der unterstellten Dienststelle verhandeln und verkehren“. Vielmehr sei es erforderlich, daß dies „über den Kommandeur und mit dessen Kenntnis“ erfolge ${ }^{190}$. Stoph äußerte daher, das „Hauptübel“ bestehe darin, „daß die Kaderarbeit noch nicht zum untrennbaren Bestandteil der Leitungsarbeit" der militärischen Stäbe geworden sei. Offenbar war aber die fehlende Kompetenz der Kommandeure in Kaderfragen die entscheidende Ursache für die seiner Auffassung nach „irrige Ansicht“ in der militärischen Truppenführung, die Kaderarbeit sei „die alleinige Angelegenheit der Kaderorgane“191.

Sofern sich daher überhaupt Freiräume in der Kaderpolitik ergaben, nutzten die Kommandeure diese offenbar häufig dazu, mißliebige Unterstellte aus dem Personalbestand ihrer Einheit zu entfernen. Der Leiter der Abteilung Kader der Politischen Verwaltung kritisierte vor diesem Hintergrund die bestehende „Abschiebepolitik" der Kommandeure ${ }^{192}$.

Die Kommandeure und Vorgesetzten waren jedoch nicht nur dazu verpflichtet, Personalfragen mit den Kaderorganen zu beraten. Vielmehr mußten sie dabei auch die Politorgane und die Leitungen der Parteiorganisationen einbeziehen ${ }^{193}$. So waren etwa Beurteilungen „im Kollektiv der Leitung der Einheit“ unter Mitarbeit des Parteisekretärs auszuarbeiten. Die Meinung der Parteiorganisation sollte dabei „eine der wichtigsten Grundlagen für die Einschätzung des Offiziers" bilden ${ }^{194}$. Auch hier wurde der ab 1957 steigende Einfluß der Parteiorganisationen deutlich sichtbar. Die Parteiorganisationen erhielten sogar ausdrücklich das Recht, „dem Kommandeur ihrer Einheit Vorschläge ... zur Auswahl und Förderung der Kader zu machen"195. Im Politbürobeschluß vom 14. Januar 1958 forderte die SED-Führung dann nochmals, den „Einfluß der Parteiorganisationen auf die Entwicklung, Förderung und Verteilung der Kader ... weiter zu erhöhen“. Bei Versetzungen und Beförderungen von Offizieren und Unteroffizieren sollte die Meinung der jeweili-

189 Ebenda, Bl. $6 \mathrm{f}$.

190 Plan zur Auswertung und Durchführung des Beschlusses des Politbüros vom 14. Januar 1958 „Über die Rolle der Partei in der NVA“, 1. Februar 1958, BA-MA, VA-P-01/7535, Bl. 162.

191 Protokoll der Delegiertenkonferenz der Parteiorganisationen der SED im Dienstbereich des Ministeriums für Nationale Verteidigung, 5.-11. März 1956, BA-MA, VA-P-01/036, Bl. 49.

192 Die Arbeit der Abteilung Kader der Politischen Verwaltung und die Arbeit mit den PolitKadern in der NVA. Protokoll Nr. 7/56 über die Sitzung des Kollegiums des Ministeriums für Nationale Verteidigung, 21. September 1956, BA-MA, VA-01/2030, Bl. 154.

193 Bestimmungen über die Arbeit mit den Offizieren der NVA, 18. Juni 1957, BA-MA, VA-01/5038, Bl. 4.

194 Ebenda, Bl. 9.

195 Instruktion für die Arbeit der Parteiorganisationen, 1957, S. 6. 
gen Parteileitung nunmehr „maßgeblich“ berücksichtigt werden ${ }^{196}$. Die Politische Verwaltung stellte im Anschluß fest, im Fall divergierender Auffassungen zwischen dem Kommandeur, dem Kaderoffizier und der betreffenden Parteileitung werde „nach umfassender Beurteilung die endgültige Entscheidung" durch ein übergeordnetes Parteiorgan gefällt ${ }^{197}$. Die Bestimmungen des Politbürobeschlusses gingen dann weitgehend wörtlich auch in die neue „Instruktion für die Arbeit der Parteiorganisationen der SED in der NVA" vom Juni 1958 ein ${ }^{198}$.

Nachdem der Einfluß der Parteiorganisationen - vor allem der Parteileitungen und -sekretäre - in der Kaderpolitik seit Mitte 1957 sukzessiv erweitert worden war, gelangten offenbar eine Reihe von Kommandeuren ,in falscher Auslegung“ des Politbürobeschlusses vom 14. Januar $1958 \mathrm{zu}$ der Schlußfolgerung, wie Dölling äußerte, „daß die Parteileitungen jetzt die Kaderpolitik alleine durchführen“ würden ${ }^{199}$. Stoph sah sich Ende 1958 genötigt, zuzugeben, die Kommandeure fühlten sich für die Kaderarbeit „nicht verantwortlich, zumal sie dabei nichts zu sagen“ hätten ${ }^{200}$. Insofern hatte die Bestimmung der neuen Innendienstvorschrift von 1959, nach der die Kommandeure verpflichtet waren, „für eine planmäßige und systematische Entwicklung der Kader" zu sorgen ${ }^{201}$, in erster Linie nur formalen Charak$\operatorname{ter}^{202}$.

Das Ziel der SED war es aber nicht allein, die Personalpolitik der Kommandeure in den Einheiten durch den Parteiapparat politisch zu überwachen und zu steuern. Vielmehr sollte auch die zentrale Personalentwicklung durch die Verwaltung Kader des Ministeriums für Nationale Verteidigung und deren Untergliederungen ständig kontrolliert werden. Auch hier bestand latent die Gefahr, daß Entscheidungen ausschließlich fachspezifisch gefällt wurden, ohne dabei politische Aspekte zu berücksichtigen, obwohl diese für die angemessene Besetzung einer operativen Führungsposition letztlich nicht relevant waren. So kritisierte etwa die ZK-Abteilung für Sicherheitsfragen 1959, daß die Verwaltung Kader in nachgeordneten Einheiten Veränderungen vorgenommen hatte, „ohne sich mit den Parteiorganisationen zu beraten" 203 . Die Politische Verwaltung hatte bereits zuvor grundsätzlich betont, es müsse klar sein, „daß die Arbeit der Kaderverwaltung, der Kaderabteilung der Politischen Verwaltung sowie der Kaderoffiziere in den Militärbezirken, Divisionen, Kommandos der Seestreitkräfte und Luftstreitkräfte im wahren [sic!] Sinne des

196 Über die Rolle der Partei in der NVA. Protokoll Nr. 4/58 der Sitzung des Politbüros des ZK der SED, 14. Januar 1958, SAPMO-BArch, DY 30/J IV 2/2/576, Bl. 195.

197 Plan zur Auswertung und Durchführung des Beschlusses des Politbüros vom 14. Januar 1958 „Über die Rolle der Partei in der NVA“, 1. Februar 1958, BA-MA, VA-P-01/7535, Bl. 163.

198 Instruktion für die Arbeit der Parteiorganisationen, 1958, S. 7 f.

199 Protokoll der Delegiertenkonferenz der Parteiorganisationen der SED in der NVA, 24.-26. Juni 1958, BA-MA, VA-P-01/038, Bl. 57.

200 Protokoll Nr. 6/58 über die Beratung des Kollegiums des Ministeriums für Nationale Verteidigung, 10. November 1958, BA-MA, VA-01/4383, Bl. 34.

201 Innendienstvorschrift der Nationalen Volksarmee DV-10/3, 1959, S. 17.

202 Substantielle Veränderungen dieser Situation leitete die SED-Führung anscheinend erst ein, als es nach dem Mauerbau militärisch opportun und politisch verantwortbar erschien, der Truppenführung in dieser Frage mehr Entscheidungsautonomie einzuräumen. Vgl. Kap. VIII.4. dieser Studie.

203 Einschätzung der Erfüllung des Politbürobeschlusses vom 14. Januar 1958, 1959, SAPMOBArch, DY 30/IV 2/12/9, Bl. 250. 
Wortes Parteiarbeit" sei204. Die Tätigkeit der Verwaltung Kader wurde deshalb maßgeblich durch die ZK-Abteilung für Sicherheitsfragen kontrolliert und angeleitet. So mußte die Verwaltung Kader geplante personelle Veränderungen von Nomenklaturkadern zunächst als Vorschläge bei der ZK-Abteilung für Sicherheitsfragen einreichen. Diese nahm in der Regel eine eigenständige Einschätzung vor, wobei die Veränderungsvorschläge der Verwaltung Kader durchaus zurückgewiesen oder korrigiert wurden. Letztlich waren die Entscheidungen der ZK-Abteilung für Sicherheitsfragen verbindlich ${ }^{205}$. Sie überwachte nicht zuletzt anhand gezielter Kontrollen - etwa im Rahmen von Brigadeeinsätzen - auch die Kaderpolitik in bezug auf die übrigen Offiziersdienststellungen ebenso wie die interne Arbeit der Verwaltung Kader selbst ${ }^{206}$.

Die SED-Führung versuchte seit 1957 zudem, die Kontrolle über die Personalentwicklung durch eine Verknüpfung der Kaderorgane für Truppenoffiziere mit den Kaderorganen für Politoffiziere weiter zu verbessern. Der Leiter der Abteilung Kader der Politischen Verwaltung hatte im September 1956 festgestellt, der Erfahrungsaustausch und die Zusammenarbeit mit der Verwaltung Kader habe sich bisher „zum überwiegenden Teil auf die Perioden der Umbesetzung und auf die Neuaufstellung der Divisionen" im Zuge der NVA-Gründung beschränkt ${ }^{207}$.

Um diesen Mangel zu beheben, wurde im Februar 1957 die „Richtlinie über die Zusammenarbeit zwischen der Verwaltung Kader und der Abteilung Kader der Politischen Verwaltung" erlassen, die die „Anwendung einheitlicher Grundsätze und Arbeitsmethoden in der Kaderarbeit" sicherstellen sollte. Sie machte beiden Institutionen vor allem die „kollektive Beratung“ der Kadervorschläge über die Auffüllung, Ernennung, Versetzung, Qualifizierung, Beförderung, Auszeichnung und Entlassung von Offizieren zur Pflicht, ebenso wie das Kennenlernen der Nomenklaturkader des Ministers für Nationale Verteidigung und des Chefs der Politischen Verwaltung „vom Standpunkt der richtigen Zusammensetzung der Leitungen und Stäbe“. Nunmehr sollten alle Befehle und Direktiven über Kaderfragen sowie die Kaderentwicklungs- und Perspektivpläne gemeinsam erarbeitet werden. Auch die Durchführung und die Ergebnisse der Arbeit waren von beiden Instanzen gemeinsam zu kontrollieren 208 .

Der Chef der Verwaltung Kader Munschke sagte jedoch knapp vier Monate später: „Obwohl bei der Besetzung von Leitungen zusammengearbeitet wird, kann man noch nicht sagen, daß wir diese Richtlinie in allen Fragen einhalten. "209 Vor

204 Plan zur Auswertung und Durchführung des Beschlusses des Politbüros vom 14. Januar 1958 „Über die Rolle der Partei in der NVA“, 1. Februar 1958, BA-MA, VA-P-01/7535, Bl. 160 .

$205 \mathrm{Vgl}$. Borning an Munschke. Bestätigung von Nomenklaturkadern, 14. Januar 1959, SAPMO-BArch, DY 30/IV 2/12/27, Bl. $83 \mathrm{ff}$.

206 Vgl. Bericht der Brigade des ZK der SED in der Verwaltung Kader des Ministeriums für Nationale Verteidigung, 15. Juni 1960, SAPMO-BArch, DY 30/IV 2/12/22, Bl. $271 \mathrm{ff}$.

207 Die Arbeit der Abteilung Kader der Politischen Verwaltung und die Arbeit mit den PolitKadern in der NVA. Protokoll Nr. 7/56 über die Sitzung des Kollegiums des Ministeriums für Nationale Verteidigung, 21. September 1956, BA-MA, VA-01/2030, Bl. 153.

208 Richtlinie über die Zusammenarbeit zwischen der Verwaltung Kader und der Abteilung Kader der Politischen Verwaltung, 14. Februar 1957, BA-MA, VA-01/5039, Bl. 25 f.

209 Bericht über die Lage im Offiziersbestand und über die Arbeit mit den Kadern in der Win- 
allem wurde es als notwendig erachtet, die "Zusammenarbeit der Kader- und Politorgane nach unten bis auf die Ebene der Divisionen und Flottillen" zu erweitern ${ }^{210}$. Doch noch 1959 monierte die ZK-Abteilung für Sicherheitsfragen, ein „Hauptmangel“ in der Kaderarbeit der Politorgane bestehe darin, daß diese „in der Hauptsache über Veränderungen bei Politoffizieren" berieten, auf Personalentscheidungen bei der „Mehrzahl der operativen Offiziere“ jedoch nur „ungenügenden Einfluß“ nähmen ${ }^{211}$.

Das ZK der SED gelangte im Anschluß an einen in der ersten Jahreshälfte 1960 durchgeführten Brigadeeinsatz zu der Überzeugung, daß die Zusammenarbeit der Verwaltung Kader mit der Kaderabteilung der Politischen Verwaltung noch immer „ungenügend" war 212 . „Um eine einheitliche Führung und Koordinierung der Kaderarbeit in der NVA zu gewährleisten“, hielt man es daher für notwendig, beide Institutionen „zu einem einheitlichen Kaderorgan“ zusammenzufassen ${ }^{213}$.

Am 12. November 1960 befahl Hoffmann auf der Grundlage der Ergebnisse des ZK-Berichtes die „Zusammenlegung der Kaderorgane für Polit-Offiziere mit der Verwaltung Kader des Ministeriums für Nationale Verteidigung bzw. den Abteilungen und Unterabteilungen Kader der Kommandos und Verbände". Die eigenständigen Nomenklaturrechte des Chefs der Politischen Verwaltung hinsichtlich der Auswahl, Ernennung, Beförderung und Qualifizierung der Politkader blieben jedoch bestehen. Die Zusammenlegung wurde darüber hinaus auch auf der Ebene der Kommandos der Teilstreitkräfte, Militärbezirke und Divisionsstäbe vollzogen. Offenbar ging es bei dieser Strukturentscheidung neben einer verbesserten Abstimmung in der Personalentwicklung vor allem um die „Gewährleistung eines ständigen Einflusses durch die Politische Verwaltung" auf die gesamte Kaderpolitik der NVA, denn "alle grundsätzlichen Fragen" in der Kaderarbeit hatte der Chef der Verwaltung Kader nunmehr mit dem Chef der Politischen Verwaltung zu bera$\operatorname{ten}^{214}$.

terausbildungsperiode. Protokoll Nr. 3/57 über die Sitzung des Kollegiums des Ministeriums für Nationale Verteidigung, 6. Mai 1957, BA-MA, VA-01/2032, Bl. 62.

210 Die Zusammenarbeit zwischen den Kaderorganen für die Kader der Waffengattungen und den Kaderorganen der Polit-Kader. Tagung der Kaderoffiziere, 17./18. Dezember 1957, BA-MA, VA-01/2377, Bl. 252.

211 Einschätzung der Erfüllung des Politbürobeschlusses vom 14. Januar 1958, 1959, SAPMOBArch, DY 30/IV 2/12/9, Bl. 251.

212 Bericht der Brigade des ZK der SED in der Verwaltung Kader des Ministeriums für Nationale Verteidigung, 15. Juni 1960, SAPMO-BArch, DY 30/IV 2/12/22, Bl. 295.

213 Ebenda, Bl. 303.

214 Zusammenlegung der Kaderorgane für Politoffiziere mit der Verwaltung Kader des Ministeriums für Nationale Verteidigung bzw. den Abteilungen und Unterabteilungen Kader der Kommandos und Verbände. Befehl Nr. 65/60 des Ministers für Nationale Verteidigung, 12. November 1960, BA-MA, VA-01/5002, Bl. $62 \mathrm{f}$. 


\section{Der Staatsapparat}

\section{Das Strafrecht}

Während die SED anhand des Parteiapparates in der NVA die militärischen Diskussions- und Entscheidungsprozesse gezielt beeinflußte, dienten das Strafrecht und die strafrechtliche Praxis ${ }^{215}$ der Partei als Instrument zur indirekten Kontrolle des Militärs.

Zunächst diente der Artikel 6 der DDR-Verfassung vom 7. Oktober 1949 der Rechtsprechung als allgemeine Norm, nach der auch politisch qualifizierte Delikte von NVA-Angehörigen strafrechtlich sanktioniert wurden ${ }^{216}$. In Absatz 2 des Artikels heißt es generalklauselartig: „Boykotthetze gegen demokratische Einrichtungen und Organisationen, Mordhetze gegen demokratische Politiker, Bekundungen von Glaubens-, Rassen-, Völkerhaß, militärische Propaganda sowie Kriegshetze und alle sonstigen Handlungen, die sich gegen die Gleichberechtigung richten, sind Verbrechen im Sinne des Strafgesetzbuches. “217 Die Tatbestandsmerkmale des Artikels waren unbestimmt und beliebig interpretierbar; darüber hinaus enthielt er keine Strafandrohung. Aus diesem Grund konnte der sogenannte „Boykottartikel“ auch im militärischen Bereich jederzeit zu politischen Zwecken instrumentalisiert werden. Für NVA-Angehörige bestand somit keine Rechtssicherheit ${ }^{218}$.

Im Anschluß an die 30. ZK-Tagung im Januar 1957 verfolgte die SED jedoch eine Differenzierung der strafrechtlichen Bestimmungen. Diese Zielsetzung sollte durch das „Gesetz zur Ergänzung des Strafgesetzbuches“ verwirklicht werden. Das sogenannte „Strafrechtsergänzungsgesetz" (StEG) wurde am 11. Dezember 1957 in der Volkskammer beschlossen und trat am 1. Februar 1958 in $\mathrm{Kraft}^{219}$. Von Seiten der Partei und der Justiz hieß es zur Erklärung, der Artikel 6 der DDR-Verfassung sei „während einer bestimmten Entwicklung ein gutes Instrument" gewesen: „Jetzt allerdings ist der Punkt erreicht, wo an die Stelle des allgemeinen Instruments zum Schutze unseres Staates speziellere, feinere Instrumente treten können." 220 Das Strafrechtsergänzungsgesetz realisierte dementsprechend eine Spezifizierung des Artikels 6 Absatz 2 in Einzeltatbestände. Der Artikel blieb zur Abdeckung möglicher Lücken im neuen Gesetz jedoch weiterhin in $\mathrm{Kraft}^{221}$.

Der Zweite Teil des Strafrechtsergänzungsgesetzes enthielt im Ersten Abschnitt elf Einzelstraftatbestände, die „Verbrechen gegen den Staat und die Tätigkeit seiner Organe" bestimmten. Diese waren für NVA-Angehörige, insbesondere Offiziere, ebenso relevant, wie die sechs im dritten Teil des Gesetzes aufgeführten „Verbre-

215 Vgl. u.a. Fricke, Politik und Justiz in der DDR, S. $319 \mathrm{ff}$., $371 \mathrm{ff}$.; Schroeder, Das Strafrecht des realen Sozialismus, S. $29 \mathrm{ff}$.; Schuller, Geschichte und Struktur des politischen Strafrechts der DDR, S. $386 \mathrm{ff}$.; Werkentin, Politische Strafjustiz in der Ära Ulbricht, S. $47 \mathrm{ff}$., $243 \mathrm{ff} ., 373 \mathrm{ff}$.

216 Buth, Die Entwicklung des militärischen Befehlsrechts, S. $126 \mathrm{ff}$.

217 Die Verfassung der Deutschen Demokratischen Republik. Vom 7. Oktober 1949, GBl. I 1949, S. 6.

218 Böckenförde, Die Rechtsauffassung im kommunistischen Staat, S. $73 \mathrm{f}$.

219 Gesetz zur Ergänzung des Strafgesetzbuches - Strafrechtsergänzungsgesetz -. Vom 11. Dezember 1957, GBl. I 1957, S. 643 ff.

220 Krutzsch, Die Bedeutung des Strafrechtsergänzungsgesetzes, S. $793 \mathrm{f}$.

221 Vgl. Schroeder, Das Strafrecht des realen Sozialismus, S. 30 f. 
chen gegen die militärische Disziplin“, da sich das Strafrechtsergänzungsgesetz nach Auffassung der Partei nicht nur "gegen die Feinde" der Arbeiter-und-BauernMacht richtete, sondern ausdrücklich auch „der Sicherung der Verteidigungsbereitschaft der DDR" diente222. Die Sicherheitskommission hatte entsprechend dieser Intention schon im April 1956 festgelegt, „dass kein besonderes Militärstrafgesetzbuch geschaffen ..., sondern die entsprechenden neu auszuarbeitenden Paragraphen in das Gesetzbuch eingearbeitet werden" sollten ${ }^{223}$.

Im Zusammenhang mit der Einführung des Strafrechtsergänzungsgesetzes rezipierte die DDR-Justiz auch den sogenannten "materiellen Verbrechensbegriff“ aus dem sowjetischen Strafrecht. Eine Handlung mußte jetzt nicht allein politisch-moralisch verwerflich, rechtswidrig und strafbar sein, sondern zudem das Tatbestandsmerkmal der "Gesellschaftsgefährlichkeit" erfüllen, um strafrechtlich als Verbrechen qualifiziert zu werden. Bei politischen Delikten galten diese Kriterien immer224. Demgemäß war bei der „Einschätzung von Gesetzesverletzungen zwischen jenen strafbaren Handlungen zu unterscheiden, die aus antagonistischen Widersprüchen" erwuchsen, weil der Täter ein grundsätzlicher Gegner des Systems war, und jenen, die „aus nichtantagonistischen gesellschaftlichen Widersprüchen“ entstanden, etwa "als Folge einer zurückgebliebenen Bewußtseinsbildung "225.

Auch im Strafrechtsergänzungsgesetz fand der materielle Verbrechensbegriff seinen Niederschlag. Zum einen legte Paragraph 8 fest: „Eine Straftat liegt nicht vor, wenn die Handlung zwar dem Wortlaut eines gesetzlichen Tatbestandes entspricht, aber wegen ihrer Geringfügigkeit und mangels schädlicher Folgen für die Deutsche Demokratische Republik, den sozialistischen Aufbau, die Interessen des werktätigen Volkes sowie des einzelnen Bürgers nicht gefährlich ist." Zum anderen sollte nach Paragraph 9 eine Bestrafung nicht erfolgen, „wenn nach der Tat im gesamten Verhalten des Täters eine grundlegende Wandlung eingetreten ist, die erwarten läßt, $\mathrm{da}$ er die sozialistische Gesetzlichkeit achten wird"226. Beide Paragraphen stellten Generalklauseln dar, die unbeschränkte Interpretationen zuließen. Zudem war jetzt rechtlich nicht mehr die Erfüllung eines Straftatbestandes, sondern die vermeintliche Einstellung des Täters entscheidend.

Hinsichtlich der Konsequenzen dieser Bestimmungen für die Rechtsprechung konstatierte Justizministerin Hilde Benjamin, „daß das Recht als ein Hebel des staatlichen Aufbaus ... mit dem Ziel angesetzt werden“ müsse, „zur revolutionären Umwälzung beizutragen“227. Unter Bezugnahme auf die sogenannte „Babelsberger Konferenz" vom April 1958, auf der Ulbricht die Rechtsprechung auf der Grundlage der Parteibeschlüsse postuliert hatte ${ }^{228}$, forderte sie die „Überwindung der

222 Volkskammer beschloß: Gesetz zur Ergänzung des Strafgesetzbuches, S. $21 \mathrm{f}$.

223 Protokoll der 9. Sitzung der Sicherheitskommission des ZK der SED, 20. April 1956, BA-MA, DVW 1/39551, Bl. 3.

224 Fricke, Politik und Justiz in der DDR, S. 371 f.

225 Thesen zum Referat „Die Aufgaben der Militärstaatsanwälte im Kampf um die Erhöhung der ständigen Einsatzbereitschaft der Organe der Landesverteidigung“, 30. Oktober 1959, SAPMO-BArch, DY 30/IV 2/12/11, Bl. 490.

226 Strafrechtsergänzungsgesetz, GBl. I 1957, S. 644.

227 Benjamin, Die dialektische Einheit von Gesetzlichkeit und Parteilichkeit, S. 365.

228 Vgl. Molnau, Die Babelsberger Konferenz von 1958, S. 231 ff. 
Formaljurisprudenz“. Dies bedeute zwar weiterhin die „strikte Einhaltung der Gesetze, aber nicht ihre formale, ... sondern ihre parteiliche Anwendung "229.

Als ein Ergebnis dieser Maßgabe blieb der aus dem sogenannten „Rechtsstaatsprinzip“ resultierende „Bestimmtheitsgrundsatz" $230 \mathrm{im}$ DDR-Strafrecht somit auch nach 1958 außer Kraft, da die Anwendung des Strafrechts nicht streng nach dem Wortlaut des Gesetzes erfolgte, sondern letztlich politischen Kriterien unterlag. Aus diesem Grund existierte in der strafrechtlichen Praxis weiterhin keine Rechtssicherheit. Die darüber hinaus fehlende Gewaltenteilung in der DDR und die vielschichtige informelle Durchdringung des Rechtssystems durch die Parteiorgane ermöglichten ebenfalls eine politische Instrumentalisierung der Strafjustiz 231. Dementsprechend waren auch die Soldaten der NVA mit einer möglichen willkürlichen Auslegung des Strafrechts durch die Justizorgane konfrontiert. Sie konnten sich nicht darüber im klaren sein, wie ihr eigenes Handeln oder Fehlverhalten strafrechtlich qualifiziert werden würde.

Der Zweite Teil des Strafrechtsergänzungsgesetzes enthielt als „Ergänzung zum Besonderen Teil des Strafgesetzbuches" im ersten Abschnitt als Einzeltatbestände zunächst "Staatsverrat" (\$13), „Spionage“ (\$14), „Sammlung von Nachrichten“ $(\$ 15)$ und "Verbindung mit verbrecherischen Organisationen und Dienststellen" $(\$ 16)$. Weitere Verbrechen im Sinne des Strafrechtsergänzungsgesetzes waren „Staatsgefährdende Gewaltakte“ ( $(17)$, „Angriffe gegen örtliche Organe der Staatsmacht“ $(\$ 18)$, „Staatsgefährdende Propaganda und Hetze“ (\$19) sowie "Staatsverleumdung“ $(\$ 20)$. Schließlich wurden "Verleitung zum Verlassen der Deutschen Demokratischen Republik“ ( $\$ 21)$, „Diversion“ (\$22), „Schädlingstätigkeit und Sabotage“ $(\$ 23)$ sowie die „Begünstigung von Staatsverbrechen“ $(\$ 25)$ und die "Nichtanzeige von Staatsverbrechen“ ( $\$ 26)$ unter Strafe gestellt ${ }^{232}$.

Im Hinblick auf die NVA bedeutete dies beispielsweise, daß sich ein Offizier bereits eines Staatsverrates strafbar machen konnte, wenn er seine grundsätzliche Opposition gegenüber der „führenden Rolle“ der SED oder der Existenz des Parteiapparates in den Streitkräften zum Ausdruck brachte, wobei es belanglos war, ob dies im verfassungsmäßigen Rahmen geschah ${ }^{233}$. Wer etwa westliche Rundfunksendungen empfing - was in der NVA durchaus üblich war - lief Gefahr, sich der „Staatsgefährdenden Hetze und Propaganda" strafbar zu machen, wenn er diese Sendungen zugleich anderen zugänglich machte. Diesen Straftatbestand erfüllten aber auch regimekritische Äußerungen oder politische Protesthaltungen ${ }^{234}$. Ferner verwirklichte ein Offizier womöglich den Straftatbestand der "Staatsverleumdung“, wenn er zum Beispiel offen die Tätigkeit des Ministeriums für Nationale Verteidigung kritisierte. Dafür bedurfte es keiner dezidiert „feindlichen“ Einstellung. Es genügte schon ein vermeintlich „zurückgebliebenes Bewußtsein“. Faktisch konnte unter dieser Norm jede kritische oder abfällige Äußerung gegen das SED-Regime oder

229 Benjamin, Die dialektische Einheit von Gesetzlichkeit und Parteilichkeit, S. $367 \mathrm{f}$.

230 Vgl. Lackner/Kühl, Strafgesetzbuch mit Erläuterungen, S. 9 f.

231 Vgl. Weinke, Strukturen und Funktionen politischer Strafjustiz in der DDR, S. $89 \mathrm{f}$.

232 Strafrechtsergänzungsgesetz, GBl. I 1957, S. $644 \mathrm{ff}$.

233 Vgl. Fricke, Politik und Justiz in der DDR, S. $376 \mathrm{f}$.

234 Vgl. ebenda, S. $407 \mathrm{f}$. 
Maßnahmen der DDR-Regierung subsumiert werden, auch dann, wenn diese privat gemacht worden waren ${ }^{235}$.

Andererseits aber führte die Anwendung des materiellen Verbrechensbegriffs dazu, daß etwa bei „Trunkenheit am Steuer“ in Anbetracht der „relativ geringen Gesellschaftsgefährlichkeit“ der Handlung „von vornherein die Durchführung eines gerichtlichen Verfahrens ausgeschlossen war“, wenn sich der Täter ausgezeichnete Verdienste um die DDR erworben hatte, wie die ZK-Abteilung für Sicherheitsfragen konstatierte ${ }^{236}$.

Zusätzlich dürfte die Existenz von Paragraph 24 des Strafrechtsergänzungsgesetzes großen politischen und psychologischen Druck auf die NVA-Angehörigen, insbesondere die Offiziere, ausgeübt haben, zumal es sich auch hier um eine Generalklausel handelte, die eine subjektive - und somit weite - Auslegung zuließ. Diese Bestimmung rechtfertigte in „schweren Fällen“ von Staatsverrat, Spionage, Diversion sowie Schädlingstätigkeit und Sabotage auch die Vollstreckung der Todesstrafe. Das galt insbesondere „, in einer Zeit erhöhter Gefährdung“ der DDR ${ }^{237}$. Dieses Kriterium hatte angesichts der Bedrohungsperzeption der SED gegenüber dem Westen Ende der fünfziger Jahre eine nicht zu unterschätzende Bedeutung 238 .

Der Dritte Teil des Strafrechtsergänzungsgesetzes enthielt schließlich gesondert aufgeführte „Verbrechen gegen die militärische Disziplin“. Nach Paragraph 32 waren dies „strafbare Handlungen, die im besonderen Maße gegen die militärische Disziplin, die Ausbildung oder die Einsatzfähigkeit der Truppe "verstießen und von Angehörigen der bewaffneten Kräfte begangen wurden ${ }^{239}$. Alle übrigen Vergehen sollten anhand der Disziplinarordnung geahndet werden ${ }^{240}$. Im einzelnen gab es als Straftatbestände „Fahnenflucht“ (\$ 33), „Unerlaubte Entfernung“ (\$ 34), „Befehlsverweigerung“ (\$35), „Angriff auf Vorgesetzte“ (\$ 36), „Mißbrauch der Dienstbefugnisse“ $(\mathbb{S} 37)$ und die "Verletzung des Dienstgeheimnisses“ $(\mathbb{S} 38)^{241}$.

Die Entscheidung jedoch, ob eine Handlung gemäß Paragraph 32 als Verbrechen gegen die militärische Disziplin oder als ein einfacher Disziplinarverstoß zu bewerten war, ließ sich auch hier nicht aus den Bestimmungen des Gesetzes ableiten, sondern war durch die Justizorgane nach Einschätzung des jeweiligen Falls individuell zu treffen. Entsprechend dem materiellen Verbrechensbegriff wurde ein Delikt da-

235 Vgl. ebenda, S. $409 \mathrm{f}$.

236 Bericht der Brigade der ZK-Abteilung für Sicherheitsfragen über die Überprüfung der Militäroberstaatsanwaltschaft, 1960, SAPMO-BArch, DY 30/IV 2/12/23, Bl. 18.

237 Strafrechtsergänzungsgesetz, GBl. I 1957, S. 645.

238 Signifikant hierfür sind etwa die Äußerungen eines DDR-Richters, nach dessen Auffassung den Bestrebungen der NATO zur gewaltsamen Beseitigung der DDR eben gerade „jene Verbrechen [dienten], deren typische Merkmale als die Tatbestände des Staatsverrats, der Spionage, Staatsgefährdung, staatsgefährdenden Hetze und Verleumdung, der Verleitung zum Verlassen der DDR, der Diversion, der Sabotage in das StEG eingegangen" waren. Er folgerte daraus: „Demgegenüber ist es wahrhaft menschlich, diejenigen, die durch Staatsverrat, Spionage, Sabotage, Diversion und Terror gegen unseren Staat ein neues Völkermorden anzetteln und unsägliches Leid und Elend über Millionen Menschen bringen wollen, mit strengsten Strafen - äußerstenfalls mit dem Tode - zu bestrafen. Eine Milde gegenüber solchen potentiellen und tatsächlichen Massenmördern wäre nicht human, sondern inhuman." Krutzsch, Die Bedeutung des Strafrechtsergänzungsgesetzes, S. $790 \mathrm{ff}$.

239 Strafrechtsergänzungsgesetz, GBl. I 1957, S. 646.

240 Volkskammer beschloß: Gesetz zur Ergänzung des Strafgesetzbuches, S. 792.

241 Strafrechtsergänzungsgesetz, GBl. I 1957, S. $646 \mathrm{f}$. 
bei wiederum durch seine Gesellschaftsgefährlichkeit als Militärstraftat qualifiziert. Dabei war nicht allein das tatbestandliche, rechtswidrige und schuldhafte Begehen einer Tat entscheidend, sondern die spezifischen Bedingungen ihrer Begehensweise. Im militärischen Rahmen erfolgte diese Bewertung, so der damalige Militäroberstaatsanwalt Richard Spank, in erster Linie im Hinblick auf die „konkrete Klassenkampfsituation“ sowie mögliche Auswirkungen der Tat auf den „politisch-ideologischen Zustand der Truppe "242. Aufgrund der unbestimmten gesetzlichen Rahmenbedingungen, die das Strafrechtsergänzungsgesetz normierte, bestand daher hinsichtlich der Frage, wann eine Handlung den Tatbestand eines Verbrechens gegen die militärische Disziplin erfüllen konnte, keine Rechtssicherheit für die Angehörigen der NVA243.

Es ist davon auszugehen, daß die Verbrechen gegen die militärische Disziplin nicht zuletzt deshalb in das Strafrechtsergänzungsgesetz aufgenommen wurden, um die anhaltend hohe Desertionsrate von Armeeangehörigen einzudämmen. Denn die Fahnenflucht wurde als „das schwerste und verabscheuungswürdigste Verbrechen gegen die militärische Disziplin" bezeichnet, für das nach Ansicht der SED in der NVA „keinerlei innere gesellschaftliche Grundlage“ bestand244. Das Justizministerium äußerte in diesem Zusammenhang im April 1959 rückblickend: „Die Schaffung der Strafrechtsnormen über Verbrechen gegen die militärische Disziplin war deshalb eine notwendige Konsequenz, damit im Interesse der ständigen Kampfbereitschaft der Truppe, außer der politisch-ideologischen Erziehung, nötigenfalls strafrechtliche Mittel zur Anwendung kommen können. “245

Mehr als ein Jahr nach dem Inkrafttreten des Gesetzes wurde von Seiten des Justizministeriums zufrieden geäußert: „Insgesamt gesehen haben die Strafvorschriften im Dritten Teil des StEG ihre Erziehungs- und Repressionsfunktion erfüllt." 246 So wurden 1959 insgesamt 1377 Ermittlungsverfahren gegen NVA-Angehörige eingeleitet; davon 149 gegen Offiziere. In Letzteren ging es unter anderem dreimal um Staatsverbrechen, vierzehnmal um Fahnenflucht, fünfmal um die Verletzung des Dienstgeheimnisses, neunmal um Befehlsverweigerung und dreiundzwanzigmal um Verbrechen gegen Volkseigentum, wobei 28 Offiziere zu Gefängnis oder Zuchthaus verurteilt wurden ${ }^{247}$. In diesem Zusammenhang räumte die Militärstaatsanwaltschaft ein, es habe bei der Anwendung des Strafrechtsergänzungsgesetzes anfangs „eine Vielzahl von Unklarheiten gegeben“, was insbesondere eine „unangebrachte Ausweitung der Straftatbestände" bewirkt habe. Die Strafpolitik habe dahin tendiert, „durch nicht immer gerechtfertigte Härte die Präventivfunktion der Strafe hervorzukehren" 248 .

242 Spank/Hillmann, Einige Probleme der Verbrechen gegen die militärische Disziplin, S. 581.

243 Buth, Die Entwicklung des militärischen Befehlsrechts, S. $131 \mathrm{ff}$.

244 Otto, Über die Anwendung der Bestimmungen des Strafrechtsergänzungsgesetzes, S. 415.

245 Begründung der vorgeschlagenen Strafrechtsnormen über Verbrechen und Vergehen gegen die Kampfkraft der Organe der Landesverteidigung der DDR, 25. April 1959, SAPMOBArch, DY 30/IV 2/12/47, Bl. 20.

246 Ebenda, Bl. 21.

247 Analyse über die in der Zeit vom 1. Januar bis 31. Dezember 1959 bearbeiteten Strafverfahren gegen Offiziere der NVA, 2. Februar 1960, BA-MA, VA-01/13496, Bl. $4 \mathrm{ff}$.

248 Thesen zum Referat „Die Aufgaben der Militärstaatsanwälte im Kampf um die Erhöhung der ständigen Einsatzbereitschaft der Organe der Landesverteidigung“", 30. Oktober 1959, SAPMO-BArch, DY 30/IV 2/12/11, Bl. 499. 
Die strafrechtlichen Normen des Strafrechtsergänzungsgesetzes bildeten auch während der folgenden Jahre die Grundlage für die Strafverfolgung in der NVA. Im Hinblick auf ihre Anwendung war vor dem Mauerbau eine gewisse Liberalisierung zu verzeichnen; dies galt insbesondere für die Zeit nach dem Inkrafttreten des sogenannten „Rechtspflegeerlasses“ des Staatsrates vom 30. Januar 1961249.

\section{Die Militärjustiz}

Im Bereich der Militärjustiz ${ }^{250}$ waren es vor allem die Militärstaatsanwälte, die den Entscheidungsspielraum und die Kompetenz der Kommandeure und Disziplinarvorgesetzten etwa in der Frage, inwieweit besondere Vorkommnisse als Disziplinarvergehen oder aber als strafbare Handlung zu bewerten seien, nachhaltig einschränkten.

Die Militärstaatsanwaltschaft wurde entsprechend der Anordnung des Generalstaatsanwalts der DDR vom 17. November 1956 auf der Grundlage des Gesetzes über die Staatsanwaltschaft der DDR vom 23. Mai 1952 geschaffen $^{251}$. Sie ging aus der im Mai 1954 gebildeten "Staatsanwaltschaft der Volkspolizei“ hervor, deren Vorläufer das 1953 eingerichtete „Untersuchungsbüro des Ministeriums des Innern" gewesen war ${ }^{252}$.

Die Militärstaatsanwaltschaft hatte allgemein vor allem die Aufgabe, die „Festigung der sozialistischen Gesetzlichkeit" in der NVA, die "Gewährleistung der gesetzlichen Rechte aller Militärangehörigen“ und die „Unterstützung der Kommandeure der Einheiten und Verbände und Chefs der Verwaltungen bei der Festigung der inneren Ordnung und Disziplin und im Kampf gegen die Kriminalität“ zu garantieren ${ }^{253}$. Geleitet wurde sie vom Militäroberstaatsanwalt, einem Stellvertreter des Generalstaatsanwalts der DDR ${ }^{254}$. Dieser war dem Minister für Nationale Verteidigung über die gesamte Tätigkeit der Militärstaatsanwaltschaft „berichtspflichtig“255. Dem Militäroberstaatsanwalt unterstanden seinerseits die Militärstaatsanwälte der Militärbezirke, Divisionen und Standortbereiche sowie die Militärstaatsanwälte der Luftstreitkräfte, der Luftverteidigungskräfte und der Seestreitkräfte 256 . In der Militärstaatsanwaltschaft selbst war die Abteilung I für die „Bekämpfung“

249 Beschluß des Staatsrates der Deutschen Demokratischen Republik über die weitere Entwicklung der Rechtspflege. Vom 30. Januar 1961, GBl. I 1961, S. 3 f.

250 Vgl. u. a. Eisert, Zu den Anfängen der Geschichte der Militärjustiz, S. 113 ff.; Kaschkat, Militärjustiz in der DDR, S. 585 ff.; Wenzke, Militärjustiz und Disziplinarrecht in der NVA, S. $41 \mathrm{f}$.

251 Anordnung des Generalstaatsanwalts der DDR über die Schaffung der Militärstaatsanwaltschaft der DDR, 17. November 1956, BA-MA, VA-01/1832, Bl. $117 \mathrm{ff}$.

252 Thesen zum Referat „Die Aufgaben der Militärstaatsanwälte im Kampf um die Erhöhung der ständigen Einsatzbereitschaft der Organe der Landesverteidigung“, 30. Oktober 1959, SAPMO-BArch, DY 30/IV 2/12/11, Bl. 492.

253 Anordnung des Generalstaatsanwalts der DDR über die Schaffung der Militärstaatsanwaltschaft der DDR, 17. November 1956, BA-MA, VA-01/1832, Bl. 117.

254 Ebenda, Bl. 119.

255 Die funktionellen Pflichten und Aufgaben der Militärstaatsanwaltschaft der DDR. Unterstellungs- und Disziplinarverhältnisse und die Rechte der Militärstaatsanwälte. 2. September 1957, BA-MA, VA-01/1832, Bl. 136.

256 Anordnung des Generalstaatsanwalts der DDR über die Schaffung der Militärstaatsanwaltschaft der DDR, 17. November 1956, BA-MA, VA-01/1832, Bl. 118. 
der Verbrechen gegen den Staat und die staatlichen Organe verantwortlich, „insbesondere für die Anleitung und Kontrolle bei der Bekämpfung von Fahnenfluchten,

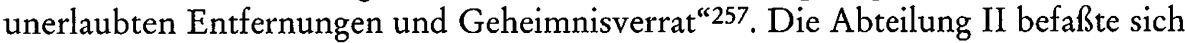
unter anderem mit der Überprüfung aller Strafverfahren gegen NVA-Offiziere, die Anklageerhebung und Anklagevertretung in der 1. Instanz sowie die Einleitung der Strafvollstreckung 258 .

Im einzelnen oblag es der Militärstaatsanwaltschaft vor allem, die Aufsicht darüber zu führen, daß in der NVA die Gesetze der DDR eingehalten wurden und militärische Befehle und Anordnungen mit diesen im Einklang standen. Zur Erfüllung dieser Aufgabe hatte sie unter anderem die „eingehenden Beschwerden und Mitteilungen über die Verletzung der Gesetzlichkeit“ zu überprüfen und „Gesetzesverletzungen im Zusammenhang mit der Untersuchung von Verbrechen" festzustellen ${ }^{259}$. Dabei sollten die Militärstaatsanwälte ihre Tätigkeit „im engsten Kontakt mit den Kommandeuren und Politorganen der von ihnen zu betreuenden Einheiten und Verbände" durchführen ${ }^{260}$.

Im Befehl des Ministers für Nationale Verteidigung über die „Bildung der Militärstaatsanwaltschaft" der DDR vom 2. September 1957 wurden umgekehrt auch alle Kommandeure dazu verpflichtet, die für ihren Bereich zuständigen Militärstaatsanwälte bei der Erfüllung der gesetzlichen Aufgaben zu unterstützen und „in enger Zusammenarbeit mit ihnen den Kampf gegen die Kriminalität und ihre Ursachen zu führen". Dies bedeutete insbesondere, daß sie die Militärstaatsanwälte von sich aus „ständig über die angefallenen besonderen Vorkommnisse“ $\mathrm{zu}$ informieren hatten ${ }^{261}$. Diese konnten dann „Weisungen für die Führung der Untersuchung erteilen"262. Letztlich entschied somit der jeweilige Militärstaatsanwalt, ob ein Delikt durch den Disziplinarvorgesetzten zu ahnden war oder aber ein Ermittlungsverfahren eingeleitet wurde 263 . Aufgrund dieser Praxis konnten die Disziplinarvorgesetzten in der NVA nicht selbständig darüber entscheiden, ob sie einen Fall an die Strafverfolgungsbehörden abgeben mußten oder ihn allein disziplinarrechtlich behandeln konnten ${ }^{264}$.

Im weiteren Verlauf der Ermittlungen hatte der zuständige Militärstaatsanwalt zu prüfen, ob die Fortdauer einer angeordneten Untersuchungshaft geboten war. Ferner erhob er im Rahmen eines eingeleiteten Strafverfahrens die Anklage und vertrat

257 Bericht der Brigade der ZK-Abteilung für Sicherheitsfragen über die Überprüfung der Militäroberstaatsanwaltschaft, 1960, SAPMO-BArch, DY 30/IV 2/12/23, Bl. 13.

258 Die funktionellen Pflichten und Aufgaben der Militärstaatsanwaltschaft der DDR. Unterstellungs- und Disziplinarverhältnisse und die Rechte der Militärstaatsanwälte. 2. September 1957, BA-MA, VA-01/1832, Bl. 148.

259 Anordnung des Generalstaatsanwalts der DDR über die Schaffung der Militärstaatsanwaltschaft der DDR, 17. November 1956, BA-MA, VA-01/1832, Bl. $120 \mathrm{f}$.

260 Ebenda, Bl. 123.

261 Bildung der Militärstaatsanwaltschaft der DDR. Befehl Nr. 71/57 des Ministers für Nationale Verteidigung, 2. September 1957, BA-MA, VA-01/1832, Bl. $52 \mathrm{f}$.

262 Anordnung des Generalstaatsanwalts der DDR über die Schaffung der Militärstaatsanwaltschaft der DDR, 17. November 1956, BA-MA, VA-01/1832, Bl. 121.

263 Vgl. Lolland, Zu Befehl, Genosse Unterleutnant, S. $177 \mathrm{f}$.

264 In der Bundeswehr beispielsweise hat ein Disziplinarvorgesetzter diese Entscheidung eigenständig zu treffen. Die Ausübung der Disziplinargewalt wird dabei nicht direkt durch die Staatsanwaltschaft, sondern durch den höheren Disziplinarvorgesetzten im Rahmen der Dienstaufsicht kontrolliert. Ilsemann, Die Innere Führung in den Streitkräften, S. 64, 66. 
diese vor Gericht. Zudem führte er sowohl die Aufsicht über den Vollzug der Untersuchungshaft als auch einer möglichen Strafe. Dies geschah jedoch nur ,in den Fällen ..., in denen er die Untersuchung geführt bzw. die Anklage erhoben" hatte ${ }^{265}$. Denn die Bearbeitung einer Reihe von Straftatbeständen fiel nicht in die Zuständigkeit der Militärstaatsanwaltschaft. Diesbezüglich stellte das MfS 1958 in einer internen Schrift unmißverständlich klar: „Sämtliche Staatsverbrechen werden von der HA IX [Hauptabteilung IX] untersucht. Die Bearbeitung von Straftaten nach dem 3. Teil des StEG erfolgt durch die Militärstaatsanwaltschaft." Sollte diese im Zusammenhang mit ihren Untersuchungen ein Staatsverbrechen feststellen, habe dementsprechend eine Übergabe an die Organe des MfS zu erfolgen ${ }^{266}$. Diese Äußerung macht deutlich, daß die Bestimmung, der Militärstaatsanwaltschaft obliege "die Aufsicht über alle Untersuchungen der Untersuchungsorgane“, ausschließlich formaler Natur war ${ }^{267}$.

Tatsächlich entschieden aber offenbar von vornherein die Verbindungsoffiziere des MfS in den Einheiten und Dienststellen der NVA, welche Qualität ein Delikt hatte und durch wen die Untersuchung zu führen war ${ }^{268}$. Die MfS-Offiziere scheinen darüber hinaus auch selbständig Untersuchungen angestellt zu haben, ohne daß die Militärstaatsanwaltschaft im Vorfeld eingeschaltet wurde oder davon Kenntnis erlangte. Im Hinblick darauf konstatierte man von Seiten des MfS: „Von der Inhaftierung einer Person erhält der Militärstaatsanwalt dadurch Kenntnis, indem ihm entsprechendes Beweismaterial bzw. in verschiedenen Fällen nach der durchgeführten Vernehmung das Protokoll vorgelegt wird und es [sic!] daraufhin den Haftbefehlsantrag bei dem zuständigen Gericht stellt.“269

Im Zuge der intensivierten politischen Durchdringung der NVA ab 1957 zielte sowohl die SED-Führung als auch die Militärstaatsanwaltschaft selbst darauf ab, den Einfluß und die Präsenz der Militärstaatsanwälte in den militärischen Leitungen und Stäben zu verbessern. Die Leitung der Militärstaatsanwaltschaft regte im September 1958 gegenüber der Leitung der Politischen Verwaltung unter anderem

265 Anordnung des Generalstaatsanwalts der DDR über die Schaffung der Militärstaatsanwaltschaft der DDR, 17. November 1956, BA-MA, VA-01/1832, Bl. 122.

266 Die Abwehrarbeit des MfS in den bewaffneten Formationen der DDR. Schulungsmaterial, Dezember 1958, BStU, ZA, JHS Sicherheitsfilm Z. 214/58, Bl. 97 f.

267 Anordnung des Generalstaatsanwalts der DDR über die Schaffung der Militärstaatsanwaltschaft der DDR, 17. November 1956, BA-MA, VA-01/1832, Bl. 121.

268 Vgl. Lolland, Zu Befehl, Genosse Unterleutnant, S. 177; Fricke, MfS intern: Macht, Strukturen, Auflösung der DDR-Staatssicherheit, S. $61 \mathrm{ff}$.

269 Die Abwehrarbeit des MfS in den bewaffneten Formationen der DDR. Schulungsmaterial, Dezember 1958, BStU, ZA, JHS Sicherheitsfilm Z. 214/58, B1. 98. Offensichtlich gab es aufgrund dieser Praxis grundsätzlich immer wieder Kompetenzkollisionen zwischen der Staatsanwaltschaft und den Organen des MfS. Ulbricht sah sich daher offenbar auf der 30. ZK-Tagung genötigt, zu diesem Problem Stellung zu nehmen: „Das Politbüro hat die Genossen der Staatssicherheit darauf aufmerksam gemacht, dass man in der Staatssicherheit offen über die politischen Fragen spricht und sich nicht einschüchtern lässt, auch nicht von den Genossen der Staatsanwaltschaft. Was ist denn los? Sie sollen lernen, zusammenzuarbeiten. Das geht aber nicht so, dass man eine konterrevolutionäre Gruppe verhaftet und dass ich dann einen Brief bekomme, in dem steht: Ihr habt ja noch gar nicht die Beweise. Muss man nicht diese Leute wieder freilassen? Das sollen die Organe untersuchen!" Stenographische Niederschrift der 30. Tagung des ZK der SED, 30. Januar - 1. Februar 1957, SAPMO-BArch, DY 30/IV 2/1/171, BI. 102. 
an, die Militärstaatsanwälte innerhalb der Kommandos und Verbände stärker in die Kollektive und Leitungen einzubeziehen und sie häufiger an Militärratssitzungen und Kommandeursbesprechungen teilnehmen zu lassen. In diesem Zusammenhang wurde insbesondere die „Beseitigung des Zustandes der bisher sporadischen und zufälligen Einladungen der Militärstaatsanwälte“ gefordert270. Zudem kritisierte man von Seiten der Partei, daß die Verbindung der Militärstaatsanwaltschaft zur Leitung des Ministeriums für Nationale Verteidigung „sehr schwach“ sei. Trotz der Anordnung Stophs habe der Militäroberstaatsanwalt nur "sehr selten“ an den Sitzungen des Kollegiums des Ministeriums für Nationale Verteidigung teilgenommen $^{271}$. Dies aber sollte „zur ständigen Praxis des Militäroberstaatsanwaltes werden“ 272 .

Die organisatorischen Voraussetzungen für seine regelmäßige Teilnahme wurden dann zunächst vor allem durch das neue Statut für das Kollegium des Ministeriums für Nationale Verteidigung vom 3. Mai 1961 geschaffen ${ }^{273}$. Darüber hinaus beabsichtigte die SED-Führung jedoch, das Zusammenwirken der Militärstaatsanwälte auch mit den nachgeordneten militärischen Führungsorganen zu verbessern. Der Verwirklichung dieser Absicht diente der Befehl des Ministers für Nationale Verteidigung vom 25. Juni 1961 zur „Verbesserung der Zusammenarbeit zwischen den Kommandeuren und den Militärstaatsanwälten". In Anknüpfung an die Regelungen im neuen Statut für die Militärräte 274 galt nunmehr für die Chefs und Kommandeure die Verpflichtung: „Zu den Beratungen der Militärräte sowie den Leitungsbesprechungen in den Verbänden ist der Militärstaatsanwalt zur Behandlung aller Fragen hinzuzuziehen, die sein Aufgabengebiet betreffen. Er hat das Recht, seine Auffassungen und Vorschläge vorzutragen." 275

Laut Befehl hatten die Kommandeure und Dienststellenleiter aller Stufen „bei der Feststellung von strafbaren Handlungen oder anderen Gesetzesverletzungen " zum einen „unverzüglich“ eigene Untersuchungen zur Aufklärung anzustellen, zum anderen aber insbesondere „sofort den Militärstaatsanwalt zu benachrichtigen“. Hinsichtlich der Entscheidungskompetenz bezüglich des weiteren Vorgehens wurde durch den Befehl eindeutig festgelegt: „Die Entscheidung über die Einleitung eines Ermittlungsverfahrens und die Notwendigkeit der Inhaftierung eines Beschuldigten trifft der Militärstaatsanwalt." Dieser mußte den Kommandeur des jeweils Beschuldigten darüber jedoch in Kenntnis setzen. Bei „Gefahr im Verzuge" konnte der Militärstaatsanwalt „auch ohne vorherige Benachrichtigung des zuständigen Vorgesetzten" einen Haftbefehl erwirken ${ }^{276}$.

270 Protokoll der Leitungssitzung der Politischen Verwaltung des Ministeriums für Nationale Verteidigung, 13. September 1958, BA-MA, VA-P-01/021, Bl. 70.

271 Bericht der Brigade der ZK-Abteilung für Sicherheitsfragen über die Überprüfung der Militäroberstaatsanwaltschaft, 1960, SAPMO-BArch, DY 30/IV 2/12/23, Bl. 13.

272 Ebenda, Bl. 27.

$273 \mathrm{Vgl}$. S. $128 \mathrm{ff}$.

274 Vgl. ebenda.

275 Verbesserung der Zusammenarbeit zwischen den Kommandeuren und den Militärstaatsanwälten. Befehl Nr. 44/61 des Ministers für Nationale Verteidigung, 25. Juli 1961, BA-MA, VA-01/5903, Bl. 85.

276 Ebenda, Bl. $86 f$. 


\section{Der Staatssicherbeitsdienst}

Mit dem Staatssicherheitsdienst verfügte die SED bereits bei der Gründung der NVA über ein Instrument der politischen Überwachung und Durchdringung des Militärs, das innerhalb der DDR-Streitkräfte über einen außerordentlich weitreichenden Aktionsradius verfügte ${ }^{277}$. Die Hauptabteilung I des MfS, die die Funktion eines militärischen Abschirmdienstes hatte, war zwar als „Verwaltung 2000“ des Ministeriums für Nationale Verteidigung formal in die Organisationsstruktur der NVA integriert. Die Operationsweise des Staatssicherheitsdienstes entzog sich jedoch einer Kontrolle durch die militärischen Leitungsgremien. Dadurch existierte ein von der militärischen Bürokratie vollständig unabhängiger Befehls- und Meldeweg, der bei der Parteiführung endete.

Das MfS war per Gesetz der DDR-Volkskammer vom 8. Februar 1950 geschaffen worden. Im Rahmen des Gesetzes wurden die zukünftigen Aufgaben des Staatssicherheitsdienstes jedoch nicht bestimmt ${ }^{278}$. Nach offizieller Lesart war das MfS zur "Gewährleistung des Schutzes und der Sicherheit der DDR vor verbrecherischen Anschlägen imperialistischer Geheimdienste und Agentenorganisationen" gebildet worden. Der Staatssicherheitsdienst hatte dabei als Organ der Arbeiterund-Bauern-Macht „spezielle Sicherheits- und Rechtspflegeaufgaben für den zuverlässigen Schutz der sozialistischen Staats- und Gesellschaftsordnung" zu erfüllen 279 .

Im Hinblick auf den militärischen Sektor war es Aufgabe der Hauptabteilung I des MfS, im Rahmen der „Militärabwehr“, für die „Gewährleistung der staatlichen Sicherheit" in der NVA zu sorgen ${ }^{280}$. Dieser allgemeine Auftrag umfaßte im einzelnen die „Verhinderung des Eindringens von Agenten imperialistischer Geheimdienste und Agentenzentralen, volksfeindlicher Organisationen und anderer feindlicher Elemente" in die NVA sowie die „Aufklärung und Entlarvung bereits eingedrungener Agenten“. Ferner ging es um die Absicherung der Streitkräfte „gegen alle feindlichen Versuche der politisch-ideologischen Diversion und Zersetzung“. Weiterhin hatte der Staatssicherheitsdienst in der NVA die Aufgabe, die „Sicherung von militärischen und Staatsgeheimnissen" zu garantieren, Fahnenfluchten zu verhindern und aufzuklären sowie alle besonderen Vorkommnisse zu untersuchen, bei denen der „Verdacht eines Staatsverbrechens" bestand 281 .

Um ihre Aufgaben optimal erfüllen zu können, verfügte die Hauptabteilung I, die schon im Dezember 1951 gebildet worden war ${ }^{282}$, über eine Organisationsstruktur "entsprechend der Struktur und dem Aufbau der einzelnen Truppenteile“

277 Vgl. u. a. Bohn, Die Aufrüstung in der Sowjetischen Besatzungszone Deutschlands, S. 39 ff.; Jungermann, Die Wehrideologie der SED, S. $92 \mathrm{f}$;; Lapp, Die Nationale Volksarmee 1956-1990, S. 1938f.; Wenzke, Die Nationale Volksarmee, S. $490 \mathrm{ff}$.

278 Gesetz über die Bildung eines Ministeriums für Staatssicherheit. Vom 8. Februar 1950, GBl. I 1950, S. 95.

279 Staatssicherheit, S. 877.

280 Chronik der Hauptabteilung I, BStU, ZA, MfS HA I 95, Bl. 135 f. Darüber hinaus fiel auch die Überwachung der Deutschen Grenzpolizei (DGP) und der Bereitschaftspolizei (BP) in den Aufgabenbereich der Hauptabteilung I des MfS.

281 Die Abwehrarbeit des MfS in den bewaffneten Formationen der DDR. Schulungsmaterial, Dezember 1958, BStU, ZA, JHS Sicherheitsfilm Z. 214/58, Bl. $10 \mathrm{f.}$

282 Chronik der Hauptabteilung I, BStU, ZA, MfS HA I 95, Bl. 64. 
der NVA 283 . Die Hauptabteilung I gliederte sich daher in fünf operative Abteilungen: Die Verantwortlichkeit für das Ministerium für Nationale Verteidigung lag bei der Abteilung I/1, die Verantwortlichkeit für die Kommandos der Militärbezirke III und V bei den Abteilungen I/2 und I/3. Die Abteilung I/4 hatte die Zuständigkeit für das Kommando der Seestreitkräfte und die Abteilung I/5 für das Kommando der Luftstreitkräfte/Luftverteidigung ${ }^{284}$. Den Divisionen der Teilstreitkräfte waren jeweils „Operativgruppen“ der Hauptabteilung I zugeteilt ${ }^{285}$, denen drei bis fünf MfS-Offiziere angehörten. Auf Regimentsebene arbeiteten zwei Verbindungsoffiziere, in selbständigen Einheiten in Bataillonsstärke war es ein Offizier. Waren mehrere Einheiten (Objekte) in einer militärischen Liegenschaft untergebracht, wurden diese in der Regel von einem operativen Mitarbeiter der Hauptabteilung I zusammen überwacht ${ }^{286}$.

Hinsichtlich der Kompetenzen des MfS in der NVA und der Modalitäten des Zusammenwirkens zwischen militärischer Truppenführung und Hauptabteilung I scheint es nach 1956 zunächst keine formale Regelung gegeben zu haben. Die Tätigkeit des Staatssicherheitsdienstes erfolgte offenbar zunächst auf der Grundlage der rechtlichen und informellen Regelungen, die auch die allgemeinen Rahmenbedingungen für die Tätigkeit des MfS im staatlichen und gesellschaftlichen Bereich bildeten. Nachdem die KVP in reguläre Streitkräfte umgewandelt worden war, wurde es aber anscheinend bald als notwendig erachtet, die Befugnisse zu präzisieren. In einer "Chronik der Hauptabteilung I" heißt es, nach der „Bildung der NVA“ sei "von der Leitung der Hauptabteilung I ein Statut ausgearbeitet und vorgelegt" worden, das "die Hauptaufgaben der Hauptabteilung und ihre Pflichten eindeutig“ festgelegt und dabei die „entstandene neue Lage“ berücksichtigt habe. Die Regelungen des Statuts seien zuvor sowohl mit dem ZK als auch dem Minister für Nationale Verteidigung „beraten und abgestimmt“ worden. Ferner konstatierte man: „Das Statut diente in der Folgezeit den Mitarbeitern der Hauptabteilung I ... als Arbeitsorientierung und Grundlage ihrer Tätigkeit in den Streitkräften der DDR.“287 Weitergehende Regelungen gab es aber bis Anfang der sechziger Jahre anscheinend nicht ${ }^{288}$.

In den Einheiten der NVA oblag den Verbindungsoffizieren der Hauptabteilung I, die dem gesamten Personalbestand einer Einheit „als offizielle Mitarbeiter des

283 Die Abwehrarbeit des MfS in den bewaffneten Formationen der DDR. Schulungsmaterial, Dezember 1958, BStU, ZA, JHS Sicherheitsfilm Z. 214/58, Bl. 11.

284 Chronik der Hauptabteilung I, BStU, ZA, MfS HA I 95, Bl. 120.

285 Wenzke, Die Nationale Volksarmee, S. 490.

286 Bohn, Die Aufrüstung in der Sowjetischen Besatzungszone Deutschlands, S. 41.

287 Chronik der Hauptabteilung I, BStU, ZA, MfS HA I 95, Bl. 135 f. Das Statut scheint im Original nicht mehr zu existieren. Sein Inhalt läßt sich jedoch rekonstruieren, da das Statut die Informationsgrundlage für Schulungsmaterial der Juristischen Hochschule des MfS zu dieser Fragestellung gebildet haben dürfte. Dieses befindet sich im Aktenbestand des BStU. Die Abwehrarbeit des MfS in den bewaffneten Formationen der DDR. Schulungsmaterial, Dezember 1958, BStU, ZA, JHS Sicherheitsfilm Z. 214/58, Bl. $3 \mathrm{ff}$.

288 Erst Ende $1963 \mathrm{kam}$ es zu einer grundlegenden „Vereinbarung über die Zusammenarbeit und das Zusammenwirken der Organe des Ministeriums für Staatssicherheit und des Ministeriums für Nationale Verteidigung". Vgl. Kap. VIII.3. dieser Studie. 
MfS bekannt" waren²89, die "gesamte Abwehrarbeit“290. In dieser Hinsicht gab es eine „offizielle Zusammenarbeit" mit den jeweiligen „Truppenkommandeuren und den politischen Organen"291. So unterhielten etwa die Abteilungsleiter der Hauptabteilung I Verbindungen zu den Chefs und Kommandeuren der Militärbezirke und Divisionen, zu den Chefs der See- und Luftstreitkräfte sowie zu deren Politstellvertretern und Stabschefs. Die MfS-Offiziere besaßen zudem „das Recht, an den Besprechungen der Leitungen bzw. der Stäbe der Einheiten teilzunehmen und von den Kommandeuren und Politoffizieren Informationen über durchgeführte Besprechungen zu empfangen" 292 . Sie hatten „Zugang zu allen Stellen im Objekt" und waren berechtigt, „an allen Arten der Dienstdurchführung teilzunehmen" 293 . Die operativen Mitarbeiter waren den Offizieren der NVA jedoch "weder unterstellt noch rechenschaftspflichtig“ und unterlagen „in keiner Weise ihrer Befehlsgewalt“. Gleichzeitig hatten die operativen Mitarbeiter aber die Pflicht, „die militärische Disziplin zu wahren und zu achten und die bestehenden Dienstvorschriften einzuhalten" 294 .

Gerade diese Verpflichtung aber wurde durch die Mitarbeiter der Hauptabteilung I in der NVA immer wieder mißachtet. Ursache hierfür war vor allem das Mißverhältnis zwischen den Kompetenzen der MfS-Offiziere innerhalb des militärischen Befehls- und Organisationsgefüges einerseits und der Kontrolle ihrer Tätigkeit in den Einheiten andererseits. Letztere wurde durch die ZK-Abteilung für Sicherheitsfragen besorgt, beschränkte sich aber schon aus Gründen der Konspiration weitgehend auf die Formulierung allgemeiner Arbeitsrichtlinien, Entscheidungen über Nomenklaturkader und die routinemäßige Kontrolle von Beschlüssen der Hauptabteilung I295. Eine Kontrolle der militärischen Abwehrarbeit durch das Ministerium für Nationale Verteidigung war aber im allgemeinen ausgeschlossen.

Dieser Zustand führte nach Angaben des MfS offenbar immer wieder dazu, daß sich operative Mitarbeiter als die „maßgebendste Person“ in ihrer Einheit betrachteten. Dies äußere sich unter anderem darin, daß „sie bestehende Befehle nicht berücksichtigten und Kommandeure bzw. Offiziere in einer ungewöhnlichen Art bevormundeten". So habe beispielsweise ein operativer Mitarbeiter in einer Einheit der Seestreitkräfte die Autorität des Kommandeurs mißachtet, indem er ohne Notwendigkeit „rücksichtslos“ Besprechungen und Sitzungen unterbrochen habe ${ }^{296}$.

Im einzelnen sollten die Offiziere der Hauptabteilung I die militärischen Leitungen und Politorgane unter anderem über ,negative und antidemokratische Stimmungen des militärischen Personals“, mögliche „Fluchtabsichten“, die „Verletzung der militärischen Disziplin“, moralische "Zersetzungserscheinungen" bei Offizieren und Mannschaften, die „Überschreitung der Disziplinarbefugnisse durch Kom-

289 Die Abwehrarbeit des MfS in den bewaffneten Formationen der DDR. Schulungsmaterial, Dezember 1958, BStU, ZA, JHS Sicherheitsfilm Z. 214/58, Bl. 20.

290 Ebenda, B1. 12.

291 Ebenda, Bl. 19.

292 Ebenda, Bl. $22 \mathrm{f}$.

293 Ebenda, Bl. 21.

294 Ebenda, Bl. 20.

295 Fricke, MfS intern: Macht, Strukturen, Auflösung der DDR-Staatssicherheit, S. $16 \mathrm{ff}$.

296 Die Abwehrarbeit des MfS in den bewaffneten Formationen der DDR. Schulungsmaterial, Dezember 1958, BStU, ZA, JHS Sicherheitsfilm Z. 214/58, Bl. 20 f. 
mandeure“, Mängel in der "Geheimhaltung militärischer Geheimnisse" oder aber über Beispiele „staatsschädigenden Verhaltens“ informieren ${ }^{297}$.

Um die Truppenführung über die Lage in den Einheiten zu unterrichten, hatten die operativen Mitarbeiter der Hauptabteilung I „periodisch mit den zuständigen Kommandeuren oder Leitungen ... informatorische Besprechungen" durchzuführen. Umgekehrt sollte der jeweilige operative Mitarbeiter „über neue Befehle, Anweisungen, Pläne oder durchzuführende Manöver oder andere dienstliche Maßnahmen, die für die Organisierung der Abwehrarbeit von Bedeutung "waren, in Kenntnis gesetzt werden ${ }^{298}$. Dazu gehörte unter anderem auch eine Überprüfung von $\mathrm{Ka}$ derentscheidungen entsprechend der Kriterien des MfS ${ }^{299}$. Oberst Karl Kleinjung, 1956-1981 Leiter der Hauptabteilung I, sagte im Mai 1957 hinsichtlich des Zusammenwirkens der Kommandeure mit den Verbindungsoffizieren des MfS: „Die Zusammenarbeit darf nicht einseitig, sondern muß wechselseitig sein. Der Verbindungsoffizier wird die Kommandeure unterrichten, wenn er bestimmte Hinweise erhält, aber andererseits muß der Kommandeur auch den Verbindungsoffizier unterrichten. Nur so wird es möglich sein, feindliche Gruppierungen und die Arbeit des Gegners zu erkennen. “300

Das Ziel der Verbindungsoffiziere war jedoch nicht nur eine fruchtbare Zusammenarbeit mit der militärischen Truppenführung, um wichtige Informationen zu gewinnen. Vielmehr bildete die Überwachung der Truppenführung und der Stäbe selbst einen eigenen Schwerpunkt in der "Abwehrarbeit" der Hauptabteilung I. Dabei ging es um die „Sicherung des Stabes gegen das Eindringen von Agenten imperialistischer Geheimdienste“, um die „Verhinderung der Bildung von Konzentrationen" regimekritischer Offiziere sowie darum sicherzustellen, daß keine "geheime[n] Angaben militärischen Charakters in die Hände der Feinde gelangen" konnten $^{301}$. Zur Begründung hieß es, daß von den „Entscheidungen und Befehlen leitender Offiziere ... im entscheidenden Moment das Leben oder der Tod der Einheit abhängen“ könne: „Deswegen müssen Feinde unter den leitenden Offizieren bzw. unfähige Offiziere rechtzeitig erkannt und aus den Dienststellungen entfernt werden. “302

Eine entscheidende Voraussetzung, um diese „Aufgaben der Sicherung der Stabsobjekte lösen zu können", war nach Auffassung des MfS, in den Einheiten der NVA über ein „qualifiziertes Netz inoff. Mitarbeiter" zu verfügen sowie „in allen Abteilungen der Stäbe GI [Gebeime Informatoren] zu besitzen"303. Dabei wurde es offenbar als notwendig erachtet, „auch GI aus den Kreisen der Militärspezialisten“ zu rekrutieren. Denn nach Ansicht des MfS waren vor allem die ehemaligen Wehrmachtsoffiziere dazu "in der Lage, ein genaues, fachlich richtiges Gutachten bei den

\footnotetext{
297 Ebenda, Bl. $23 \mathrm{f}$.

298 Ebenda, Bl. 24.

299 Vgl. Borning an Honecker, 26. September 1957, SAPMO-BArch, DY 30/IV 2/12/30, Bl. 1 f.

300 Protokoll Nr. $3 / 57$ über die Sitzung des Kollegiums des Ministeriums für Nationale Verteidigung, 6. Mai 1957, BA-MA, VA-01/2032, Bl. 79.

301 Die Abwehrarbeit des MfS in den bewaffneten Formationen der DDR. Schulungsmaterial, Dezember 1958, BStU, ZA, JHS Sicherheitsfilm Z. 214/58, Bl. 67.

302 Ebenda, Bl. 70.

303 Ebenda, Bl. 67.
} 
verschiedensten Vorkommnissen abzugeben, was die Grundlage weiterer operativer Maßnahmen oder Entscheidungen sein" konnte ${ }^{304}$.

Grundsätzlich sah das MfS „zur Abwehr der feindlichen Tätigkeit“ gegen die Streitkräfte der DDR ein „umfangreiches Netz von IM“ als „unerläßlich“ an ${ }^{305}$. Als eine wesentliche Voraussetzung für den effizienten Einsatz der IM und GI galt dabei deren „zweckmäßige Werbung“306. Die Rekrutierung von Einheits- oder Teileinheitsführern war in der Regel zu vermeiden. „Vollkommen unzweckmäßig“, so das MfS, sei die Anwerbung von GI aus den Kreisen der Politoffiziere sowie der Partei- und FDJ-Sekretäre: „Mit diesen Genossen arbeitet der op. Mitarbeiter offiziell zusammen." ${ }^{307}$ Neben Offizieren, Unteroffizieren und Soldaten warben die MfS-Offiziere jedoch auch IM unter den Zivilangestellten der NVA und den Zivilisten in der Umgebung der Einheiten an ${ }^{308}$.

Die IM sollten im Auftrag der operativen Mitarbeiter unter anderem die "politischen, charakterlichen Eigenschaften“ und die „dienstliche Einstellung von ArmeeAngehörigen" studieren, die Einblick in wichtige militärische Geheimnisse hatten oder technische Ausrüstungen bedienten. Ferner hatten sie den engeren Bekanntenkreis der NVA-Angehörigen innerhalb ihrer Einheit und unter der Zivilbevölkerung aufzuklären sowie solche Armeeangehörigen zu identifizieren, die „feindliche Gerüchte, Flugblätter und Hetzschriften" verbreiteten, „Befehlsverweigerungen“ oder Handlungen begingen, die die „Einsatzbereitschaft der Einheit gefährden“ konnten. Auch sollten die IM über Soldaten berichten, die sich „besonders stark für militärische Geheimnisse“ interessierten, die nicht zu ihrem Dienstbereich gehörten, und die „verdächtige Verbindungen mit zivilen Personen“ unterhielten. Vor allem aber hatten sie den jeweiligen Verbindungsoffizier der Hauptabteilung I darüber in Kenntnis zu setzen, wenn sie „Anzeichen oder Äußerungen, die auf eine geplante Desertion eines Armeeangehörigen" hinwiesen, festgestellt hatten ${ }^{309}$. Hierzu zählten etwa „Unlust am Dienst“, das Versenden der persönlichen Sachen nach Hause, das Äußern einer Fluchtabsicht, die „Verherrlichung“ der Zustände in Westdeutschland und Westberlin, "Gedanken der Entlassung" ohne „stichhaltige Gründe“ oder „zu harte Strafen" von Vorgesetzten 310 .

Aufgrund der Tatsache, daß es einem operativen Mitarbeiter der Hauptabteilung I in der Praxis nicht möglich war, regelmäßig alle IM einer NVA-Einheit zu treffen, ohne sich „in seiner Arbeit zu verzetteln“, und sich die Verbindung auch „im Einsatz unter Kampfhandlungen" nur schwerlich durchgehend aufrechterhalten ließ311, betrieben die MfS-Offiziere zusätzlich die „Schaffung von Netzen der Geheimen Hauptinformatoren" $(\mathrm{GHI})^{312}$, die in der Regel aus vier bis zehn GI bestan-

304 Ebenda, Bl. 70.

305 Die Rolle, Bedeutung und die Arbeit mit GHI in den bewaffneten Kräften der DDR. Schulungsmaterial, April 1960, BStU, ZA, JHS MF Z. 11/61, Bl. 3.

306 Die Abwehrarbeit des MfS in den bewaffneten Formationen der DDR. Schulungsmaterial, Dezember 1958, BStU, ZA, JHS Sicherheitsfilm Z. 214/58, Bl. 38.

307 Ebenda, Bl. 40 f.

308 Ebenda, Bl. 44.

309 Ebenda, Bl. $58 \mathrm{f}$.

310 Ebenda, Bl. $88 \mathrm{f}$.

311 Ebenda, Bl. 59 f.

312 Die Rolle, Bedeutung und die Arbeit mit GHI in den bewaffneten Kräften der DDR. Schulungsmaterial, April 1960, BStU, ZA, JHS MF Z. 11/61, Bl. 3. 
den ${ }^{313}$. Durch die „Übergabe eines Teils der GI an den GHI“ werde der operative Mitarbeiter in die Lage versetzt, sich intensiver mit den wichtigsten IM und der Arbeit an operativen Vorgängen zu beschäftigen, hieß es von Seiten des MfS 314 . Für die Funktion eines GHI wurden Personen herangezogen, die „als inoffizielle Mitarbeiter ihre besondere Qualifikation und ihre unbedingte Zuverlässigkeit bereits bewiesen" hatten "und aufgrund ihrer beruflichen und politischen Stellung in der Lage" waren, „konspirative Verbindungen zu mehreren geheimen Informatoren aufrecht zu erhalten und diese im Auftrag des operativen Mitarbeiters anzuleiten und zu erziehen“315.

Für die militärische Truppenführung war die Präsenz und Tätigkeit der MfS-Verbindungsoffiziere immer dann besonders spürbar, wenn es um die Behandlung und Sanktionierung besonderer Vorkommnisse ging. Denn die „leitenden Offiziere“ waren dazu verpflichtet, „die operativen Mitarbeiter über alle besonderen Vorkommnisse, die die Einsatzbereitschaft und Sicherheit" einer Einheit gefährden konnten, „zu informieren“316. In diesen Fällen führte der operative Mitarbeiter der Hauptabteilung I von Beginn an „seine eigene Untersuchung" parallel zu den eingeleiteten Maßnahmen der militärischen Leitung 317 . Dabei waren die MfS-Offiziere befugt, jeden NVA-Angehörigen „ohne vorhergehendes Einverständnis der Truppenkommandeure unter Einhaltung der Dienstvorschriften vorzuladen“. Eine Vorladung von "Offizieren des Stabes oder anderen verantwortlichen Offizieren“ konnte jedoch „nur mit Genehmigung der Hauptabteilung I erfolgen“318.

In bezug auf besondere Vorkommnisse, die als Verbrechen gegen die militärische Disziplin gemäß den Vorschriften des Strafrechtsergänzungsgesetzes qualifiziert wurden, hatten die operativen Mitarbeiter des MfS die Aufgabe, insbesondere „durch das Netz inoff. Mitarbeiter die verantwortlichen Kommandeure und die Militärstaatsanwaltschaft bei der Aufdeckung und Verhinderung" dieser Straftaten zu unterstützen $^{319}$. Deren Bearbeitung ebenso wie die anderer krimineller Delikte ${ }^{320}$ erfolgte im Anschluß durch die Militärstaatsanwaltschaft. Von den Organen des MfS wurden lediglich „schwere Fälle ... im Zeichen erhöhter Gefährdung der DDR “ übernommen $^{321}$. Handelte es sich bei dem besonderen Vorkommnis um ein Staatsverbrechen, so wurde dieses immer durch die für Staatsverbrechen zuständige Hauptabteilung IX des MfS untersucht. Im Rahmen ihrer Ermittlungen waren die Organe des MfS in der NVA auch dazu befugt, einzelne Armeeangehörige in Untersuchungshaft zu nehmen. Das MfS verfügte dementsprechend über eigene Untersuchungsgefängnisse ${ }^{322}$. Zur Inhaftierung einer Person bedurfte es dabei keines gerichtlich erwirkten Haftbefehls. Vielmehr wurde der Militärstaatsanwalt in der Regel offenbar erst zu einem späteren Zeitpunkt eingeschaltet, wenn „entsprechen-

313 Ebenda, Bl. 26.

314 Ebenda, Bl. 7.

315 Ebenda, Bl. 4.

316 Die Abwehrarbeit des MfS in den bewaffneten Formationen der DDR. Schulungsmaterial, Dezember 1958, BStU, ZA, JHS Sicherheitsfilm Z. 214/58, Bl. 25.

317 Ebenda, B1. 92.

318 Ebenda, Bl. 21.

319 Ebenda, Bl. 97.

320 Ebenda, Bl. 98.

321 Ebenda, Bl. 97.

322 Holzweißig, Militärwesen in der DDR, S. 122. 
des Beweismaterial" vorhanden war, woraufhin er auf der Grundlage der Vernehmungsprotokolle des Staatssicherheitsdienstes "den Haftbefehlsantrag bei dem zuständigen Gericht stellt $/ e]^{\text {“. }}$. Das MfS betonte in diesem Zusammenhang: „Ein Austausch irgendwelcher Materialien zwischen den op. Abteilungen und den Militärstaatsanwaltschaften in den bewaffneten Kräften erfolgt nicht.“323

\section{Das Militär}

\section{Kollegium des Ministeriums für Nationale Verteidigung und Militärräte der Militärbezirke und Teilstreitkräfte}

Zusätzlich zu den militärischen Führungsstäben gab es in der NVA auf der Ebene des Ministers für Nationale Verteidigung sowie auf der Ebene der Chefs der Militärbezirke und Teilstreitkräfte ${ }^{324}$ besondere Beratungsgremien: Sowohl das „Kollegium des Ministeriums für Nationale Verteidigung“ als auch die „Militärräte“ der Militärbezirke dienten der SED dazu, ihre politische Kontrolle und Einflußnahme gegenüber den höchsten Leitungsgremien der militärischen Truppenführung durchzusetzen. Denn neben deren Vertretern gehörten dem Kollegium und den Militärräten jeweils auch hochrangige Funktionsträger der Partei- und Staatsorgane an.

Im Befehl über die „Bildung des Ministeriums für Nationale Verteidigung" vom Februar 1956 hatte es geheißen, im Bereich des Ministeriums sei ein Kollegium zu schaffen ${ }^{325}$. Dieses sollte laut Statut als „das beratende Organ des Ministers“ fungieren, der selbst den Vorsitz innehatte und die Sitzungen einberief. Es hatte die Aufgabe, "sich mit der Vorbereitung und Führung der Truppen und Dienststellen" der NVA zu befassen. Im einzelnen sollten dabei vor allem die „Erziehung und Entwicklung der Kader" sowie Maßnahmen zur Verwirklichung von Beschlüssen des ZK und des Politbüros, von Gesetzen der Volkskammer und Beschlüssen der Regierung sowie von Befehlen und Anweisungen des Ministers für Nationale Verteidigung im Mittelpunkt der Arbeit stehen. Ferner behandelte das Gremium Fragen der „militärischen Disziplin“, des „politisch-moralischen Zustandes“, des „Niveaus der Kampfausbildung“, der „Bewaffnung" und „Versorgung“ der NVA sowie ihrer

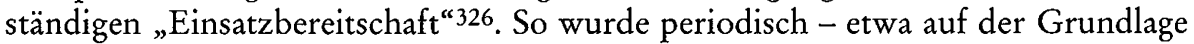
der Berichte über den politisch-moralischen Zustand ${ }^{327}$ - die Lage der Truppe im

323 Die Abwehrarbeit des MfS in den bewaffneten Formationen der DDR. Schulungsmaterial, Dezember 1958, BStU, ZA, JHS Sicherheitsfilm Z. 214/58, Bl. 98.

324 Die NVA war in fünf Militärbezirke gegliedert: Militärbezirk I - Ministerium für Nationale Verteidigung (Strausberg), Militärbezirk II - Luftstreitkräfte/Luftverteidigung (Strausberg/ Eggersdorf), Militärbezirk III - Landstreitkräfte (Leipzig), Militärbezirk IV - Seestreitkräfte bzw. ab 3. November 1960 Volksmarine (Rostock), Militärbezirk V - Landstreitkräfte (Neubrandenburg). Vgl. Lapp, Die Nationale Volksarmee 1956-1990, S. 1910.

325 Bildung des Ministeriums für Nationale Verteidigung. Befehl Nr. 2/56 des Ministers für Nationale Verteidigung, 10. Februar 1956, BA-MA, VA-01/1808, Bl. $1 \mathrm{f}$.

326 Statut des Kollegiums des Ministeriums für Nationale Verteidigung, 13. März 1956, BA-MA, VA-01/6098, Bl. $256 \mathrm{f}$.

$327 \mathrm{Vgl}$. Bericht über den politisch-moralischen Zustand in den Einheiten der Land-, Luft- und Seestreitkräfte. Protokoll Nr. 7/56 über die Sitzung des Kollegiums des Ministeriums für Nationale Verteidigung, 21. September 1956, BA-MA, VA-01/2030, Bl. $84 \mathrm{ff}$. 
allgemeinen und gemäß den Zuständigkeitsbereichen der Kollegiumsmitglieder analysiert und eingeschätzt.

Durch das neue Statut vom Mai 1961 stärkte die SED noch einmal Einfluß und Kompetenzen des Kollegiums sowohl in militärischer als auch in politischer Hinsicht. Es wurde dazu verpflichtet, den Minister für Nationale Verteidigung „durch kollektive Beratung" in allen "wichtigen politischen und militärischen Fragen, die in Durchführung der von der Partei- und Staatsführung der Nationalen Volksarmee gestellten Aufgaben für die gesamte Armee von Bedeutung waren“, zu unterstützen 328 .

Dem Kollegium gehörten der Minister für Nationale Verteidigung, seine Stellvertreter einschließlich des Chefs der Politischen Verwaltung, die Chefs der Rückwärtigen Dienste und der Verwaltung Kader sowie die Chefs der Teilstreitkräfte und Militärbezirke an. Darüber hinaus nahmen an den Sitzungen mit "beratender Stimme" der Leiter der ZK-Abteilung für Sicherheitsfragen und als Vertreter des Staatssicherheitsdienstes der Chef der Verwaltung 2000 im Ministerium für Nationale Verteidigung teil. Ferner konnten weitere Generale und Offiziere, vor allem Kommandeure und Politstellvertreter sowie Angehörige der Militäroberstaatsanwaltschaft nach Bedarf zu den Kollegiumssitzungen hinzugezogen werden ${ }^{329}$.

Im ersten Statut des Kollegiums des Ministeriums für Nationale Verteidigung war ferner festgelegt, daß der Minister „bei den Militärbezirken und bei den Chefs der See- und Luftstreitkräfte Militärräte bilden" konnte ${ }^{330}$. Auf der Grundlage dieser Bestimmung befahl Stoph am 31. Mai 1956 die „Bildung von Militärräten bei den Militärbezirken III und V und den Luft- und Seestreitkräften“ zum 1. Juni des Jahres ${ }^{331}$. Am 1. März 1957 wurde der Militärrat der Luftstreitkräfte im Zuge des Aufbaus der NVA in den Militärrat der Luftstreitkräfte und Luftverteidigung umgewandelt 332 .

Die ständigen Mitglieder der Militärräte, die vom Minister bestätigt wurden, waren jeweils der Chef des Militärbezirkes, sein 1. Stellvertreter, der Chef des Stabes, der Politstellvertreter, der Chef der Artillerie und der Leiter der Luftverteidigung. An den Sitzungen konnten darüber hinaus der "bevollmächtigte Mitarbeiter" der ZK-Abteilung für Sicherheitsfragen und der „Vertreter des Ministeriums für Staats-

328 Statut des Kollegiums des Ministeriums für Nationale Verteidigung. Protokoll der 5. Sitzung des Nationalen Verteidigungsrates der DDR, 3. Mai 1961, BA-MA, DVW 1/39462, Bl. 70 .

329 Ebenda, $72 \mathrm{f}$.

330 Statut des Kollegiums des Ministeriums für Nationale Verteidigung, 13. März 1956, BA-MA, VA-01/6098, Bl. 256. Otto Wenzels Annahme, die Einführung von Militärräten sei auf der 5. Sitzung des Nationalen Verteidigungsrates am 3. Mai 1961 beschlossen worden, entspricht nicht den Tatsachen. Sie ist auf die ausschließliche Auswertung der Quellen dieses Gremiums zurückzuführen. Wenzel, Kriegsbereit: Der Nationale Verteidigungsrat der DDR, S. $60 \mathrm{f}$. Tatsächlich wurde die Bildung von Militärräten bei den Militärbezirken, den Luft- und Seestreitkräften bereits am 31. Mai 1956 durch den Minister für Nationale Verteidigung befohlen.

331 Bildung von Militärräten bei den Militärbezirken, den Luft- und Seestreitkräften. Befehl Nr. 43/56 des Ministers für Nationale Verteidigung, 31. Mai 1956, BA-MA, VA-01/1811, Bl. 78 .

332 Bildung eines Militärrates der Luftstreitkräfte und Luftverteidigung. Befehl Nr. 119/56 des Ministers für Nationale Verteidigung, 15. Dezember 1956, BA-MA, VA-01/2110, Bl. 79. 
sicherheit beim Militärbezirk" teilnehmen ${ }^{333}$. Hierzu waren auch die Mitglieder des Kollegiums des Ministeriums für Nationale Verteidigung genauso wie vom Minister beauftragte Generale und leitende Offiziere befugt ${ }^{334}$. Analog zum Kollegium des Ministeriums sollten auf der darunterliegenden Ebene die Militärräte der Militärbezirke als „beratendes Organ“ der Chefs der Militärbezirke fungieren. Dabei hatte sich der Militärrat „mit allen wichtigen Fragen der Führung und der Ausbildung der Verbände, Truppenteile und Dienststellen des Militärbezirkes" zu befassen. Insbesondere ging es um die „Erziehung und Entwicklung der Kader" und die „Auffüllung“ der Einheiten, „Maßnahmen zur Durchführung der Befehle und Anweisungen“ des Ministers sowie des Chefs des Militärbezirkes, die „militärische Disziplin“, den politisch-moralischen Zustand und die „ständige Erhöhung des Niveaus der Kampfausbildung“ 335 .

Offenbar gelang es aber zunächst nicht, die Arbeit der Militärräte so zu organisieren, daß diese zur Tätigkeit des Chefs und der Leitung des Militärbezirkes auch unter Berücksichtigung politischer Gesichtspunkte Stellung nahmen. Dölling bemerkte rückblickend, die Sitzungen hätten „den Charakter von Dienstbesprechungen“ gehabt: „Eine offene und schöpferische Aussprache fehlte. “336 Aus diesem Grund entschied die SED-Führung im Politbürobeschluß „Über die Rolle der Partei in der NVA“ vom 14. Januar 1958, die "Zusammensetzung und den Charakter" der Militärräte zu verändern. Sie sollten jetzt das Recht erhalten, entsprechend den Beschlüssen des ZK, der Regierung und den Befehlen und Direktiven des Ministers „Beschlüsse zu fassen, von denen der Kommandeur bei der Befehlsgebung auszugehen" hatte, wodurch ihre Interventionsmöglichkeiten im Rahmen der militärischen Truppenführung nachhaltig erweitert wurden. Weiterhin beschloß das Politbüro, die 1. Sekretäre der SED-Bezirksleitungen, in deren Bezirken sich Militärräte befanden, „als ordentliche Mitglieder“ in die Gremien aufzunehmen. Bezüglich Fragen, die andere Bezirke betrafen, sollten die Ersten Sekretäre der jeweiligen Bezirksleitungen „als Gäste“ hinzugezogen werden ${ }^{337}$. Ziel der SED war es dabei offensichtlich, den Anteil ziviler Parteifunktionäre zu erhöhen, um auf diese Weise die politische Kontrollfunktion der Militärräte zu stärken. Die Ersten Sekretäre der Bezirksleitungen waren keine Militärs.

Dölling erläuterte die Konsequenzen des Politbürobeschlusses im darauffolgenden Monat: „In Verbindung mit der Durchsetzung der führenden Rolle der Partei[,] eines Systems der kollektiven Beratung der wichtigsten Probleme unserer Arbeit, vor der Befehlsgebung, kommt der Tätigkeit der Militärräte ganz besondere Bedeutung zu." Der Hauptgedanke bei der Veränderung der Zusammensetzung und des Charakters der Militärräte sei daher, „ein wirklich beratendes und beschließendes

333 Bildung von Militärräten bei den Militärbezirken, den Luft- und Seestreitkräften. Befehl Nr. 43/56 des Ministers für Nationale Verteidigung, 31. Mai 1956, BA-MA, VA-01/1811, Bl. 80.

334 Statut für die Militärräte in den Militärbezirken. Befehl Nr. 43/56 des Ministers für Nationale Verteidigung, 31. Mai 1956, BA-MA, VA-01/1811, Bl. 82.

335 Ebenda, Bl. $82 \mathrm{f}$.

336 Plan zur Auswertung und Durchführung des Beschlusses des Politbüros vom 14. Januar 1958 „Über die Rolle der Partei in der NVA“, 1. Februar 1958, BA-MA, VA-P-01/7535, Bl. 164.

337 Über die Rolle der Partei in der NVA. Protokoll Nr. 4/58 der Sitzung des Politbüros des ZK der SED, 14. Januar 1958, SAPMO-BArch, DY 30/J IV 2/2/576, Bl. 196. 
Kollegium zu schaffen“, in dem die "grundlegenden Probleme schöpferisch diskutiert und die richtungweisenden Beschlüsse gefaßt" würden, an die ein Kommandeur anschließend gebunden sei338.

Diese Vorgaben fanden dann ihren Niederschlag im neuen Statut für die Militärräte, das am 30. Juni 1958 von der Sicherheitskommission beschlossen wurde. Dort heißt es: „Der Militärrat ist ein kollektives Organ bei den Kommandos, das zur Gewährleistung der Einzelleitung durch die kollektive Beratung aller grundsätzlichen politischen und militärischen Aufgaben und Maßnahmen mit dem Recht der Beschlußfassung und der Kontrolle geschaffen ist." Dies bedeutete vor allem, daß die Beschlüsse des Militärrates nunmehr „für die Befehlsgebung und die Arbeit aller Kommandeure verbindlich" waren. Zudem erhielt der Militärrat auch das Recht, die „Durchführung“ seiner Beschlüsse durch die beauftragten militärischen Stellen zu kontrollieren, um so „Fehler und Mängel aufzudecken und für ihre Beseitigung durch entsprechende Beschlüsse und unmittelbare Einflußnahme zu sorgen“. Die „persönliche Verantwortung, die Autorität und die Rolle der Kommandeure als Einzelleiter" im Sinne einer uneingeschränkten Entscheidungskompetenz wurde „durch die gründliche kollektive Beratung der grundsätzlichen Fragen, prinzipielle Beschlußfassung und durch unmittelbare Hilfe" aber offensichtlich nicht, wie im Statut postuliert, gestärkt, sondern eher geschwächt. Dies galt vor allem für den Chef des Militärbezirkes und die militärische Leitung selbst ${ }^{339}$.

Denn durch das neue Statut wurde die sachliche Zuständigkeit des Militärrates im Hinblick auf Fragen der militärischen Truppenführung, zu denen er „kollektive Beratungen durchzuführen und Beschlüsse zu fassen" hatte, deutlich erweitert. Der Militärrat sollte sich jetzt auch mit der „Erhöhung und Aufrechterhaltung der Einsatzbereitschaft" der Einheiten und der „operativ-taktischen Truppenführung" befassen. Darüber hinaus hatte er das "Verhältnis und die Verbindung der Verbände, Truppenteile und Dienststellen zu den örtlichen Partei- und Staatsorganen und zu den Werktätigen" sowie die "Teilnahme der Soldaten, Unteroffiziere und Offiziere am gesellschaftlich-politischen Leben ihres Standorts" zu kontrollieren ${ }^{340}$.

Mit dem Ziel, eine ausschließlich sachbezogene Führungsarbeit zu unterbinden, stärkte man in den Militärräten zudem auch in personeller Hinsicht den Einfluß der SED. In Erfüllung des Politbürobeschlusses vom 14. Januar 1958 wurden zusätzlich der Erste Sekretär der Bezirksleitung Leipzig in den Militärrat des Militärbezirkes III, der Erste Sekretär der Bezirksleitung Neubrandenburg in den Militärrat des Militärbezirkes V und der Erste Sekretär der Bezirksleitung Rostock in den Militärrat der Seestreitkräfte berufen. In den Militärrat der Luftstreitkräfte und Luftverteidigung sollte zu einem späteren Zeitpunkt ein Mitglied des ZK entsandt werden ${ }^{341}$.

Das „Statut der Militärräte der Kommandos der Militärbezirke, der Luftstreit-

338 Plan zur Auswertung und Durchführung des Beschlusses des Politbüros vom 14. Januar 1958 „Über die Rolle der Partei in der NVA“, 1. Februar 1958, BA-MA, VA-P-01/7535, Bl. $164 \mathrm{f}$.

339 Statut für den Militärrat bei den Kommandos der Militärbezirke, der Seestreitkräfte und der Luftstreitkräfte und Luftverteidigung. Protokoll der 22. Sitzung der Sicherheitskommission des ZK der SED, 30. Juli 1958, BA-MA, DVW 1/39564, Bl. 81 ff.

340 Ebenda, Bl. $83 \mathrm{f}$.

341 Mitteilung des Chefs des Hauptstabes Hoffmann an Stoph, 31.Juli 1958, BA-MA, VA-01/4370, Bl. 106. 
kräfte/Luftverteidigung und der Volksmarine" vom 3. Mai 1961 legte dann die Zusammensetzung der Militärräte abschließend fest: Diese bestanden jetzt aus den Chefs der Militärbezirke beziehungsweise der Teilstreitkräfte, ihren Stellvertretern - also auch den Politstellvertretern - und den Leitern der Abteilung Kader. In Abwandlung der vorhergehenden Bestimmungen waren ständig auch alle Divisionskommandeure und Chefs der Flottillen Mitglieder der Militärräte. Neben den Ersten Sekretären der Bezirksleitungen Leipzig, Neubrandenburg und Rostock als „ordentliche Mitglieder" der Militärräte nahmen die Militärstaatsanwälte der Teile und Militärbezirke „mit beratender Stimme“ an den Sitzungen teil ${ }^{342}$.

\section{Die militärischen Führungsgrundsätze}

Die politische Durchdringung der NVA wird auch im Hinblick auf die militärischen Führungsgrundsätze ${ }^{343}$ deutlich. Um ihren Einfluß auf die militärische Truppenführung zu erweitern, unterzog die SED das gültige Führungsprinzip - die sogenannte Einzelleitung - einem substantiellen Bedeutungswandel.

Im Grundsatz bestimmte die Einzelleitung, daß die alleinige Befehlsbefugnis und die Verantwortung für die militärische Truppenführung beim jeweiligen Kommandeur beziehungsweise vorgesetzten Offizier lag. Die NVA übernahm die Einzelleitung als Führungsprinzip von den sowjetischen Streitkräften. Sie war zuvor auch schon in der KVP gültig gewesen.

Die Rote Armee hatte die Einzelleitung 1925 unter Frunse eingeführt, nachdem die doppelte Führung durch den militärischen Kommandeur und den politischen Kommissar nicht zuletzt wegen ihrer Ineffizienz aufgegeben worden war. Die Einzelleitung wurde dann mit Ausnahme der Zeit zwischen 1937 und 1942 in den sowjetischen Streitkräften beibehalten ${ }^{344}$. Das Militär der UdSSR implementierte mit der Einzelleitung jedoch keinen spezifisch sozialistischen Ansatz, sondern adaptierte letztlich das Führungsprinzip aller modernen Streitkräfte. Dies wurde mit der Berufung auf Lenins Zentralisationsgebot gerechtfertigt, welches als Verwaltungsprinzip im sozialistischen Staat die „unbedingte Unterordnung der Massen unter den einheitlichen Willen der Leiter des Arbeitsprozesses" vorsah ${ }^{345}$.

Auch bei der Gründung der DDR-Streitkräfte 1956 konstatierte man mit dem Hinweis auf die Existenz von „objektiven Gesetzmäßigkeiten ... des Militärwesens, der Kriege und der Führung der Truppen", die militärische Führung in der NVA müsse notwendigerweise in Form der Einzelleitung verwirklicht werden ${ }^{346}$. Da jedoch auch in „bürgerlichen Armeen“ die Kommandeure die „volle Befehlsgewalt" besaßen, betonte die SED, es gebe "trotz dieser äußerlichen Gleichheit von Einzelleitung und imperialistischer Truppenführung" zwischen beiden "grundlegende

342 Statut der Militärräte der Kommandos der Militärbezirke, der Luftstreitkräfte/Luftverteidigung und der Volksmarine. Protokoll der 5. Sitzung des Nationalen Verteidigungsrates der DDR, 3. Mai 1961, BA-MA, DVW 1/39462, Bl. $77 \mathrm{f}$.

343 Vgl. Glaser, Zur Entwicklung der militärischen Einzelleitung; Hoffmann, Für die volle Durchsetzung der Einzelleitung, S. 7 ff.; Kallmann, Einzelleitung und kollektive Beratung sind eine dialektische Einheit, S. 2.

$344 \mathrm{Vgl}$. Scott/Scott, The Armed Forces of the USSR, S. $259 \mathrm{ff}$.

345 Lenin, Die nächsten Aufgaben der Sowjetmacht [1918], in: Ders., Werke, Bd. 27, S. 260.

346 Über das Prinzip der Einzelleitung in der Nationalen Volksarmee, S. 658. 
Unterschiede": Während das Führungsprinzip in imperialistischen Streitkräften „unüberbrückbare Klassengegensätze“ zwischen dem Kommandeur und seinen Untergebenen widerspiegele, verkörpere das Prinzip der Einzelleitung „seinem Wesen nach das direkte Gegenteil“347. Denn „Inhalt und Form“ der Einzelleitung würden „stets vom politischen Charakter, der Funktion und der Rolle der jeweiligen Streitkräfte und damit von den Zielen und den Aufgaben der betreffenden herrschenden Klasse bestimmt“, weshalb hier „ein grundsätzlicher Unterschied“ bestehe ${ }^{348}$.

Gemäß der allgemeinen Definition galt ab 1956 zunächst der Grundsatz, dem Kommandeur obliege als Einzelleiter „die gesamte Verantwortung“ für seine Einheit ${ }^{349}$. Obwohl er jede Entscheidung mit seinen Stellvertretern zu beraten ${ }^{350}$ und der Parteileitung die militärischen und politischen Aufgaben zu erläutern hatte ${ }^{351}$, sollte er im Rahmen der Einzelleitung jedoch ausdrücklich „letztlich ... allein den Entschluß" fassen ${ }^{352}$. In den ersten anderthalb Jahren des Bestehens der NVA galt im Gegensatz zur Folgezeit in dieser Hinsicht eindeutig die Maßgabe, daß das „Prinzip der kollektiven Leitung nicht in einer Volksarmee anwendbar" sei. 1956 hieß es vielmehr, eine „zentrale Führung“ sei die Grundlage der modernen Truppenführung 353 .

Es erwies sich aber bald als problematisch, daß zwar die militärischen Strukturen zügig aufgebaut wurden, die parallele Erweiterung der politischen Einflußnahme auf die Entscheidungen der militärischen Truppenführung dahinter jedoch zurückblieb. In einer Zeit, in der ihr Regime innen- wie außenpolitisch wenig gefestigt war, mußte die SED erkennen, daß sie über das junge NVA-Offizierskorps nicht die gewünschte Kontrolle ausüben konnte. Zudem erwies sich die Vorstellung, der Offizier einer sozialistischen Armee werde automatisch auch den neuen Typus eines sozialistischen Offiziers verkörpern, als ideologische Fiktion. Gerade die zunächst postulierte Form der Einzelleitung dürfte der von der SED nicht intendierten Autonomisierung des Militärs Vorschub geleistet haben. Die NVA-Offiziere sahen sich nicht zuletzt wegen ihrer anfangs bestehenden umfassenden Vollmachten dazu legitimiert, sich dem Einfluß der Partei zu entziehen ${ }^{354}$.

Im eigenen Machtinteresse mußte die SED ein mögliches Entgleiten der NVA und des Offizierskorps aus der Parteikontrolle jedoch verhindern. Die Partei machte daher deutlich, daß die Einzelleitung ,auf keinen Fall eine Art Selbstherrschaft" der Kommandeure bedeuten könne ${ }^{355}$. Honecker bemerkte rückblickend,

347 Ebenda, S. 659.

348 Glaser, Die Initiative des Zentralkomitees der SED, S. 295.

349 Über das Prinzip der Einzelleitung in der Nationalen Volksarmee, S. 657.

350 Ebenda, S. 658.

351 Ebenda, S. 657.

352 Ebenda, S. 658.

353 Ebenda.

354 Vgl. Kap. VI. dieser Studie.

355 Plan zur Auswertung und Durchführung des Beschlusses des Politbüros vom 14. Januar 1958 „Über die Rolle der Partei in der NVA“, 1. Februar 1958, BA-MA, VA-P-01/7535, Bl. 153. 
es sei daher notwendig gewesen, „verschiedene Tendenzen der Überbetonung der Rolle der Einzelleitung zu beseitigen" 356 .

Dieser Absicht diente die Implementierung kollektiver Führungsmechanismen durch den erweiterten Einfluß der Parteiorganisationen in der NVA ab Mai 1957. Angesichts der veränderten Rahmenbedingungen in der Führungsarbeit mußte jetzt jedoch auch das gültige militärische Führungsprinzip neu definiert werden.

Die Einzelleitung wurde nunmehr als „organisatorische Form für die Einheit von politischer und militärischer Führung" verstanden ${ }^{357}$. Der Offizier sollte nicht mehr nur militärischer Vorgesetzter, sondern zugleich auch politischer Funktionär sein, der sich von nun an ohne Einschränkungen der Parteidisziplin zu unterwerfen hatte. Damit vollzog die SED einen grundlegenden Paradigmenwechsel. Dessen große Herausforderung bestand vor allem darin, bei der Neudefinition der Einzelleitung die tradierte Vorstellung von der alleinigen Befehlsgewalt des Vorgesetzten mit dem Prinzip der kollektiven Führung behutsam zu verbinden, ohne daß der grundsätzlich vorhandene Widerspruch zwischen beiden Führungsprinzipien allzu deutlich hervortrat. Denn die Reaktionen des Offizierskorps auf die Veränderungen waren nur schwer zu kalkulieren ${ }^{358}$.

Stoph leitete die neue Interpretation der Einzelleitung auf der Eggersdorfer Tagung im Juni 1957 ein. Sein Ziel war es, „falsche Auffassungen über das Wesen der Einzelleitung" zu korrigieren, um „völlige Klarheit über die Führungsprinzipien in der Nationalen Volksarmee“ zu schaffen und dieses „bewährte Prinzip“ der Einzelleitung "voll und ganz" durchzusetzen. Dabei versuchte Stoph, jedem möglichen Protest von Seiten der militärischen Truppenführung von vornherein die Spitze zu nehmen. Er konstatierte, daß angesichts der gestiegenen Intensität, Komplexität und Dynamik der modernen Gefechtsführung auch die „Bedeutung der einheitlichen Befehlsgewalt" sowie der „zentralen Führung und Leitung der Truppen“ zunehme ${ }^{359}$.

Gleichzeitig machte Stoph aber deutlich, die Aufgaben eines Offiziers könnten sich nicht allein auf diesen Bereich beschränken, sondern müßten einen weiteren Aspekt einschließen. Er sagte, „das Wesen der Einzelleitung in einer sozialistischen Armee" bestehe eben auch darin, daß „der Kommandeur als Einzelleiter die Einheit von politischer und militärischer Führung "verkörpere. Das ergebe sich aus den militärischen und politischen Erfordernissen. Eine „Trennung in militärische und politische Führung“, so Stoph, sei deshalb „nicht zulässig“, weil militärische Truppenführung "nicht nur Befehlsgebung“ bedeute, „sondern vor allem die politische Erziehung und Führung" 360 . Und gerade weil die militärische Führung auch diese Aufgabe umfasse, sei es „völlig falsch, ... einen Widerspruch zwischen der Stellung des Kommandeurs als Einzelleitung und seiner Stellung als Parteimitglied zu entwickeln“. Abschließend formulierte Stoph den richtungweisenden Leitsatz: „Die

356 Protokoll der Delegiertenkonferenz der Parteiorganisationen der SED in der NVA, 24.-26. Juni 1958, BA-MA, VA-P-01/038, Bl. 350.

357 Entwurf des Referats des Ministers für Nationale Verteidigung für die Eggersdorfer Tagung, 1957, SAPMO-BArch, DY 30/IV 2/12/10, Bl. 6.

358 Vgl. Hübner, Zur Rolle der Partei in der Nationalen Volksarmee, S. 426.

359 Protokoll der Eggersdorfer Tagung, 12./13. Juni 1957, BA-MA, VA-P-01/037, Bl. $43 \mathrm{f}$.

360 Ebenda, Bl. $44 \mathrm{f}$. 
Einzelleitung stellt den Kommandeur nicht über das Kollektiv, sondern setzt vielmehr die kollektive Beratung voraus .... "361

Der Politbürobeschluß vom 14. Januar 1958 bekräftigte dann die neugefaßte Definition der militärischen Führungsgrundsätze: „Die Einzelleitung in der Armee, die Einheit von politischer und militärischer Führung[,] ist durch die kollektive Beratung aller wichtigen politischen und militärischen Maßnahmen ... zu gewährleisten. "362 Diese grundsätzliche Festlegung wurde dann auch in der neuen NVA-Innendienstvorschrift von 1959 umgesetzt $^{363}$.

Der immanente Gegensatz zwischen beiden Prinzipien blieb jedoch bestehen und ließ sich weiterhin nicht überzeugend auflösen. Die SED versuchte daher, die praktische Unvereinbarkeit beider Ansätze dogmatisch zu überwinden, indem sie befand: „Einzelleitung und kollektive Beratung bilden eine dialektische Einheit.“ Die "Tätigkeiten der Parteiorganisation und des Kommandeurs" wurden demzufolge als „ein geschlossener Prozeß, eine Einheit“ begriffen ${ }^{364}$. Der Chef der Politischen Verwaltung Dölling sah sich jedoch zu der Feststellung gezwungen: „Die Verantwortung des Einzelleiters wird damit nicht geringer."365 Nach Auffassung der SED sollte die kollektive Beratung die „persönliche Entscheidung“ des Kommandeurs nicht ersetzen, sondern diesem helfen, „den richtigen Entschluß zu fassen“366.

Gerade die Verringerung der Entscheidungsfreiheit der vorgesetzten Offiziere war jedoch letztlich eine Konsequenz der neuen Definition der Einzelleitung. Die Kommandeure wurden zunehmend zu Ausführungsorganen kollektiv getroffener Entscheidungen degradiert. Faktisch reduzierte sich ihre Eigenständigkeit weitgehend auf den formalen Akt der Befehlsgebung. Wegen der kollektiven Beratung war die Unabhängigkeit und damit auch die Selbstverantwortlichkeit in der Entscheidungsfindung der Vorgesetzten umfassend beschränkt. Andererseits trug ein Kommandeur als Einzelleiter jedoch weiterhin die „volle Verantwortung für seine Handlungen, seine Befehle und Anordnungen und für die Resultate derselben, einmal vor der vorgesetzten Dienststelle, der er rechenschaftspflichtig “ war, „aber auch gleichzeitig vor der Parteiorganisation, der er als Mitglied“ angehörte ${ }^{367}$.

Dieses Mißverhältnis zwischen Entscheidungskompetenz und Verantwortlichkeit dürfte nicht nur die Ursache für den Unmut im Offizierskorps gewesen sein, sondern vor allem eine initiativreiche und eigenverantwortliche militärische Führung massiv gehemmt haben. Die SED untergrub die autonome Befehlsgewalt als zentrales Element der militärischen Selbstorganisation auch durch die Implementierung des kollektiven Führungsprinzips in den militärischen Führungsgrundsätzen tiefgreifend.

361 Ebenda, Bl. 52.

362 Über die Rolle der Partei in der NVA. Protokoll Nr. 4/58 der Sitzung des Politbüros des ZK der SED, 14. Januar 1958, SAPMO-BArch, DY 30/J IV 2/2/576, Bl. 193.

363 Innendienstvorschrift der Nationalen Volksarmee DV-10/3, 1959, S. $15 \mathrm{ff}$.

364 Kallmann, Einzelleitung und kollektive Beratung sind eine dialektische Einheit, S. 2.

365 Protokoll Nr. 1/58 über die Sitzung des Kollegiums des Ministeriums für Nationale Verteidigung, 24. Februar 1958, BA-MA, AZN/28178, Bl. 16.

366 Kallmann, Einzelleitung und kollektive Beratung sind eine dialektische Einheit, S. 2.

367 Plan zur Auswertung und Durchführung des Beschlusses des Politbüros vom 14. Januar 1958 „Über die Rolle der Partei in der NVA“, 1. Februar 1958, BA-MA, VA-P-01/7535, Bl. 153. 


\section{Die innere Ordnung}

Die politische Durchdringung der militärischen Autonomie tritt deutlich auch im Hinblick auf die innere Ordnung der NVA zutage ${ }^{368}$. Vor allem die politisch motivierten Modifikationen der Innendienstvorschrift und der Disziplinarordnung zeigen dies zum einen im Zusammenhang mit der Stellung und den Kompetenzen der Vorgesetzten, zum anderen hinsichtlich der Offiziersehrengerichte und -räte als Institutionen korporativer Selbstkontrolle.

So fixierte die nach Gründung der NVA zunächst noch gültige Vorläufige Innendienstvorschrift der KVP von 1953, der Vorgesetzte habe „im Rahmen der ihm übertragenen Verantwortung selbständig" zu handeln ${ }^{369}$. Als direkter Vorgesetzter des gesamten Personalbestandes hatte er dementsprechend die „volle Verantwortung" für die politische und fachliche Ausbildung, den politisch-moralischen $\mathrm{Zu}$ stand, die Einhaltung und Festigung der Disziplin und die Einsatzbereitschaft seiner Einheit ${ }^{370}$.

In der neuen Fassung der Innendienstvorschrift vom Februar 1959 wurde diese bürokratische Festlegung des Vorgesetztenverhältnisses dann jedoch aufgegeben und die Stellung der Vorgesetzten unter politischen Prämissen neu bestimmt. Die Vorgesetzten handelten jetzt ausdrücklich als „politische Funktionäre“, die ihre Aufgaben „im Auftrage der Partei der Arbeiterklasse“ durchzuführen hatten. Ein Regimentskommandeur etwa hatte zwar weiterhin die Verantwortung für alle politischen und fachlichen Belange seiner Einheit, war jetzt jedoch dezidiert dazu verpflichtet, die „Einheit der politischen und militärischen Führung in Zusammenarbeit mit der Parteileitung zu verwirklichen“. Folglich mußte er den Parteisekretär zu den Beratungen der militärischen Leitung hinzuziehen und bei allen wichtigen Entscheidungen die Meinung der Parteiorganisationen berücksichtigen ${ }^{371}$.

Die veränderte Stellung des Kommandeurs wird ebenfalls im Hinblick auf seine Rolle als Disziplinarvorgesetzter sichtbar. In der Disziplinarordnung der KVP von 1954 heißt es, der jeweilige Vorgesetzte habe in „den Fällen, in denen für das begangene Vergehen unabhängig vom Grad der Schuld gerichtliche und disziplinare [sic!] Bestrafung vorgesehen" sei, zu entscheiden, ob der Beschuldigte einem Gericht zu übergeben oder disziplinarisch zu bestrafen sei. Eine doppelte Bestrafung war dabei durchaus möglich ${ }^{372}$.

In der überarbeiteten Disziplinar- und Beschwerdeordnung, die im November 1957 in Kraft trat, wurde auch hier das Mitspracherecht der Partei verwirklicht. Zwar hieß es, dem Disziplinarvorgesetzten könne die „Anwendung oder Unterlassung einer Disziplinarmaßnahme ... nicht befohlen werden“; für „seine diesbezügliche Entscheidung“ trage er selbst die „volle Verantwortung“373. Er hatte jedoch „die Pflicht, sich vor der Entscheidung über eine Disziplinarmaßnahme" unter anderem die Meinung des Parteisekretärs einzuholen. Wenn in der Dienstvorschrift behauptet wurde, daß dadurch die "allseitige Verantwortung“ des Disziplinarvorgesetzten für die

368 Vgl. Die Nationale Volksarmee. Politführung und inneres Gefüge, S. $26 \mathrm{ff}$.

369 Vorläufige Innendienstvorschrift der Kasernierten Volkspolizei DV-10/3, 1953, S. 17.

370 Ebenda, S. $21 \mathrm{f}$.

371 Innendienstvorschrift der Nationalen Volksarmee DV-10/3, 1959, S. $15 \mathrm{ff}$.

372 Disziplinarordnung der Kasernierten Volkspolizei DV-10/6, 1954, S. 10.

373 Disziplinar- und Beschwerdeordnung der Nationalen Volksarmee DV-10/6, 1957, S. 8. 
„Richtigkeit und Zweckmäßigkeit der Disziplinarmaßnahme“ nicht beeinträchtigt werde, bezog sich das in erster Linie auf die Rechenschaftspflicht hinsichtlich des Ergebnisses. Die Entscheidung, ob eine Disziplinarstrafe überhaupt angemessen und berechtigt war, konnte der jeweilige Disziplinarvorgesetzte nicht mehr selbständig treffen. Sie unterlag vielmehr der Einflußnahme durch die Parteiorganisationen und die Parteisekretäre. Der Disziplinarvorgesetzte konnte letztlich nur noch das Strafmaß bestimmen. So legte die Disziplinar- und Beschwerdeordnung fest, die „freie Entscheidung des Disziplinarvorgesetzten“ bestehe darin, „im Rahmen seiner Befugnisse die erzieherische, zweckmäßigste Maßnahme zu wählen“374.

Neben den Disziplinarvorgesetzten gab es in der NVA noch eine weitere Instanz, die in bezug auf das Offizierskorps für die Festlegung von Disziplinarmaßnahmen zuständig war: die Offiziersehrengerichte. Nach dem Inkrafttreten des Abschnittes XVI der Disziplinarordnung von 1954 waren schon im Mai 1955 in der KVP Offiziersehrengerichte geschaffen worden ${ }^{375}$, die nach Gründung der NVA ihre Arbeit fortsetzten. Die SED orientierte sich bei der Einführung dieses Erziehungsorgans zunächst anscheinend an der gleichnamigen Institution in den sowjetischen Streitkräften ${ }^{376}$. Nur so läßt es sich erklären, daß ein Instrument der korporativen Selbstkontrolle, das es auch in der preußischen Armee gegeben hatte, in den sozialistischen Streitkräften der DDR zu neuem Leben erweckt wurde. In Anbetracht der Tatsache, daß die Ehrengerichte des Offizierskorps in der Reichswehr der Weimarer Republik bereits abgeschafft und durch Ehrenräte mit nur begrenzter Kompetenz ersetzt worden waren ${ }^{377}$, mußte die Wiedereinführung derartiger Einrichtungen in der NVA als Anachronismus wirken.

Die Ehrengerichte sollten die „Wahrung der Würde und Ehre der Offiziere“ garantieren. Sie hatten dabei die Aufgabe, zu untersuchen, ob bestimmte Handlungen eines Offiziers „unwürdig“ waren, die „Offiziersehre untergraben“ konnten oder mit der „allgemeinen Moral“ nicht im Einklang standen ${ }^{378}$. Der jeweilige Kommandeur einer Einheit, in deren Dienstbereich ein Offiziersehrengericht existierte, hatte nach der Analyse der Untersuchungsmaterialien zu entscheiden, ob der Beschuldigte dem Ehrengericht zu übergeben war oder ob das Vergehen durch eine Disziplinarstrafe geahndet werden sollte. An der Sitzung eines Ehrengerichtes konnten jeweils nur die Offiziere einer Einheit teilnehmen, die den gleichen oder einen höheren Dienstgrad als der Angeklagte besaßen ${ }^{379}$. Mit der Mehrheit der stimmberechtigten Mitglieder konnte das Ehrengericht dem Disziplinarvorgesetzten dann Strafen von der "Erteilung eines Tadels“ bis hin zur „Entlassung“ aus der Armee vorschlagen. Ein Einspruch gegen die Urteile des Ehrengerichtes war dabei höchstens aus formalen Gründen möglich ${ }^{380}$.

Die Ehrengerichte spielten jedoch als ein Selbsterziehungsinstrument des Offizierskorps und als Beratungsgremium der Kommandeure in Disziplinarfragen of-

374 Ebenda, S. 59.

375 Befehl Nr. 29/55 des Chefs der KVP, 24. Februar 1955, BA-MA, DVH 3/2212, Bl. 28.

376 Vgl. Owsjanko, Offiziersehrengerichte, S. $93 \mathrm{f}$.

377 Vgl. Meier-Welcker, Offiziere im Bild von Dokumenten aus drei Jahrhunderten, S. 87, 92 ff., 102.

378 Disziplinarordnung der Kasernierten Volkspolizei DV-10/6, 1954, S. 39.

379 Ebenda, S. 43.

380 Ebenda, S. $45 \mathrm{f}$. 
fenbar von Anfang an nur eine geringe Rolle ${ }^{381}$. Stoph beklagte schon im ersten Jahr des Bestehens der NVA, die Offiziersehrengerichte als „wichtiges Erziehungsmittel“ des Kommandeurs würden „nicht richtig eingeschätzt und zu wenig oder falsch angewendet “382. Darüber hinaus artikulierte er jedoch auch grundsätzliche Zweifel an dieser Institution: „Ich bin nicht sicher, ob die Bezeichnung ,Ehrengericht' richtig gewählt wurde. Vielleicht sollte man überlegen, ob man etwas besseres findet.“383

Auf der Sitzung des Kollegiums des Ministeriums für Nationale Verteidigung im Februar 1957 wurde dann vorgeschlagen, die Ehrengerichte in Ehrenräte als Organe der „Selbsterziehung der Offiziere“ umzuwandeln. Ihre Tätigkeit sollte zukünftig nicht mehr auf der Grundlage der Disziplinarordnung erfolgen. Die bisherige Praxis habe "faktisch zu zweifachen Verfahren mit gleichem Inhalt" geführt, da die Ehrengerichte „als eine zweite Disziplinar-Institution betrachtet“ worden seien ${ }^{384}$.

Die Offiziersehrengerichte wurden daraufhin bis Ende Juli 1957 aufgelöst. Statt dessen schuf man Offiziersehrenräte mit dem Ziel, den Tätigkeitsschwerpunkt dieser Einrichtung von der Entscheidungsfindung in Disziplinarfragen hin zu einer primären Erziehungsfunktion zu verlagern. Die NVA-Führung hatte kritisiert, die Verhandlungen der Ehrengerichte seien bisher als „eine Art Gerichtsverfahren“ durchgeführt worden ${ }^{385}$.

Entsprechend der allgemeinen Zielsetzung einer Implementierung kollektiver Entscheidungsprozesse bestimmte daher der Befehl über die „Bildung der Offiziers-Ehrenräte der NVA“ vom 27. Juni 1957: „Die Offiziers-Ehrenräte sind gewählte Organe des Offizierskorps zur kollektiven erzieherischen Einflußnahme auf den politisch-moralischen Zustand sowie zur Wahrung der Ehre und Würde des Offizierskorps der Nationalen Volksarmee." 386 Diese sollten nunmehr in erster Linie ein Organ „zur Unterstützung der Erziehungsarbeit der Kommandeure“ sein und in diesem Zusammenhang "der gegenseitigen Erziehung der Offiziere“ dienen ${ }^{387}$. Die Offiziersehrenräte hatten jetzt die Aufgabe, zu „Handlungen und Vergehen" von Offizieren „Stellung zu nehmen“, die die Offiziersehre untergraben oder verletzen konnten und "mit der sozialistischen Moral unvereinbar" waren, sofern diese nicht durch die Justizorgane verfolgt wurden ${ }^{388}$.

381 Vgl. Slawisch, Mehr Aufmerksamkeit den Offiziersehrengerichten, S. 2.

382 Referat des Ministers für Nationale Verteidigung zur Erläuterung der Ausbildungsaufgaben für das Ausbildungsjahr 1956/57 vor den Regimentskommandeuren, 1956, BA-MA, VA-01/5043, Bl. 24.

383 Protokoll Nr. 7/56 über die Sitzung des Kollegiums des Ministeriums für Nationale Verteidigung, 21. September 1956, BA-MA, VA-01/2030, Bl. 125.

384 Protokoll Nr. 1/57 über die Sitzung des Kollegiums des Ministeriums für Nationale Verteidigung, 25. Februar 1957, BA-MA, VA-01/2031, Bl. 29.

385 Erläuterungen zu den Bestimmungen für die Arbeit der Offiziers-Ehrenräte in der NVA. Befehl Nr. 48/57 des Ministers für Nationale Verteidigung, 27. Juni 1957, BA-MA, VA-01/1831, Bl. 55.

386 Bildung der Offiziers-Ehrenräte der NVA. Befehl Nr. 48/57 des Ministers für Nationale Verteidigung, 27. Juni 1957, BA-MA, VA-01/1831, B1. 39.

387 Erläuterungen zu den Bestimmungen für die Arbeit der Offiziers-Ehrenräte in der NVA. Befehl Nr. 48/57 des Ministers für Nationale Verteidigung, 27. Juni 1957, BA-MA, VA-01/1831, Bl. 55.

388 Bestimmungen für die Arbeit der Offiziers-Ehrenräte in der NVA. Befehl Nr. 48/57 des Ministers für Nationale Verteidigung, 27. Juni 1957, BA-MA, VA-01/1831, Bl. 47. 
Die Kommandeure, in deren Dienstbereich ein Offiziersehrenrat existierte, hatten jeweils zu entscheiden, ob das Vergehen eines Offiziers im Ehrenrat, dem der Kommandeur selbst jedoch nicht angehörte, behandelt werden sollte ${ }^{389}$. Bei „schuldhaftem Verhalten“ eines Offiziers war es dann die Aufgabe des Offiziersehrenrates, dieses im Rahmen einer gemeinsamen Stellungnahme zu bewerten. Darüber hinaus konnte das Gremium dem Kommandeur die Anwendung bestimmter Disziplinarmaßnahmen vorschlagen. Dieser mußte die Stellungnahme des Offiziersehrenrates zur Kenntnis nehmen, war daran in seiner Entscheidung aber „nicht gebunden" 390 .

Maßgebenden Einfluß auf seine Entscheidungsfindung hatten vielmehr die Parteiorganisationen. Denn die Kommandeure und Vorsitzenden der Offiziers-Ehrenräte mußten „bei ihrer Tätigkeit eng mit den Leitungen der Parteiorganisationen zusammenarbeiten“391. Dieses Mitspracherecht der Partei höhlte die Stellung und die Autorität des Kommandeurs als Disziplinarvorgesetztem jedoch weiter aus.

Die SED entschied sich jedoch schließlich, die Offiziersehrenräte nach nur vierjähriger Existenz zum 31. August 1961 aufzulösen. Im vollziehenden Befehl des Ministers für Nationale Verteidigung lautete die Begründung hierfür, die Kommandeure, Politorgane und Parteiorganisationen nähmen einen „immer wirkungsvolleren erzieherischen Einfluß auf die Offiziere". Diese Entwicklung habe es dem Nationalen Verteidigungsrat gestattet, die Beendigung der Arbeit der Offiziersehrenräte zu beschließen ${ }^{392}$.

Diese Argumentation lenkte jedoch bewußt vom eigentlichen Grund für die Auflösung ab. Denn den behaupteten wirkungsvolleren erzieherischen Einfluß auf die Offiziere hatte man in erster Linie durch die Anwendung des Prinzips der Kritik und Selbstkritik in den Parteiversammlungen erzielt. Infolge dessen war die Erziehungsfunktion der Ehrengerichte und -räte ab 1957 zunehmend auf die Parteiorganisationen übergegangen, weshalb die Ehrenräte in der Praxis bedeutungslos wurden. Im Befehl des Ministers kam deshalb nichts anderes als das Scheitern dieser Institutionen zum Ausdruck.

Dieses Scheitern der Offiziersehrengerichte und -räte als autonome Erziehungsinstrumente zur internen Selbstkontrolle des Offizierskorps war jedoch von Anfang an vorprogrammiert gewesen. Wegen der wachsenden ideologischen Durchdringung des Militärs und der großen Abhängigkeit von der SED hatte das Offizierskorps kaum einen Freiraum, eigene Werte als Grundlage eines korporativen Selbstverständnisses zu entwickeln, das als Orientierungsschema einer Selbstkontrolle hätte dienen können. Für die Offiziere waren letztlich die politischen, sozialen und rechtlichen Normen des SED-Systems und nicht eigene Werte - etwa ein autonom sanktionierbarer Ehrbegriff - verbindlich.

389 Ebenda, B1. 47.

390 Ebenda, Bl. $52 \mathrm{f}$.

391 Erläuterungen zu den Bestimmungen für die Arbeit der Offiziers-Ehrenräte in der NVA. Befehl Nr. 48/57 des Ministers für Nationale Verteidigung, 27. Juni 1957, BA-MA, VA-01/1831, Bl. 56f.

392 Beendigung der Arbeit der Offiziers-Ehrenräte. Befehl Nr. 47/61 des Ministers für Nationale Verteidigung, 27. Juli 1961, BA-MA, VA-01/5903, Bl. 100. 